\title{
Das Geschlechtsverhältniss bei den Geburten in 0esterreich.
}

\author{
Von \\ M. U. Dr. 0. Srdínko, \\ Professor an der böhm. Universität in Prag.
}

Einleitung.

Die Anzahl der männlichen und weiblichen Individuen ist bei den Lebewesen, welcher Gattung sie auch sein mögen, in der Regel sehr ungleich. Bei der einen Gattung sind mehr Männchen als Weibchen, bei der anderen ist dies wieder umgekehrt. . Aber auch bei der einen und derselben Gattung bleibt die Verhältnisszahl der männlichen und weiblichen Individuen nicht fest bestehen, sondern sie vergrössert sich unter den verschiedensten Umständen. zu Gunsten des einen oder des anderen Geschlechtes.

Auch bei dem Menschen tritt nicht überall eine gleiche Anzahl Männer und Frauen auf, sondern in manchen Gegenden und Ländern ist das männliçhe, in anderen wieder das weibliche Geschlecht überwiegend. Und auch der Grad, in welchem das eine Geschlecht das andere überwiegt, ist sehr veränderlich.

Es ist eine bekannte Thatsache, dass man bei der Volkszählung in allen Staaten Europas, bis auf wenige Ausnahmen, immer einen Ueberschuss oder ein Uebergewicht des weiblichen Geschlechtes vorfindet. So fallen nach der Volkszählung aus dem Jahre 1900 auf 1000 Männer:

in Oesterreich überhaupt. . 1035 Frauen

im Königreiche Böhmen . . 1056 "

in der Markgrafschaft Mähren 1077 "

Die grössten Abweichungen von der Durchschnittszahl (1035) von ganz Cisleithanien weisen Krain und Dalmatien auf. Auf 1000 Männer kommen

$$
\begin{array}{lc}
\text { in Krain . . . } & 1102 \text { Frauen } \\
\text { in Dalmatien . . } & 968
\end{array}
$$


Aus den angeführten Ziffern ist ersichtlich, dass das Geschlechtsverhältniss in den verschiedenen Ländern Oesterreichs, ohne Rücksicht auf das Alter der Bevölkerung, ein sehr verschiedenes ist, und wenn wir die Volkszählungen aus den Jahren 1890 und 1880 vergleichen, finden wir, dass das Verhältniss der beiden Geschlechter sich ändert oder schwankt. Es wäre sehr wichtig und auch zugleich interessant das Schwanken dieses Verhältnisses während einer Reihe von Jahren zu beobachten und die Gründe dazu zu suchen. Es würde sich ganz sicher herausstellen, dass die Gründe dieses Schwankens sehr verschieden sind, und zwar innere, welche auf den Eigenschaften der Organismen der Bevölkerung beruhen, und äussere, wobei neben den zufälligen Erscheinungen (Epidemien, Kriege u. a.) die Auswanderung eine nicht unbedeutende Rolle spielt.

Den Entwicklungsforscher interessiren nicht diese allgemeinen Verbältnisszahlen der Geschlechter der Bevölkerung einzelner Länder, Nationen oder Staaten, sondern nur zwei Zahlengruppen, welche das Verhältniss der Geschlechter unter bestimmten Umständen bestimmen. Die eine Gruppe wird von Zahlen gebildet, welche das Verhältniss ausdrücken, in dem die beiden Geschlechter in der Zeit ihrer geschlechtlichen Productionsthätigkeit (von der Geschlechtsreife bis zum Verschwinden der Productionsthätigkeit) zu einander stehen, die andere Gruppe bilden wiederum jene Zahlen, welche das Zahlenverhältniss der Geschlechter bei den Geburten ausdrücken.

Diese Abhandlung beschäftigt sich bloss mit der zweiten der beiden angeführten Zahlengruppen, d. i. mit dem Zahlenverhältniss der Geschlechter bei den Geburten in Oesterreich. Es.kann schon im vorhinein bemerkt werden, dass man in Oesterreich bei der näheren Untersuchung des Geschlechtsverhältnisses bei den Geburten zu interessanten Zahlen gelangt, wie dann noch später angeführt werden wird. Die Ursache, dass das Verhältniss der Geschlechter in diesem Reiche so ganz versehieden von allen anderen Ländern und Staaten schwankt, ist wohl die sowohl nationale als auch geographische Gliederung des Reiches.

Es ist eine bekannte Thatsache, dass die neugeborenen Kinder in Bezug auf ihr Geschlecht in einem bestimmten Zahlenverhältniss zu einander stehen. So fand z. B. in Preussen Karl Düsing bei den Geburten, welche er in 13 Jahren (1875-1887) zusammenstellte, dass das Verhältniss der Geschlechter bei allen Geburten 
(d. i. bei ehelich und unehelich, todt oder lebendig geborenen Kindern) 106,305 beträgt. Dabei kann noch bemerkt werden, dass man in dieser Fachliteratur gewöhnlich die Ziffer angiebt, welche die Anzahl der auf 100 Mädchengeburten kommenden Knabengeburten ausdrückt. Die Düsing'sche Zahl bedeutet also, dass in Preussen während der 13 untersuchten Jahre auf 100 Mädchen 106,305 Knaben kommen. Diese Ziffer wurde von Düsing aus der Gesammtzahl von mehr als 13 Millionen Geburten berechnet.

Aehnlich stellte auch ich alle Geburten in Oesterreich während 12 Jahre (1891-1902) zusammen und fand, dass das Verhältniss der Geschlechter bei allen Geburten, deren es im Ganzen 11577627 gab, 106,557 ist.

Diese Zahl ist aber nicht constant, sondern sie bildet bloss ein Centrum, von dem dann Abweichungen in der Richtung nach oben und unten erfolgen.

Aus den beiden genannten Zahlen Oesterreichs und Preussens ist ersichtlich, dass bei den Geburten das männliche Geschlecht überwiegt, dagegen beweisen uns die früher genannten Zahlen wieder, dass bei der lebenden Bevölkerung das weibliche Geschlecht vorherrscht.

Rechnen wir jene oben angeführten Zahlen, welehe angeben, wieviel Frauen auf 1000 Männer kommen, nach, finden wir in der cisleithanischen Hälfte der Monarchie folgendes Verhältniss der Geschlechter:

Nach der Volkszählung vom Jahre 1900 war das Verhältniss der Geschlechter der gesammten Bevölkerung in Oesterreich 96,61, Böhmen 94,67, Mähren 92,85, Krain 90,74, Dalmatien 103,30.

Aus diesem erhellt also, dass das Verhältniss der Geschlechter von der Geburt angefangen bis zum weiteren Alter sieh überall verkleinert. So wie überall sinkt es auch in Oesterreich von den früheren 106.557 auf 96,61. In den meisten im Reichsrathe vertretenen Königreichen und Ländern sinkt das Geschlechtsverhältniss bis unter 100, so dass es dann gerade umgekehrt wird. Das Uebergewicht des männlichen Geschlechtes bei den Geburten wird zur Minorität und das weibliche Gewicht überwiegt dann.

Es wäre sehr interessant, das Sinken dieses Verhältnisses der Geschlechter von der Geburt aus die einzelnen Lebensstadien hindurch bis zu den äussersten Grenzen einzelner Generationen zu verfolgen. Aber dies fält nicht in den Rahmen unserer Abhandlung. 
Aber nicht allein bei dem Menschen, sondern auch bei den Thieren kann man constatiren, dass das Verbältniss der Geschlechter irgend einer Thiergattung ein anderes bei der Geburt und wieder ein anderes später im reiferen Alter ist. So wie z. B. bei dem Menschen anfangs das männliche Geschlecht überwiegt, so ist dagegẹn bei den Fröschen das weibliche Geschlecht überwiegend, und so wie dann später bei dem Menschen das Verhältniss der Geschlechter zu Ungunsten der Männer sinkt, so steigt es wieder bei den Fröschen zu Gunsten der männlichen Individuen.

Das Verhältniss der Geschlechter bei den Geburten ist bei vielen Thieren schon bekannt und es seien nur folgende von ihnen erwähnt:

Das Verhältniss der Geschlechter bei den Geburten der Pferde wurde von einer ganzen Reibe Forscher, wie Hofacker, Goehlert, Baumeister, Darvin, Düsing untersucht und alle fanden, dass dieses Verhältniss kleiner als 100 ist, und dass es um die mittlere Zahl 96,57 schwankt. Das bedeutet also, dass bei den Pferden mehr weibliche Individuen geboren werden als männliche. Düsing, der mehr als 700000 Geburten bei den Pferden zusammenstellte, fand, dass im Ganzen auf 350682 männliche 357728 weibliche Individuen kamen, was also der Verhältnisszahl 98,03 entspricht.

Heyer stellte eine Tabelle der Verhältnisse der Geschlechter verschiedener Thiergattungen zusammen. Darnach ist dieses Verhältniss :

$$
\begin{aligned}
& \text { bei den Schafen in Deushland . . 105,87 }
\end{aligned}
$$

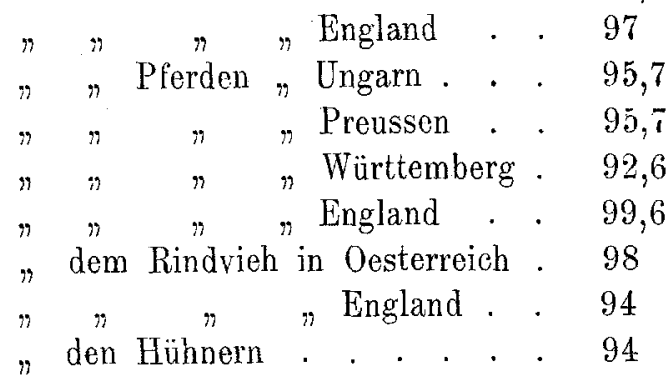

Auch bei einigen Pflanzen, mit getrenntem Geschlecht, wurden ähnliche Untersuchungen vorgenommen und da fand man z. B.:

$$
\begin{aligned}
& \text { bei dem Hanf in Deutschland . . . . 89,76 }
\end{aligned}
$$

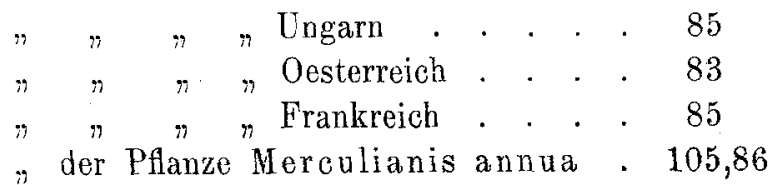


Das Uebergewicht des weiblichen Geschlechts im erwachsenen Alter zeigt sich besonders bei den polygamischen Thieren, aber auch bei diesen Thieren ist das Verhältniss der Geschlechter bei der Geburt ein ganz anderes als später. Es ist aber kein blosser Zufall, dass das eine Thier ein solches, das andere wieder ein anderes Verhältniss der Geschlechter aufweist, sondern es besteht eine Beziehung zwischen der Grösse dieses Verhältnisses und den Lebensumständen des Thieres. Dies lässt sich bei der Gattung der polygamischen Thiere nachweisen, was aus der Abhandlung von Düsing folgendermaassen hervorgeht:

Zwischen dem weiblichen und männlichen Erzeuger ist in Folge der Arbeitstheilung insofern Unterschied in der Productionsthätigkeit, als das Weibchen den Stoff zum Aufbau des Fötus bietet, während das Männchen bloss die Aufgabe hat, das Weibchen zu befruchten; dem Weibchen fällt also die schwerere Aufgabe zu, und daraus folgt weiter, dass die Intensität der Vermehrung besonders von der Anzahl der Weibchen abbängig ist.

Als wichtig muss auch das hier angeführt werden, dass die Intensität der Vermehrung der Thiere auch abhängig ist von der Steigung der Sterblichkeit unter ihnen. Das Thier, das so vielen Feinden ausgesetzt ist, muss besonders viele Jungen produciren, wenn es nicht aussterben soll.

Zu solchen Thieren gehören viele Pflanzenfresser. Sie bilden die Nahrung für die Fleischfresser, viele kommen um und müssen sich demnach stärker vermehren. Die Intensität der Vermehrung ist aber von der Anzahl Weibchen abhängig und da eine starke Vermehrung nur aus einer grösseren Zahl der Weibchen geschehen kann, herrscht auch bei diesen Thieren die Polygamie.

Schon Darwin bemerkte, dass die Domestication der Thiere zu ihrer Polygamie führe. Die Hausthiere haben nämlich einen grossen Feind in dem Menschen, dem sie auch in grosser Zahl zum Opfer fallen. Die Henne z. B. legt eine ungeheure Anzahl Eier und doch bleibt die Zahl der Hühner verbältnissmässig dieselbe, weil der Mensch die Eier beständig verbraucht. Die Sterblichkeit der Hühner (denn auch das Ei muss selbstverständlich mit einberechnet werden) ist sehr gross. Daher ist auch die starke Vermehrung durch die grosse Zahl der Weibchen unterstützt. Wir erkennen daraus, dass durch die Domestication die Folygamie theilweise gebildet und verstärkt wird. Die Wildente ist z. B. 
streng monogamisch, die Hausente dagegen polygamisch. Wir sehen also, dass die auftretende Polygamie in Beziehung zur Vermehrung der Thiere steht, und dass diese Vermehrung von der Zahl der Feinde und von noch anderen Umständen abhängig ist. Die Polygamie ist also eine Anpassung an bestimmte Lebensumstände.

Kehren wir aber za unserer Aufgabe zurück. Es ist Thatsache, dass 1. die Geschlechter in der Zeit ihrer Vermehrung in einem bestimmten numerischen Verhältniss zu einander stehen, und 2. dass auch die Jungen in gleicher Weise in einem bestimmten Verbältniss der Geschlechter geboren werden. Man kann also annehmen, dass die Grösse der Verhältnisszahl zwischen den Geschlechtern bei allen Lebewesen in Beziehung zu ihren Lebensverhältnissen stehe. Das Verhältniss der Geschlechter ist daher etwas Bestimmtes, es ist eine Zahl, die unter denselben Umständen wieder zurückkehrt.

Zur Bestimmung des Verhältnisses der Geschlechter ist eine kleine Anzahl von Geburten nicht hinreichend, sondern dazu sind sehr grosse Zahlen nothwendig. Bei kleinen Zahlen schwankt das Verhältniss der Geschlechter sehr stark, denn, wie allgemein bekannt ist, haben manche Eltern bloss Knaben, andere wieder bloss Mädchen. Aber abgesehen von dem starken Schwanken in den Einzelheiten, bleibt die Verhältnisszahl der Geschlechter stets ziemlich constant. Wie geschieht das, muss man hier fragen. Wie wird diese Schwankung ausgeglichen, wie corrigirt sich und regulirt sich das Verhältniss der Geschlechter? Düsing, der in dieser Richtung umfangreiche Studien unternahm, kommt zu der Antwort, dass die abnormen Abweichungen wieder dahin wirken, dass in Folge von Ueberfluss des einen Geschlechts mehr Individuen des anderen Geschlechts geboren werden. Nur so ist es möglich, dass ein solches Verhältniss der Geschlechter ziemlich constant bleibt.

Nach Düsing könnte man annehmen, dass alle Thiere die für ihre Vermehrung nützlichen Eigenschaften besitzen, dass bei Uebergewicht der Individuen des einen Geschlechts mehr Individuen des anderen Geschlechts geboren werden. Dass eine solche nützliche Eigenschaft wirklich existirt, beweist $D$ üsing mit Facten nicht bloss aus dem Reiche der Thiere und des Menschen, sondern auch aus dem Pflanzenreiche. 


\section{Uebersicht der determinirenden Einflüisse.}

Es sei hier gestattet, an dieser Stelle kurz jene Momente anzuführen, von denen viele Gelehrte annehmen, dass sie auf die Regelung des Verhältnisses der Geschlechter bei den Säugethieren und Menschen einen Einfluss haben.

Die verlässlichsten Angaben, die da hereinfallen, stammen von Düsing und Wilkens. Düsing gab statistische Daten von der Bevölkerung Preussens, von den Gestüten und Pferdezuchtanstalten in Preussen an, welche deswegen einen grossen Werth besitzen, weil sie vom biologischen Standpunkt aus ans einem ungeheuren Material zusammengestellt wurden. Die Forschungen von Wilkens beziehen sich auf Haussäugethiere.

Das Problem, dessen Lösung die Arbeiten von Düsing, Wilkens, Janke a. a. anstreben, lautet folgendermaassen: Welche Einflüsse bewirken die Differenzirung des Geschlechts in ein männliches oder weibliches Individuum?

Nach der Meinung Düsing's giebt es hier nicht eine alleinige Ursache der Differencirung, sondern es wirken hier mehrere, von einander unabhängige Einflüsse. Und da wir noch nicht wissen, wann die Differenzirung vor sich geht, glaubt Düsing, dass jene Einflüsse gleichzeitig oder nach einander auf die Geschlechtsproducte wirken können und dies zwar vor der Befruchtung, im Laufe dieser oder endlich nach Befruchtung des Eies.

Wilkens führt alle diese, nach seiner Meinung bedeutenden Einflüsse auf die Ernährung des Embryos zurück. Nach seiner Erfahrung differenzirt sich das Geschlecht erst nach der Befruchtung.

Wir werden hier einige Gruppen anführen, in die man die verschiedenartigen, zur Differenzirung des Geschlechts als wichtig bezeichneten äusseren Einflüsse einreihen kann.

\section{Der Einfluss des Mangels an Individuen des einen Geschlechts.}

Der Mangel an Männern, d. i. die Verminderung der Anzahl Männer in irgend einem Lande oder bei einer Nation, ein Umstand, der z. B. durch einen Krieg eintreten kann, zieht die Folge nach sich, dass in den folgenden Jahren. mehr Knaben geboren werden als früher, wodurch die Abnahme der Männer mit der Zeit ausgeglichen wird. Dieser Fall ist in Holstein aufgetreten, wo das V.d. G., welches in den Jahren 1835-1845 105,76 war, 
nach der Kriegsperiode 1846-1853 auf 106,67 stieg. Dasselbe wurde auch in Preussen nach den Kriegsjahren 1815, 1864, 1866 und 1870 constatirt.

Ploss legt diese Erscheinung dahin aus, dass im Kriege die Volksernährung sehr leidet, und dass dann in Folge der schlechteren Ernährung der Mütter mehr Knaben geboren werden. (Auf den Einfluss der Nahrung kommen wir noch später zu sprechen.)

Düsing sieht in dieser Erscheinung die besonders zur Vermehrung der Menschen und Thiere nützliche Eigenschaft, dass im Falle der Abnahme der Individuen des einen Geschlechts mehr Jungen desselben Geschlechts geboren werden. Er erklärt diesen Umstand folgendermaassen: Bei Mangel z. B. an Männchen, sind die übrigen Männchen genöthigt, den geschlechtlichen Act öfters zu verrichten, wodurch ihre erzeugten Spermatozoen bald wieder verbraucht werden und die Eier mit verhältnissmässig jungen Spermatozoen befruchtet werden. Nach der Düsing'schen Theorie entstehen aus den mit jungen Spermatozoen befruchteten Eiern mehr männliche Individuen. Wenn es an Weibchen mangelt, liegt die Wahrscheinlichkeit sehr nahe, dass jedes Ei, welches kaum gereift ist, schon wieder befruchtet wird, und Düsing schliesst aus seinen Forschungen, dass aus solchen jungen Eiern mehr weibliche Individuen sich entwickeln.

Daraus ersieht man aber, dass die eigentliche Ursache der Differenzirung der Geschlechter durch diese Hülfsauslegung Düsing's noch nicht erklärt ist.

\section{Der Einfluss der verzögerten Befruchtung des Individuums.}

Durch viele Forscher wurde einstimmig festgestellt, dass ältere Erstgebärende, also jene Frauen, die auf die erste Conception länger warten mussten, eine grössere Anzahl Knabengeburten aufweisen; so ist z. B. d. V. d. G. bei den über 30 Jahre alten Erstgebärenden 120 bis 130 . Düsing behauptet, dass sich auch bei den Mehrgebärenden mehr Knaben in dem Falle zeigen, wenn zwischen den einzelnen Geburten grössere Zwischenräume sind. Und zwar ist:

bei der Unterbrechung von

1 J. d. V. d. G. $=108,6$

\begin{tabular}{|c|c|c|c|}
\hline & $"$ & $n$ & $2-3$ J. d. V. d. G. $=109,6$ \\
\hline$n$ & $m$ & r & 4 J. d. V. d. G \\
\hline & n & 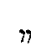 & 6-11 J. d. V. d. G \\
\hline
\end{tabular}

Diese Zahlen werden aus 4903 Geburten zusammengestellt. 
Düsing erklärt diese Erscheinung ähnlich wie den Fall, wo Mangel an Männern eintritt. Welchen physikalischen oder chemischen Verwandlungen das Ei der älteren Erstgebärenden unterliegt, so dass sich aus ihm ein männlicher Fötus entwickelt, kann man noch nicht angeben.

Die Erstgebärenden weisen überhaupt mehr Knaben auf als Mädchen. Es warde auch constatirt, dass am Anfang der Ehe mehr Knaben geboren werden als zum Schluss.

Nach Düsing könnte man sich eine grössere Anzahl Knabengeburten als Ausdruck der verzögerten Befruchtung erklären; bei jungen Erstgebärenden kann man eine grössere Zahl Knabengeburten als Folge der unzureichenden Ernährung des Embryos auffassen, welche durch die noch nicht vollständig entwickelten genitalen Organe der jungen Erstgebärenden bedingt ist. Eine schlechte Ernährung des Embryo unterstützt nach Düsing mehr die Entwickelung eines männlichen, eine gute Ernährung die Entwickelung eines weiblichen Fötus. Darauf weist auch die verhältnissmässig grosse Anzahl Knabengeburten aus Müttern mit unregelmässigen (engen) Becken hin, wo man eine schlechte Ernährung der Genitalien und des Fötus voraussetzen könnte.

\section{Der Einfluss des öfteren geschlechtlichen Actes.}

Düsing und Janke versuchten zu beweisen, dass, wenn das Männchen aus irgend welchen Gründen genöthigt ist, den geschlechtlichen Act öfters zu verrichten, seine Nachkommenschaft überwiegend männlichen Geschlechts ist.

Die binnen 19 Jahren in den preussischen Pferdezuchtanstalten zusammengestellten Geburten (im Ganzen 708410 Fälle) weisen folgendes Verhältniss der Geschlechter auf: bei Hengsten, die mehr als 50 Sprünge das Jahr verrichtet haben, ist d. V. d. G. ihrer Nachkommenschaft $=99,8$, bei Hengsten, welche 20-50 Sprünge jährlich gemacht haben, ist d. V. d. G. $=96,4$.

In den Jahren 1887 und 1888 veröffentlichte $D$ üsing eine neue Statistik aus der Gesammtzahl von 190461 Geburten. Bei Hengsten,

welche 20-34 Sprünge verrichtet haben, war d. V. d. G. $=95,6$ 60 $n$ "

d. V. d. G: $=101,2$

Ferner stellte noch Düsing 4722 Geburten darnach zusammen, wie viele Sprünge der Vaterhengst den Tag verrichtet hatte, und er fand: 
bei einem Sprung täglich war d. V. d. G. seiner Nachkommenschaft $=91,6$ "zwei Sprüngen " "d. V.d. G. " Nachkommenschaft $=102,3$ ndrei $\quad n \quad n$ d. V.d.G. $n$ Nachkommenschaft $=104,9$

Endlich stellte auch noch Düsing 4787 Füllengeburten darnach zusammen, nach wievieltem Sprung die Conception eingetreten ist, und er fand, dass das V. d. G. bei der Nachkommensehaft, die schon nach dem ersten Sprunge desselben Tages empfangen wurde, 93,9 war, nach dem zweiten Sprunge des Tages war es 98,4 und nach dem dritten Sprunge 112,4.

Der amerikanische Rindviehzüchter Fiquet combinirte den Einfluss der gúten oder schlechten Ernährung mit dem Einfluss des öfteren oder seltenen geschlechtlichen Aktes und er fand, dass man in den meisten Fällen je nach Belieben einen Stier oder eine Färse erzielen könne.

Den Einfluss des öfteren oder seltenen geschlechtlichen Aktes erklärt Düsing ebenso wie den Einfluss des Mangels oder Ueberflusses an männlichen Individuen, wovon schon früher eine Erwähnung gemacht wurde.

\section{Der Einfluss der frühzeitigen oder verzögerten Befruchtung des Eies.}

Thury stellte eine Theorie auf, nach der aus dem frühzeitig befruchteten Ei ein weiblicher Fötus entsteht, aus dem spät befruchteten ein männlicher Fötus. $\mathrm{Zu}$ dieser Theorie gelangte Thury nur auf Grund von sehr geringen Fällen aus der Praxis und mit Hülfe dieser wollte man das grössere Procent Knabengeburten bei den Juden erklären. Nach den religiösen Vorschriften ist bei den Juden 7 Tage nach der Menstruation der Coitus untersagt, wodurch dann die Befruchtung des Eies sich verzögere, und deshalb werden procentual mehr Knaben geboren. In dieser Auslegung stimmt aber Düsing nicht mit Thury überein, sondern er legt diese Erscheinung als Folge des Mangels an Individuen des einen Geschlechts aus.

\section{Einfluss der Ernährung.}

Es ist eine durch das practische Leben bestätigte Thatsache, dass die Ernährung des Menschen sowie auch des Thieres einen Einfluss auf das Verhältniss der Geschlechter der Nachkommen- 
schaft ausübt. So wurde z. B. beobachtet, dass die Zahl der Knaben bei einer wirthschaftlich gut gestellten Nation fällt. Gute Ernährungsverhältnisse führen also zur Vermehrung von Geburten weiblichen Geschlechts, schlechte Ernährungsverhältnisse zur Vermehrung von Geburten männlichen Geschlechts.

Ploss hat das Steigen und Fallen der Preise von Nahrungsmitteln mit dem Schwanken des Verhältnisses der Geschlechter verglichen und hat die oben angeführten Sätze bestätigt.

Hampe berechnete das Verhältniss der Geschlechter bei Kindern armer Eltern auf 115, bei Kindern reicher Eltern auf 104,5.

Dasselbe können wir bei der Vergleichung armer und reicher Länder beobachten.

Hierber gehört auch das grosse Uebergewicht von Knabengeburten bei aussterbenden Nationen (in Amerika und Australien), so dass Düsing meint, der Ueberfluss an Knabengeburten bedeute ein schlechtes Zeichen für die Zukunft des bezüglichen Volkes.

Es ist eine allbekannte Thatsache, dass auf dem Lande mehr Knaben geboren werden als in der Stadt. So war in Preussen binnen 13 Jahren $(187 \check{0}-1887)$

$$
\begin{aligned}
& \text { d. V. d. G. am Land . . }=106,56 \\
& n " n n \text { in den Städten. }=105,81
\end{aligned}
$$

Düsing und Ploss erklären diese Erscheinung durch die bessere Ernährung und durch die leichtere körperliche Arbeit der Stadtbewohner.

Aehnliches beobachten auch Wilkens bei Versuchen an Pferden und Rindvieh, Fiquet beim Rindvieh und Martegoute bei den Schafen.

Der Einfluss der Ernährung wurde auf verschiedenen Wegen untersucht. Das eine Mal berücksichtigte man bloss die Ernährung der Mutter, das andere Mal nahm man Rücksicht auf die Ernährung beider Eltern, und zwar vor der Conception, bei der Conception und nach der Befruchtung.

Düsing erklärt den Einfluss der Ernährung folgendermaassen: Eine gute Ernährung hat Einfluss auf die Geschlechtsorgane und auf ihre Productionsthätigkeit. Die Erhöhung der Reproduction bezieht sich auf die Anzahl der Geburten überhaupt und hauptsächlich aber auf Geburten weiblichen Geschlechts. Diese erhöhte Reproduction des weiblichen Geschlechts bei guter Ernährung und die grössere Anzahl Knabengeburten bei schlechter Ernährung ist nach Düsing eine eigenthümlich nützliche Eigenschaft zur Ver- 
mehrung der Thiere und Menschen, welche durch natürliche Ausbildung mit der Zeit entstanden ist. In der Periode der schlechten Ernährung werden deshalb mehr Männchen geboren, damit die Vermehrung etwas eingeschränkt werde, und dass dann wegen der reducirten Nachkommenschaft bessere Ernährungsverhältnisse eintreten. Sobald dies erreicht ist, werden wieder weniger Männchen geboren, die Weibchen sind im Uebergewicht, so dass das V. d. G. beständig schwankt.

Diese Erscheinung, welche der Düsing'schen Auslegung unterlegt ist, wurde sehr oft wahrgenommen. Die eigentliche Erklärung der Differenzirung der Geschlechter bietet uns aber weder diese Theorie noch alle übrigen.

\section{Einfluss der Jahreszeit.}

Düsing constatirte an den Geburten in Preussen binnen 13 Jahren, dass im Frühling und im Sommer verhältnissmässig mehr Kinder concipirt werden als in den anderen Jahreszeiten, und zwar hauptsächlich mehr Mädchen, während im Herbst und im Winter (December ausgenommen) weniger Kinder concipirt werden, wobei ein grösserer Procentsatz Knaben ist.

Diese Erscheinung kann man auf verschiedene Art erklären. Düsing ist der Meinung, dass durch die grössere Wärme im Frühling und im Sommer die Anzahl der Conceptionen erhöht wird und glaubt, dass gerade die Wärme die Ursache einer intensiven Geschlechtsthätigkeit und vielleicht anch der Conceptionsthätigkeit ist.

\section{Einfluss des Alters der Eltern.}

a) Einfluss des absoluten Alters.

Die Beobachtungen Hofacker's und Stieda's haben ergeben, dass das Alter des Mannes einen Einfluss auf das Geschlecht der Nachkommenschaft habe. Düsing hat dies an 314456 Geburten bestätigt und fand, dass bei demselben Alter der Mutter jüngere Männere (15-30 Jahre) und ältere (über 45 Jahre) mehr Knaben erzeugen als im mittleren Alter (30-45 Jahre).

Wilkens ist der entgegengesetzten Meinung. Er beobachtete nämlich, dass

1. die über 14 Jahre alten Stuten mit Hengsten verschiedenen Alters verhältnissmässig mehr männliche Nachkommenschaft haben, 
2. die 9-14 Jahre alten Stuten mit Hengsten verschiedenen Alters haben mehr weibliche Nachkommenschaft,

3. endlich Stuten, Erstgebärerinnen, mit Hengsten verschiedenen Alters haben auch verhältnissmässig mehr weibliche Nachkommen. Deshalb glaubt Wilkens, dass das Alter der Hengste keinen Einfluss besitze.

Was das Alter der Mutter anbelangt, beweist eine ganze Reihe Forscher, dass, je jünger die Mutter ist (die jüngsten bis 19 Jahre ausgenommen), desto mehr Mädchen gebiert sie:

d.V. d.G. bei der Nachkommenschaft der Mutter 17--19 J. alt $=122$,

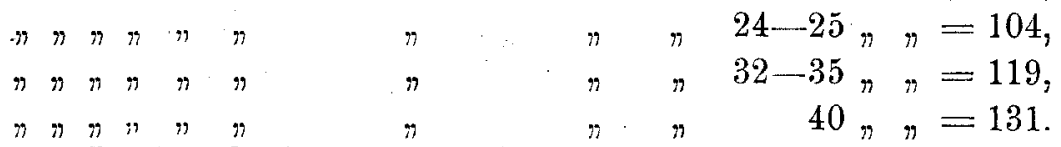

Je älter die Mutter ist, desto mehr Knaben gebiert sie.

Dasselbe wurde auch bei Pferden constatirt:

bei bis 9 Jahre alten Stuten war d.V. d. G. ihrer Nachkommenschaft $=95,5$

$" 9-14 n \quad " \quad n n n " n$ Nachkommenschaft $=92$

"14 u. darüber $" \quad n " n n "$, Nachkommenschaft $=107,0$

Daraus ist also ersichtlich, dass im mittleren Alter der Frau und auch des Thieres, wo die Productionsfähigkeit am grössten ist, am meisten weibliche Nachkommen geboren werden.

Diesen Einfluss des absoluten Alters der Mütter führte man auf den Einfluss der Ernährung zurück.

Die Geschlechtsorgane der noch ganz jungen Mütter sind noch nicht so entwickelt und die Ernährung der Genitalien und des Fötus nicht. so ausreichend, und deshalb gebären solche Mütter mehr Knaben. Die Mütter mittleren Alters, bei denen für die Ernährung der Genitalien und des Fötus die günstigsten Bedingungen bestehen, gebären mehr Mädcher.

b) Einfluss des relativen Alters.

Hofacker und Sadler legten ein grosses Gewicht auch auf das relative Alter der Eltern, das heisst, ob der Vater jünger oder älter als die Mutter ist, oder auch umgekehrt. Aus dem sogenannten Hofacker-Sadler'schen Gesetz erhielt sich, und zwar nur bei einigen Autoren, der Satz, dass in den Ehen, wo der Vater weit älter als die Mutter ist, mehr Knabengeburten constatirt werden. 


\section{Einfluss der Kreuzung.}

Düsing beobachtete, dass in den religiös gemischten Familien (wo man also auf eine grössere oder entferntere Kreuzung schliessen kann) mehr Mädchen geboren werden, als in den ungemischten. Auch in der Stadt, wo in Folge des Fremdenverkehrs eine grössere Kreuzung ist, giebt es mehr Mädchen als auf dem Lande. In den Fabriksorten, wo auch grösstentheils bei der Schliessung der Ehen eine grosse Kreuzung ist, giebt es auch ein verhältnissmässig grösseres Procent Mädchen und das Verhältniss der Geschlechter bei den Geburten ist demnach kleiner. Bei den Bergleuten dagegen, wo die Familien beständig ansässig bei einander leben und durch Ehen mit einander verwandt werden, findet man ein grösseres V. d. G., welcher Umstand durch die kleinere Kreuzung erklärt wird. Das Verhältniss der Geschlechter bei unehelichen Kindern, wo man also eine grössere Kreuzung voraussetzen kann, ist kleiner.

Bei den in Preussen binnen 13 Jahren zusammengestellten unehelichen Geburten ist d. V. d. G. $=105,54$ ehelichen

d. V. d. G. $=106,37$

Bei den Juden, bei denen bekanntlich grösstentheils verwandtschaftliche Ehen geschlossen werden, und wobei man in Eolge dessen eine geringe Kreuzung voraussetzen kann, wurde thatsächlich eine grössere Anzahl Knabengeburten constatirt.

Die in Preussen binnen 13 Jahren aus der Gesammtzahl von 134840 G. zusammengestellten jüdischen Geburten weisen ein V. d. G. $=107,64$; bei den Christen (10 Millionen Geburten) ist d. V. d. G. $=106$.

In den 8 angeführten Gruppen sind alle bisher bekannten Einflüsse aufgezählt, von denen man mit Recht oder Unrecht annimmt, dass sie auf die Bestimmung des Geschlechts des Fötus einwirken. Die genannten Factoren führen die Regulation des Verhältnisses der Geschlechter bei den Geburten durch und sind gewissermaassen gegenseitige Rivalen. Das Geschlecht wird durch die stärkere Gruppe gleich wirkender Einflüsse bestimmt.

Eine ganz andere Ansicht über die Entwickelung dieses oder jenes Geschlechts hat Orsansky ausgesprochen. Nach diesem Autor wird das Geschlecht des Fötus nach einem der Eltern geerbt. Die Erblichkeit nach Orsansky, d. i. der Einfluss der Eltern auf ihre Nachkommenschaft zeigt sich in zwei Richtungen: 
in der Aehnlichkeit oder der Uebertragung des Typus und in der Uebertragung des Geschlechts.

Zur Erklärung des cardinalen Unterschieds zwischen der männlichen und weiblichen Geschlechtszelle führt Orsansky eine Erwägung von Geddes und Thompson an, die folgendermaassen lautet: In jedem Lebewesen spielen sich zwei Arten von biologischen Processen ab, welche sich in zwei chemischen Richtungen deutlich machen und zwar: ein constructiver, synthetischer oder anabolischer Vorgang und ein destructiver, analytischer oder katabolischer Vorgang. Auf Grund ihrer Studien behaupten beide Autoren, der fundamentale Unterschied zwischen den beiden Geschlechtern bestehe darin, dass bei dem weiblichen Geschlecht die Synthesis vorherrscht, bei dem männlichen Geschlecht dagegen die Destruction. Wenn also die äusseren Einflüsse derart sind, dass sie nach diesem Princip den Anabolismus oder die Synthesis unterstützen, was durch die Ernährung, Temperatur, das Licht und durch andere physikalische Factoren erreicht werden kann, so ist dadurch die Möglichkeit zur Entstehung eines weiblichen Individuums gegeben. Im anderen Falle wird der Katabolismus unterstützt, und es entsteht eher ein männliches Individuum. Bemerkenswerth bei dieser Theorie ist der Umstand, dass die Autoren den Unterschied zwischen dem männlichen und weiblichen Geschlecht als etwas Primäres ansehen, obgleich aber bekannt ist, dass bei den niederen Thieren dieser Unterschied nicht besteht; deshalb ist diese Theorie nicht so allgemein gültig, wie sie ihre Urheber aufgestellt haben.

Charakteristisch für das weibliche Geschlecht ist die Menstruation, eine Erscheinung, welche dem Leben des Weibes einen periodischen Charakter aufdrückt. Die rhythmische Anlage der sexuellen Function brachte schon lange die Beobachter auf den Gedanken, dass sich im ganzen Leibe des Weibes ein periodischer Process mit monatlicher Wiederkehr abspiele, und dass die Menstruation bloss ein Theil dieses Processes sei. In jüngster Zeit kehrte Goodman wieder zu dieser Ansicht zurück und nach ihm spielen sich alle Lebensprocesse, wie Circulation des Blutes, Athmung, Austausch der Stoffe, Secretion bei dem Weibe in einem regelmässigen monatlichen Rhythmus ab, d. i. im Laufe des Monats stellt sich ein Steigen und Fallen aller dieser Processe ein. Nach seiner Meinung giebt es gar keine Beziehung zwischen der Ovulation und Menstruation. Goodmann theilt die Zeit zwischen zwei Menstruationen in 2 Hälften ein: in der einen Hälfte beob- 
achtet er ein Steigen aller Lebensvorgänge, d. i. Vermehrung der Wärmeproduction, höheren Blutdruck, vermehrte Harnabsonderung, iu der anderen eine Verminderung der Intensität der Lebensprocesse. In die Uebergangszeit von der einen Hälfte zur anderen fällt die menstruale Blutung. Die Menstruation ist das Endresultat der periodisch im ganzen Leibe auftretenden Veränderungen, welche auf den periodisch erscheinenden Contractionen der Gefässmusculatur beruhen. Die dynamische Ursache dieser periodischen Thätigkeit der Vasoconstrictoren, welche die Ueberfüllung der Capillaren unả der kleinen Venen mit. Blut bewirkt, beruht in den Nervencentren, welche in den Gefässwänden eingelagert sind.

Aus dieser Ansicht Orsansky's geht hervor, dass er zwar das Geschlecht als geerbt von einem der Eltern betrachtet, dass er aber doch äussere Einflüsse zulässt, welche in diesem Sinne auf die Erblichkeit einwirken.

Düsing behauptet dagegen, dass von einem Erben des Geschlechts nicht die Rede sein kann. Nach seiner Ansicht sind alle Eigenschaften der Thiere und der Pflanzen, die einen Einfluss auf die Bildung des Geschlechts ausüben, durch natürliche Auslese entstanden. Diese Eigenschaften sind für die Vermehrung der Thiere sehr nützlich und bewirken eine Ueberproduction des einen Geschlechts unter solchen Umständen, unter welchen dies zur längeren Lebensdauer der Pflanzen und Thiere nützlich ist. Mit Hülfe dieser Eigenschaften wird das Verhältniss der Geschlechter regulirt und bewegt sich um eine beständig wiederkehrende Mittelzahl. Unter bestimmten Umständen kann ein normales Verhältniss der Geschlechter für die längere Existenz der Gattung nützlich sein.

Von einem Erben des Geschlechts kann man hier nicht reden. Die Art, wie das eine oder das andere Geschlecht sich entwickelt, wird zwar geerbt, sagt Düsing, aber darüber, welches Geschlecht sich entwickeln soll, entscheidet nicht die Erblichkeit, sondern dies hängt von äusseren Einflüssen ab.

Die da hereinfallenden Eigenschaften der Organismen wurden durch die Accommodirung an die allgemeinen oder speciellen Lebensumstände gewonnen. Jene Umstände können theils gleichzeitig, theils nach einander auftreten und ihre Wirkungen werden sich in ihrem Einfluss auf das Geschlecht gegenseitig entweder unterstützen oder abschwächen. Je mehr die anfänglichen Einflüsse in ihren Wirkungen unterdrückt werden, desto eher gelangen dann die nachfolgenden Einflüsse oder Momente zur Gültigkeit. 
Wenn z. B. das Ei in der Zeit befruchtet ist, in welcher es noch sozusagen neutral ist, d. h. wenn die Tendenz, sich z. B. In ein weibliches Geschlecht zu entwickeln, in Folge der Alterung sich in die entgegengesezte umwandelt, da macht noch die Eigenschaft des Spermatozoon ihren Einfluss leichter geltend. Endlich tritt eine Zeit ein, wo das Geschlecht nach einer vielleicht mehrmaligen Umwandlung der Tendenz sich soweit entwickelt hat dass kein, auch der stärkste Einfluss es nicht mehr umwandeln kann, und das Geschlecht des Fötus ist dann definitiv bestimmt.

\section{Eintheilung und Zweck der Arbeit.}

Ich habe mir zur Aufgabe gemacht, das Verhältniss der Geschlechter bei den Geburten in Oesterreich überhaupt, in Böhmen besonders auszuforschen. Dabei bin ich so vorgegangen, dass ich das Verhältniss der Geschlechter bei solchen Geburten untersuchte, die von verschiedenen Lebensumständen begleitet waren. Diese auch bei der Conception gültigen sind folgende: Ich untersuchte das Verhältniṣs der Geschlechter bei ehelichen und unehelichen Kindern, bei todt- oder lebendgeborenen Kindern, bei Geburten in verschiedenen Jahreszeiten, bei Geburten ạm Lande, in den Städten und Grossstädten, bei Geburten nach den verschiedenen Religionen, nach der Dauer der Ehe, nach dem absoluten Alter der Mutter und nach dem relativen Alter beider Eltern, nach dem Beruf der Eltern; ich beobachtete das Verhältniss der Gesehlechter bei Kindern, die aus Zwillingen und aus Mehrgeburten stammen und endlich das Verhältniss der Geschlechtor bei Geburten bei den verschiedenen Nationen, welche Oesterreich, bewohnen.

Zuerst hatte ich die Absicht, bloss das Verhältniss der Geschlechter bei den Geburten in der kgl. böhmisehen Landesgebäranstalt zu untersuchen. Bald überzeugte ich mich aber, dass die Zahlen, welche ich so erhalten würde, wenig Bedeutung hätten, weil sie aus einer kleinen Zahl von Geburten berechnet wären. Es gab z. B. in der ersten geburtshülflichen Klinik des Herrn Hofrath Pawlík in dem ganzen Zeitraum von 25 Jahren, von dem Jahre 1881-1995 bloss 26751 Geburten, und es wäre deshalb unmöglich, irgend einen Schluss aus dem ausgerechneten Verhältniss zu ziehen. Daher sah ich mich genöthigt, zu einem grösseren Material zu greifen, wie es die Statistik einzelner, jm Reichrathe vertretener Königreiche und Länder und von ganz Cisleitanien bietet.

Auf diesem Wege stand mir ein viel grösseres Material zum 
Studium dieser Frage zur Verfügung und die ausgerechneten Zahlen erreichen einen viel grösseren Werth. Es gab in der ganzen Zeit, auf die sich die Untersuchung ausgedehnt hatte, nämlich von dem Jahre 1891-1902 in ganz Oisleithanien mehr als 11/2 Millionen Geburten, und es giebt einzelne Gruppen dieser Gesammtsumme, die gross genug sind, um dafür Bürgschaft zu leisten, dass die aus ihnen abgeleiteten Schlussfolgerungen richtig seien.

\section{Begriff des wahrscheinlichen Fehlers.}

In der Regel sind die Abweichungen von der Mittelzahl des Verhältnisses der Geschlechter desto grösser, je kleiner die Anzahl der behandelten Geburten ist. Solche Abweichungen werden fast alle durch blossen Zufall hervorgerufen. Jene Abweichungen, welche bei der Statistik der Länder und Reiche durch die Nichtangabe von Geburten oder durch andere Umstände entstehen, verschwinden in der Gesammtsumme. Aus den aus einer kleinen Anzahl von Geburten berechneten Abweichungen sehloss man früher, dass unter bestimmten Umständen mehr Mädchen, unter anderen wieder mehr Knaben geboren werden. Da diese Untersuchungen nur auf Grund von wenigen Fällen geführt wurden, so konnte diese Verschiedenheit des Verhältnisses der Geschlechter gerade so gut durch einen Zufall herbeigeführt werden, wie auch durch eine andere bestimmte Ursache.

Um solchen Fehlern auszuweichen, hielt ich es für nöthig, gerade so wie Düsing, in meine Abhandlung einen sogenannten wahrscheinlichen Fehler des Verhältnisses der Geschlechter einzuführen, um abschätzen zu können, welche Schlussfolgerungen ich aus dem berechneten Verhältniss ziehen könne.

Schon Lexis und nach ihm Carl Düsing machten auf die Wichtigkeit des wahrscheinlichen Fehlers aufmerksam.

Wenn von $g$ Geburten $k$ Geburten Knaben sind, so ist dann die empirische Wahrscheinlichkeit für die Knaben

$$
v=\frac{k}{g} \text {. }
$$

Der wahrscheinliche Fehler des Verhältnisses der Geschlechter wird aus der Anzahl von Geburten ausgerechnet:

$$
g=\frac{100 \varrho \sqrt{2 v(1-v)}}{(1-v)^{2} \sqrt{g}},
$$

wo die Constante $\varrho=0,4769360$ ist. 
Vergleichen wir nun zwei Verhältnisse der Geschlechter, von denen jedes einen nach jener Formel berechneten wahrscheinlichen Fehler a bezw. b besitzt, so ist dann der wahrscheinliche Fehler ihrer Differenz $=\sqrt{a^{2}+b^{2}}$. Wenn ihre wirkliche Differenz kleiner. ist als der wahrscheinliche Fehler, so ist dies auf jeden Fall ein blosser Zufall und auf nichts anderes, als auf einen Zufall kann man auch schliessen. Ist aber der Untersehied zweimal so gross oder noch grösser, als der wahrscheinliche Fehler, so hat man dies immer einer bestimmten Ursache zuzuschreiben. Auf diese Art erhalten wir einen Maassstab für den Werth der Beweisbarkeit unserer Zahlen.

Ich führe bloss an, wieviel nach Düsing'schen Berechnungen der wahrscheinliche Fehler des Verhältnisses der Geschlechter beträgt:

\begin{tabular}{crcc} 
aus & \multicolumn{4}{c}{100 Geburten } & 15,7 \\
$"$ & 500 & $n$ & 7 \\
$"$ & 1000 & $n$ & 4,8 \\
$"$ & 10000 & $n$ & 1,44 \\
$"$ & 50000 & $"$ & 0,65 \\
$"$ & 100000 & $"$ & 0,45 \\
$"$ & 1000000 & $"$ & 0,14 \\
$"$ & 10000000 & $"$ & 0,045 u. s. w.
\end{tabular}

Dies sind die wahrscheinlichen Fehler der in Deutschland berechneten Verhältnisse der Geschlechter. Aehnliche Tabellen muss man auch für alle Geburten in Oesterreich berechnen, ferner Tabellen für lebendgeborene Geburten, für todtgeborene und ähnliche noch mehr.

Ein specielles Beispiel erläutert am besten den ganzen Vorgang. Nach der Arbeit von Düsing gab es in Preussen am Lande während der erwähnten 13 Jahre im Ganzen 8889044 Lebendgeborene, davon waren 4568070 Knaben und 4320974 Mädchen. Ihr Verhältniss der Geschlechter ist 105,71. In derselben Zeit gab es in Preussen am Lande 371024 Todtgeborene, wovon 209142 Knaben und 161882 Mädchen waren, was also dem Verhältniss der Geschlechter von 129,19 entspricht. Der Unterschied zwischen den Verhältnissen der todt und lebendig Geborenen in Preussen beträgt also 23,48. Der wahrscheinliche Fehler des Verhältnisses bei den lebendig Geborenen ist nach der oben angeführten Tabelle 0,05. Der wahrscheinliche Fehler des Verhältnisses der Geschlechter bei den todtgeborenen beträgt 0,29. 
Der wahrscheinliche Fehler der Differenz beider Verhältnisse der Geschlechter $=\sqrt{0,05^{2}+0,29^{2}}$ oder 0,29. Da daraus ersichtlich ist, dass die Differenz jener zwei Verhältnisse der Geschlechter $=23,48$ weit grösser als der zweifache wahrscheinliche Fehler ist, kann man daraus mit Bestimmtheit schliessen, dass jenes hohe Verhältniss der Geschlechter bei den todtgeborenen Kindern durch keinen blossen Zufall verursacht wurde, sondern durch bestimmte, bei der Entwickelung jener todtgeborenen Kinder mitwirkende Ursachen. Bei der Anwendung des wahrscheinlichen Fehlers bei den Verhältnissen der Geschlechter und des wahrscheinlichen Fehlers der Differenz einzelner Verhältnisse erlangen die Untersuchungen eine grössere Bestimmtheit und lassen auch sichere Schlussfolgerungen zu.

Ehe ich aber die Resultate nach den einzelnen Gruppen der Lebensumstände der Eltern mittheilen werde, führe ioh jene Zahlen an, welche das Schwanken des Verhältnisses der Geschlechter bei den Geburten in Oesterreich überhaupt und in Böhmen besonders binnen 12 Jahren, und zwar von den Jahren 1891-1902 vorstellen.

\section{Das Verhältniss der Geschlechter bei den Geburten in Oesterreich und in Böhmen.}

Der Ausweis von den Geburten und Sterbefällen in allen im Reichsrathe vertretenen Königreichen und Ländern wird in den einzelnen Jahren unter dem Namen: „Bewegung der Bevölkerung der im Reichsrathe vertretenen Königreiche und Länder" veröffentlicht. Diese und noch andere statistische Publicationen werden unter dem Collectivtitel: "Oesterreichische Statistik" von der K. K. statistischen Centralcommission in Wien herausgegeben. H. Pelz, Hofrath bei der Statthalterei des Königreiches Böhmen, hat während einiger Jahre eine Statistik der Bewegung der Bevölkerung für das Königreich Böhmen herausgegeben; zu meiner Arbeit wurden aber die Daten der statistischen Centralcommission benützt, weil sie alle Jahre einbegreifen und zu den Zwecken unserer Untersuchung geeigneter zusammengestellt sind.

Auf Tab. 1 ist das Verhältniss der Geschlechter aller Geburten (also der ehelichen und unehelichen, der todt- oder lebendgeborenen Kinder) in der Zeit von 12 Jahren (1891-1902) angeführt. Die erste Zahlenreihe giebt das Verhältniss der Geschlechter in Böhmen, die zweite das Verhältniss der Geschlechter in Oesterreich an. 
Tabelle 1 .

\begin{tabular}{l|l|l}
\hline \hline Jahr & Böhmen & Oesterreich \\
\hline 1891 & 106,56 & 106,85 \\
1892 & 107,55 & 106,99 \\
1893 & 107,87 & 107,23 \\
1894 & 107,09 & 106,47 \\
1895 & 106,56 & 106,39 \\
1896 & 105,72 & 106,52 \\
1897 & 106,40 & 106,38 \\
1898 & 106,36 & 106,34 \\
1899 & 105,50 & 106,32 \\
1900 & 106,93 & 106,70 \\
1901 & 105,77 & 106,11 \\
1902 & 106,98 & 106,40
\end{tabular}

Die z. B. für das Jahr 1891 in der Reihe für Böhmen angeführte Zahl 106,56 zeigt also an, dass in diesem Jahre auf 100 Mädchen immer 106,56 Knaben geboren wurden, oder auf 10000 Mädchen 10656 Knaben. Aus der Tabelle ist weiter ersichtlich, dass die Zahl der Verhältnisse der Geschlechter bei den Geburten nicht constant bleibt, sondern dass sie sich jedes Jahr ändert. Im Ganzen sehwankt sie aber in Böhmen und in Oesterreich um die Zahl 106,5, wobei sie in Böhmen mehr von der Mittelzahl nach oben und unten abweicht als in Oesterreich. Diese grösseren Abweichungen des ausgerechneten Verhältnisses in Böhmen werden dadurch verursacht, dass in Böhmen jährlich weniger Kinder geboren werden als in ganz Oesterreich. Es wurden nämlich in Böhmen in jenen Jahren durchschnittlich jährlich 225000 Kinder geboren, in Oesterreich dagegen durchschnittlich jährlich fast 1000000 Kinder. Je kleiner die Anzahl der Geburten ist, welche wir zur Berechnung des Verhältnisses der Geschlechter benützen, desto mehr weicht die Verhältnissnummer von der Normalzahl ab. Auf Tab. 2 ist das Schwanken des Verhältnisses der Geschlechter in Böhmen (Linie I) und in Oesterreich (Linie II) graphisch dargestellt.

Tabelle 2 .

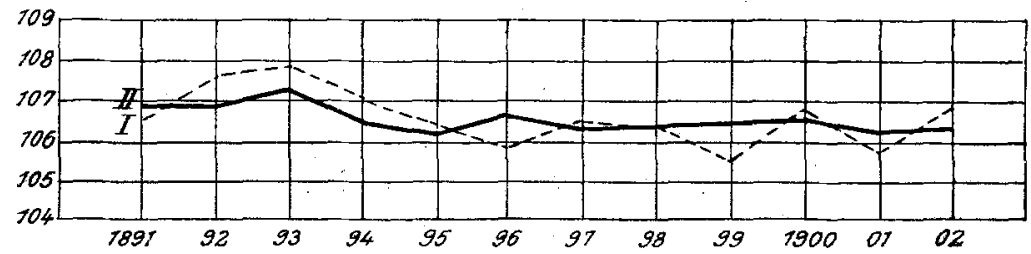


Links auf der Senkrechten sind in gleichen Abständen die Zahlen des Verhältnisses der Geschlechter von 104-109 aufgetragen. Auf der Basis sind die Jahre von 1891-1902 aufgetragen. Aus den beiden Linien ersieht man, dass das Verhältniss der Geschlechter in Oesterreich sich in diesen Jahren zwischen den Zahlen 106 und 107 bewegte, und dass dasselbe bloss im Jahre 1893 über die Zahl 107 hinausgeschritten ist. Besonders constant bleibt das Verhältniss der Geschlechter während der Jahre 1894-1902. In den Jahren 1891-1893 stand es höher als in den folgenden Jahren 1894-1902. Das Verhältniss der Geschlechter bei den Geburten in Böhmen schwankt zwar in grösseren Entfernungen als in Oesterreich, doch haben im Ganzen beide Linien wie für Oesterreich so auch für Böhmen einen übereinstimmenden Verlauf, was besonders in den Jahren 1892-1895 deutlich hervortritt. Den Culminationspunkt für Oesterreich sowie auch für Böhmen bildet das Jahr 1893, in welchem also verbältnissmässig die meisten Knaben und die wenigsten Mädehen geboren wurden. In diesem Jahre endigt auch die Jahresperiode mit höherem Verhältniss der Geschlechter, denn auch die vorhergehenden Jahre 1891 und 1892 stehen bedeutend noch über der Normalzahl $(106,5)$. Da mir aber die Zahlen des Verhältnisses der Geschlechter der Zeit vor 1891 vor der Hand noch nicht bekannt sind, kann ich noch nicht schliessen, wie lange jene Jahresperiode mit höherem Verhältniss der Geschlechter gedauert hat, und es ist mir aus diesem Grunde nicht möglich, irgend eine A uslegung dieser Erscheinung zu unternehmen.

Die amtlichen statistischen Daten in Oesterreich ermöglichen uns, dies Verhältniss der Geschlechter bei den Geburten nach folgenden 9 Gruppen zu durchforschen, welche den verschiedenen Lebensumständen der. Eltern entsprechen. Darnach wird das Verhältniss der Geschlechter untersucht, und zwar nach der:

I. Vitalität und Legitimität.

II. Jahreszeit.

III. Grösse des Ortes.

IV. Confession.

V. Dauer der Ehe.

VI. Alter der Eltern.

VII. Beruf der Eltern.

VIII. Zwillinge und Mehrgeburten.

IX. Nationalität. 


\section{Capitel I.}

\section{Das Verhältniss der Geschlechter, zusammengestellt nach der Vitalität und Legitimität.}
a) Im Königreich Böhmen.

Die Geburten nach der Vitalität und Legitimität können wir mittels der Combination im Ganzen in 9 Gruppen zusammenstellen. Diese Gruppen sind auf der folgenden Tabelle 3 dargestellt, wo alle Geburten in Preussen während 13 Jahren, und $z$ war vom Jahre 1875 bis zum Jahre 1887 zusammengestellt sind. Düsing führt in seinem Werke die Zahlen aller 9 Gruppen an und daraus habe ich meine beigelegte Tabelle 3 zusammengestellt, wobei in allen 9 Gruppen noch ein Unterschied zwischen den Geburten am Lande und in den Städten gemacht wird. Die dritte Rubrik, welche das Verhältniss der Geburten aller Geburten in Preussen überhaupt (in den Städten und auf dem Lande) enthält, habe ich selbst nach den Zahlen ven Düsing berechnet.

T.a b e lle 3.

\begin{tabular}{l|l|l|l|l}
\hline \hline \multirow{2}{*}{ Vitalität und Legitimität der Geburten } & \multicolumn{2}{|c|}{ Preussen } & Preussen \\
& & Städte & Land & uberhaupt \\
\cline { 2 - 5 } & & & & \\
\hline & & & & \\
\hline
\end{tabular}

Aus dieser Tabelle ist ersichtlich, dass das Verhältniss der Geschlechter 106,305 ist, und bei der näheren Untersuchung dieser Geburten nach der Vitalität, d. h. nach den lebend- oder todtgeborenen Kindern, finden wir einen grossen Unterschied. Das Verhältniss der Geschlechter bei den Lebendgeborenen ist 105,46 , bei den Todtgeborenen 128,61. Da die Ziffern, welche uns das Verhältniss der Geschlechter angeben, aus einer sehr grossen Anzahl von Geburten berechnet wurden, und da der wahrscheinliche 
Fehler sehr gering ist, kann man mit Bestimmtheit schliessen, dass diese. grosse Differenz zwischen den Verhältnissen der Geschlechter bei den todt oder lebendig Geborenen durch eine bestimmte Ursache und durch keinen blossen Zufall herbeigeführt wurde. Auch bei der Zusammenstellung der Geburten nach der Legitimität kann man feststellen, dass auch ein Unterschied zwischen dem Verhältniss der Geschlechter aller ehelichen Geburten (todten und lebendigen) und zwischen dem aller unehelichen existire. Dieser Unterschied ist zwar nicht so gross, wie bei den Verhältnissen der todt und lebendig geborenen Kindern, denn bei den ehelichen Geburten beträgt es 106,37, bei den unehelichen 105,54, aber mit Rücksicht darauf, dass diese Ziffern aus einer immensen Anzahl von Geburten berechnet wurden, und dass diẹse Differenz doch 0,83 beträgt, kann man behaupten, dass hier kein blosser Zutall mitgewirkt batte, sondern dass die Ursache davon ein wesentlicher Umstand ist, unter dessen Einfluss die Entwickelung des Fötus vor sich geht. Betrachten wir die ehelichen Geburten, was die Vitalität anbelangt, so sehen wir, dass das Verhältniss der Geschlechter bei den ehelichen lebendigen Geburten gleich 105,53, bei den ehelichen todten Geburten gleich 129,41 ist. Bei den unehelichen lebendigen Geburten beträgt das Verhältniss der Geschlechter 104,69, bei den unehelichen todten Geburten 121,98. Daraus ersehen wir, dass das Verhältniss der Geschlechter bei den ehelichen und unehelichen lebendigen Geburten ein viel kleineres ist, als bei den ehelichen und unehelichen todten Geburten.

Wir kommen nun zur Tabelle 4, auf der alle Geburten im Königreich Böhmen während 12 Jahre (vom Jahre 1891-1902)

T a b e 11 e 4 .

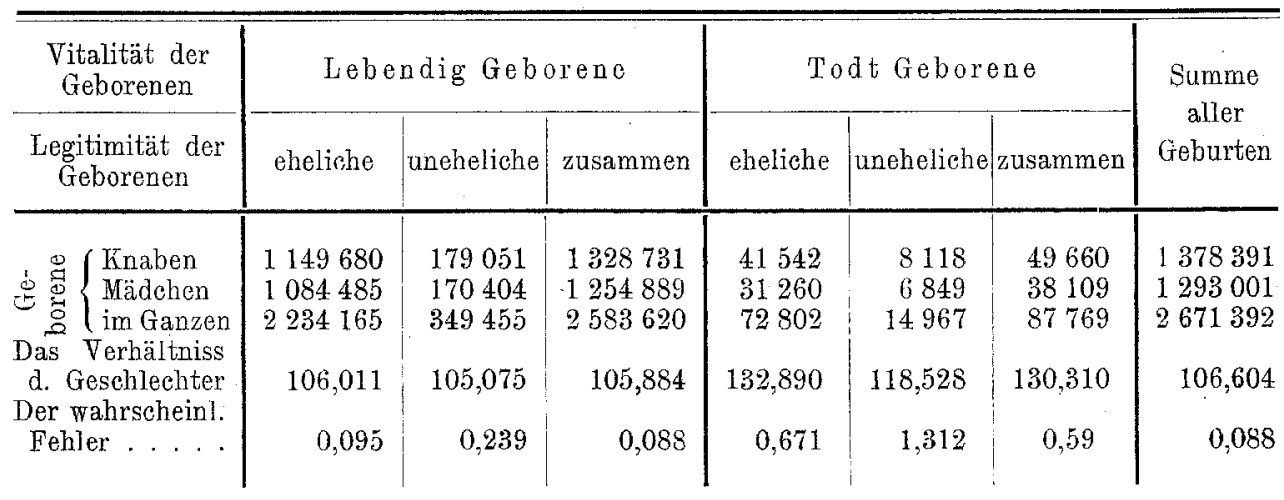


nach der Vitalität und Legitimität zusammengestellt sind. Auf dieser Tabelle sind immer angeführt die Anzahl von Knabengeburten, die dazu gehörige Anzahl von Mädchengeburten, die Gesammtsumme aller Geburten, das Verhältniss der Geschlechter aller dieser Geburten und endlich auch der bei der Berechnung des Verhältnisses der Geschlechter begangene wabrscheinliche Fehler. Wie aus der Tabelle ersichtlich ist, besitzt die Gruppe der todten unehelichen Gruppen die wenigsten Fälle. Demnach ist auch der wahrscheinliche Fehler des zugehörigen berechneten Verhältnisses am grössten. Nit Rücksicht darauf, dass das Verhältniss der Geschlechter bei den todtgeborenen unehelichen Geburten 118,528 beträgt, während das Verhältniss der Gesehlechter bei den lebendig geborenen unehelichen Geburten bloss gleich 105,075 ist, ist aus dem wahrscheinlichen Fehler der Differenz beider Verhältnisse ersichtlich, dass die Ursache eines so grossen Verhältnisses der Geschlechter bei den todtgehorenen unehelichen Geburten kein blosser Zufall sein wird, sondern gewiss ein wichtiger Umstand, unter welchem sich der Fötus entwickelte.

Die mittlere Zahl, das ist das Verhältniss der Geschlechter aller Geburten während der genannten Zeit im Königreich Böhmen, beträgt 106,604; mit anderen Worten, es wurden in Böhmen während dieser Zeit auf 100000 Mädchen 106604 Knaben geboren. Bei der Analysis aller Geburten finden wir ebenso wie Düsing in Preussen gefunden hatte, dass das Verhältniss der Geschlechter bei den lebendigen Geburten 105,88 beträgt, bei den todten Geburten 130,31. Bei der Zusammenstellung aller Geburten nach der Legitimität, finden wir bei allen ehelichen Geburten das Verbältniss der Geschlechter $=106,76$, bei allen unehelichen $=105,59$, die Differenz ist also 1,47. Bei den lebendigen ehelichen Geburten ist das Verhältniss der Geschlechter ebenfalls grösser $(106,01)$, als bei den unehelichen $(105,07)$ und auch bei den todten ehelichen Geburten beträgt das Verhältniss der Geschlechter 132,89, bei den unehelichen bloss 118,52. Daraus sehen wir also, dass dieselbe Erscheinung, welche Düsing bei unehelichen Geburten in Preussen constatirte, sich auch bei den Geburten im Königreich Böhmen zeigt.

In der folgenden Zusammenstellung ist das Verhältniss der Geschlechter aller jener neun Gruppen von Geburten nach der Vitalität und Legitimität in Böhmen übersichtlich angeführt. 


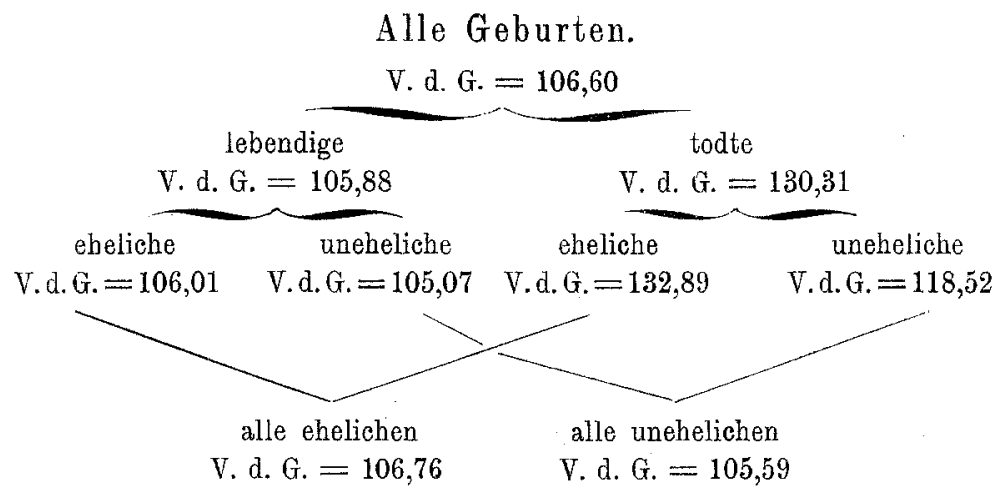

b) In ganz Oesterreich.

Auf Tabelle 5 sind nach Tabelle 4 alle Geburten in Oesterreich während 12 Jahre (1891-1902) nach der Vitalität und Legitimität zusammengestellt.

T a b e 11 e 5 .

\begin{tabular}{|c|c|c|c|c|c|c|c|}
\hline \multirow{2}{*}{$\frac{\begin{array}{c}\text { Vitalität der } \\
\text { Geburten }\end{array}}{\begin{array}{c}\text { Legitimität der } \\
\text { Geburten }\end{array}}$} & \multicolumn{3}{|c|}{ Lebendige Geburten } & \multicolumn{3}{|c|}{ Todte Geburten } & \multirow{2}{*}{$\begin{array}{l}\text { Summe } \\
\text { aller } \\
\text { Geburten }\end{array}$} \\
\hline & eheliche & uneheliche & Summe & eheliche & uneheliche & Summe & \\
\hline 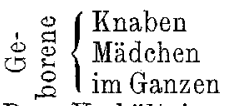 & $\begin{array}{l}4967023 \\
4691656 \\
9658679\end{array}$ & $\begin{array}{r}819694 \\
771981 \\
1591675\end{array}$ & $\begin{array}{r}5786717 \\
5463637 \\
11250354\end{array}$ & $\begin{array}{l}149856 \\
112179 \\
262035\end{array}$ & $\begin{array}{l}36025 \\
29213 \\
65238\end{array}$ & $\begin{array}{l}185881 \\
141.392 \\
327273\end{array}$ & $\begin{array}{r}5972598 \\
5605029 \\
11577627\end{array}$ \\
\hline $\begin{array}{l}\text { Das Verhältniss } \\
\text { d. Geschlechter } \\
\text { Der wahrscheinl. } \\
\text { Fehler d.V.d.G. }\end{array}$ & $\begin{array}{r}105,911 \\
0,045\end{array}$ & $\begin{array}{r}106,180 \\
0,113\end{array}$ & 105,913 & 133,586 & $\begin{array}{r}123,318 \\
0,824\end{array}$ & 131,465 & $\begin{array}{r}106,557 \\
0,042\end{array}$ \\
\hline
\end{tabular}

Aus dieser Tabelle ist ersichtlich, dass das Verhältniss der Geschlechter in Oesterreich (eheliche und uneheliche, todt oder lebendig (Geborene) 106,557 beträgt; dies bedeutet also, dass in dieser Zeit auf 100000 Mädchen 106557 Knaben geboren wurden. Vergleichen wir die beiden Zahlen von Böhmen und Oesterreich mit einander, so sehen wir, dass sie sich nur in sehr geringem Maasse von einander unterscheiden. Bei der Eintheilung aller Geburten in einzelne Gruppen finden wir genau so wie früber in Böhmen, auch in Oesterreich, dass das Verhältniss der Geschlechter bei den lebendigen Geburten ein viel kleineres ist $(105,90)$, als bei den todten Geburten $(131,46)$ : Betrachten wir aber die Geburten nach der Legitimität, finden wir, dass Oesterreich eine Ausnahme von allen dem bildet, was wir sonst überall vorgefunden 
haben, und was auch in dieser Arbeit bei Böhmen und Preussen angeführt worden ist, dass nämlich das Verhältniss der Geschlechter bei den ehelichen Geburten ein grösseres ist, als bei den unehelichen. Bei den Geburten von ganz Oesterreich finden wir, dass die unehelichen Geburten mehr Knaben aufweisen, als die ehelichen. Diese Erscheinung finden wir bestätigt bei den ehelich und unehelich lebendig Geborenen (105,91 gegen 106,18) und auch bei den gesammten ehelichen und unehelichen Geburten (106,51 gegen $106,80)$.

Die Differenzen der Geschlechtsverhältnisse aller dieser Gruppen ersieht man am deutlichsten aus der folgenden Zusammenstellung.

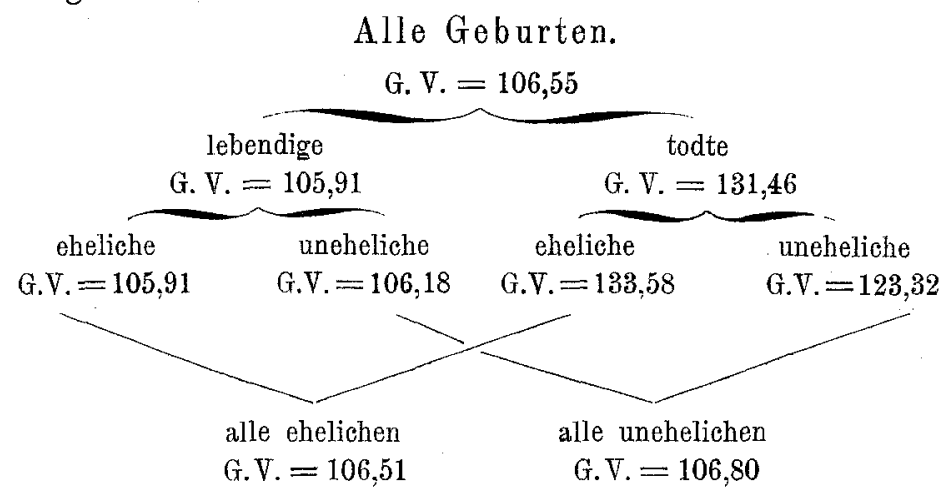

Nun stellt sich die Frage, wie dieser Ausnahmezustand bei den Geburten in Oesterreich zu erklären ist. Ich bemerke kurz, dass ich zur folgenden Erklärung gekommen bin. Die Vergrösserung des Geschlechtsverhältnisses bei allen unehelichen Geburten, sowie auch bei den lebendigen unehelichen Geburten hat man in den unehelichen jüdischen Geburten zu suchen, deren es in Oesterreich eine sehr grosse Anzahl giebt. Obgleich die Juden in Oesterreich nur 4,69 pCt: von der Gesammtbevölkerung bilden, ist. die Zahl der lebendigen unehelichen Geburten bei ihnen 215275 während der genannten Zeit (aller unehelichen lebend. Geburten gab es 1065 157), oder obgleich es der Juden nur so ein kleines Procent giebt, bilden doch alle ihre unehelichen lebendigen Geburten 20,2 pCt. der ganzen Summe. Die ehelichen jüdischen Geburten bilden nur die Hälfte dieser ganzen Summe. Ebenso gab es zweimal so viel todtgeborene jüdische uneheliche Kinder (nämlich 6443), als eheliche (3269). Da ferner alle jüdischen Geburten überhaupt, die unehelichen aber besonders ein hohes Verhältniss der Geschlechter aufweisen, d. h. 
da bei den Juden unverhältnissmässig mehr Knaben auf eine gleiche Anzahl Mädchen geboren werden, finde ich die Ursache jener Erscheinung, dass die unehelichen Geburten in Oesterreich ein höheres Geschlechtsverhältniss aufweisen, als die ehelichen, gerade in jenen unehelichen jüdischen Geburten, bei denen das Geschlechtsverhältniss gleich 114 ist. Es wird nicht uninteressant sein, zur Vollständigkeit anzuführen, dass eine überwiegende Mehrheit jener unehelichen Geburten auf Galizien kommt. Ich habe alle Geburten in Galizien während 12 Jahren zusammengestellt und habe gefunden, dass aus 3800722 Geburten 1962060 Knaben und 1838662 Mädchen waren, was also dem Geschlechtsverhältnisse 106,71 entspricht, worin ein wahrscheinlicher Fehler von 0,07 enthalten ist. Bei der Eintheilung von allen Geburten in Galizien nach der Confession zeigte es sich aber, dass das Geschlechtsverhältniss bei den katholischen Geburten (römisch-katholisch und griechisch-katholisch) bloss 106,00 ist, bei den jüdischen Geburten dagegen 112,06 .

Für meine Erklärung jener Erhöhung des Geschlechtsverhältnisses bei den unehelichen Geburten in Oesterreich spreehen auch die Resultate, welche im IV. Capitel dieser Abhandlung angeführt werden und wo alle Geburten in Oesterreich nach ihrer Confession gruppirt werden.

Nun stellt sich die Frage, wie man das kleinere Verhältniss der Geschlechter bei den unehelichen Geburten und die Erhöhung dieses Verhältnisses bei den todten Geburten erklären soll.

Ich stimme mit der Erklärung von Düsing überein, wonach man die Ursache des verkleinerten Verhältnisses der Geschlechter bei den unehelichen Kindern in der grösseren Kreuzung zu suchen hat, welche sich bei der Erzeugung unehelicher Kinder häufig darbietet, während die ehelichen und jüdischen Geburten besonders, welche sich beide durch die grössere Anzahl Knaben auszeichnen, Verbindungen entstammen, bei denen nur eine kleine Kreuzung der Eltern eintritt.

Das hohe Verhältniss der Geschlechter bei den todt Geborenen hat man dadurch zu erklären, dass das männliche Geschlecht schon während seiner embryonalen Entwickelung schneller wächst; sich mehr entwickelt und demnach auch mehr Nahrung braucht, als das weibliche Geschlecht, und wenn es an Nahrung mangelt oder wenn andere, mit diesem gleichwerthige Umstände eintreten, so leidet auch das männliche Geschlecht mehr durch diese Unzu- 
länglichkeiten, als das weibliche. Die Ursache der grösseren Anzahl der todt geborenen Knaben ist also der Umstand, dass gerade die Knaben, mit Rücksicht auf ihre Ernährungsansprüche, bei ihrer Entwickelung den ungünstigen Verhältnissen mehr unterliegen, als die Mädchen.

Zu diesem Capitel füge ich noch Resultate hinzu, welche ich bei der Untersuchung des klinischen Materials aus der böhmischen Gebäranstalt erhalten habe.

An der I. Gebärklinik des Hofraths Prof. Dr. K. Pawlik in der Landesgebäranstalt in Prag gab es in der Zeit ron 25 Jahren vom Jahre 1881-1905 im Ganzen: 26751 Geburten, davon waren 13946 Knaben und 12,805 Mädehen.

Das Verhältniss der Geschlechter dieser Geburten wird durch die Zahl 108,91 ausgedrückt. Diese Zahl ist bedeutend grösser als die für alle Geburten in ganz Böhmen auf.Tab. 4 angeführte Ziffer 106,60 .

Da aber die Geburten auf der erwähnten Klinik fast ausschliesslich unehelich sind, muss man ihr Verhältniss der Geschlechter mit der zugehörigen Zahl auf d. Seite 766 vergleichen und da findet man alle unehelichen Geburten in Böhmen die Zahl 105,59 angeführt. Dann -ist aber der Unterschied noch grösser. Die Schuld an diesem hohen Verhältniss der Geschlechter 108,91 tragen die todten Geburten, deren Zahl in jenen 25 Jahren 1186 (691 Knaben und 495 Mädchen) betrug mit dem V. d. G. $=139,5$. Rechnen wir diese todten Geburten ab, so stellt sich bei den übrig bleibenden Geburten ein V.d. G. von 107,42 heraus. Diese Zahl ist mit jener auf $\mathrm{S}$. $766 \mathrm{zu}$ vergleichen, wo alle lebendigen unehelichen Geburten und ihr V. d. G. $=105,07$ verzeichnet sind. Bei dieser Vergleichung ersieht man, dass G. V. bei den unehelichen Geburten auf der genannten Klinik ein bedeutend grösseres ist, als G. V. der unehelichen Geburten in ganz Böhmen und in ganz Oesterreich (siehe S. 766 und 767).

Nun stellt sich die Frage, wie diese Erhöhung zu erklären ist. Ich deute mir diese Erscheinung dahin aus, dass auf die unentgeltliche Abtheilung jener Klinik nur Mütter aus ärmeren Schichten der Bevölkerung kommen und dass ihre unzulängliche Ernährung die Ursache des erhöhten Verhältnisses der Geschlechter ihrer Nachkommenschaft ist. Meine Erklärung wird noch durch die weitere Thatsache unterstützt, dass das G. V. der auf der zahlbaren Abtheilung jener Klinik geborenen Kinder, wohin nur Mütter aus besser 
situirter Umgebung kommen, ein viel niedrigeres ist. $\mathrm{Zu}$ diesem Zwecke habe ich die Geburten vom Jahre 1881-1897 auf allen drei Klassen der zahlbaren Abtheilung zusammengestellt. Im Ganzen habe ich 742 Geburten (374 Knaben und 368 Mädchen) festgestellt, deren V. d. G. 101,6 beträgt. Diese Zahl unterstützt meine Vermuthung, weitere Folgen kann man aber daraus nicht ziehen, da die Anzahl von Geburten, aus der sie berechnet wurde, sehr klein ist.

Auf Tab. 6 habe ich nebeneinander die Zahlen des Verhältnisses der Geschlechter in Oesterreich und Preussen nach jenen nach der Vitalität und Legitimität combinirten neun Gruppen zusammengestellt. Auf den ersten Anblick ist ersichtlich, dass die Zahlen für Preussen etwas kleiner sind.

$\mathrm{T} a \mathrm{~b}$ e $\mathrm{ll}$ e 6 .

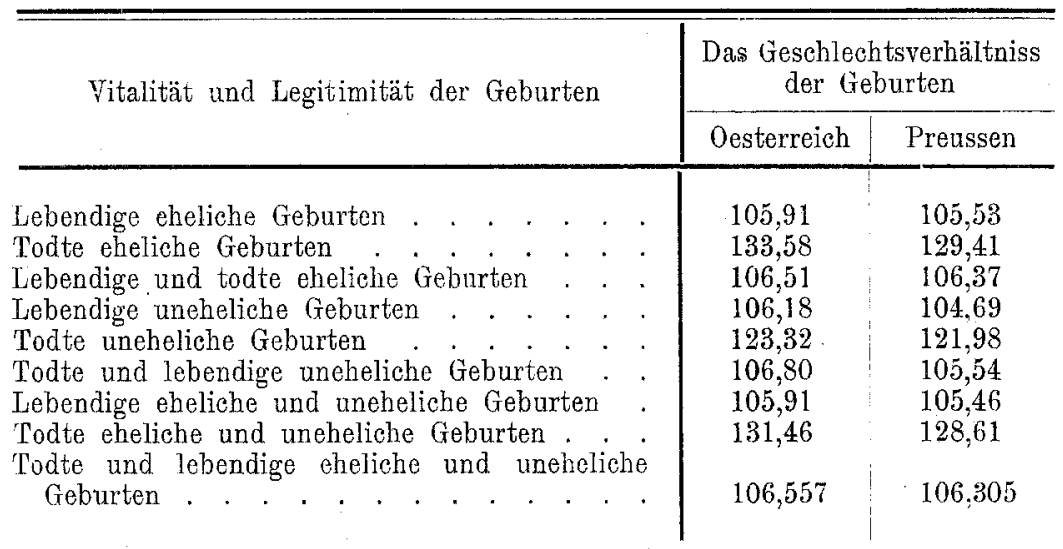

Auch hier sind irgend welche Umstände vorhanden, welche die Ursache davon bilden und zwar sind die Zahlen für Preussen deshalb um etwas kleiner, weil 1. in Preussen ein viel kleineres Procent Juden leben als in Oesterreich und 2. weil die in Preussen lebenden Slaven, nämlich die Polen sich durch ein kleineres Geschlechtsverhältniss bei den Geburten auszeichnen, was auch Düsing selbst bestätigt. In Oesterreich dagegen lebt ein viel grösseres Procent Juden mit einem hohen Geschlechtsverhältniss bei den Geburten, was auch später noch angeführt sein wird, und deshalb sind die Zahlen für Oesterreich um etwas grösser. Ausserdem wird noch später bewiesen, dass die Deutschen Oesterreichs in den deutschen Gegenden ein viel höheres Geschlechtsverhältniss bei den Geburten aufweisen. Rechnen wir alle jüdischen Geburten bei Preussen und Oesterreich ab und betrachten wir bloss alle Geburten 
Oesterreichs und Preussens ohne die.slavischen Geburten, bekommen wir bestimmt grössere Zahlen für Preussen. Der Beweis dazu wird im 4. und 9. Capitel dieser Abhandlung geliefert.

\section{Capitel II.}

\section{Das Geschlechtsverhältniss bei den Geburten nach der Jahreszeit.}

Düsing hat die Geburten Preussens nach den Monaten zusammengestellt und kam dabei zu dem Schluss, dass im Frühling mehr Kinder und zwar mehr Mädchen als im Herbst concipirt werden, während die Zahl der im Herbst erzeugten Kinder kleiner ist und unter ihnen giebt es wieder mehr Knaben.

Ich habe ebenfalls alle Geburten Böhmens sowie auch Oesterreichs nach den einzelnen Monaten zusammengestellt und das Ergebniss theile ich kurz in folgenden Tabellen mit. Die Tabellen 7 und 8 enthalten alle Geburten in Böhmen während 12 Jahren (1891-1902). Darin ist auch neben dem Monat der Conception und dem Monat der Geburt die durchschnittliche Anzahl Eheschliessungen angeführt, welche auf den Monat der Conception fällt, weiter die Anzahl der Knaben- und Mädchengeburten, die Gesammtanzahl aller Geburten, dann die durchschnittliche Geburtsanzahl und endlich das Geschlechtsverhältniss bei den Geburten nach den einzelnen Monaten.

In Preussen fand Düsing, dass sich bei einem Maximum der täglichen Anzahl Conceptionen, welches in den Frühling fällt, immer ein Minimum des Geschlechtsverhältnisses bildet, wogegen das Minimum der Conceptionsanzahl im Herbst immer von einem Maximum des Gesehlechtsverhältnisses begleitet wird. Daraus schliesst Düsing, dass im Frühling mehr Kinder, besonders aber mehr Mädchen als im Herbst gezeugt werden, während im Herbst weniger Conceptionen eintreten, darunter wieder mehr Knaben. Bei der näheren Betrachtung unserer Tabellen 7 und 8 finden wir, dass in Böhmen das Maximum der Geburten in den Conceptionsmonat Juli fällt und das Minimum in den Conceptionsmonat März. Das Maximum des Geschlechtsverhältnisses finden wir im März (Conceptionsmonat Juni) und das Minimum im December (Conceptionsmonat März).

Dies ist also nicht vollkommen übereinstimmend mit dem, was Düsing in Preussen gefunden hatte, und man kann bloss das bemerken, dass die tägliche Anzahl der Geburten in Böhmen vom März bis zum Juli steigt und vom August bis zum Februar fällt. 
Tabelle 7 .

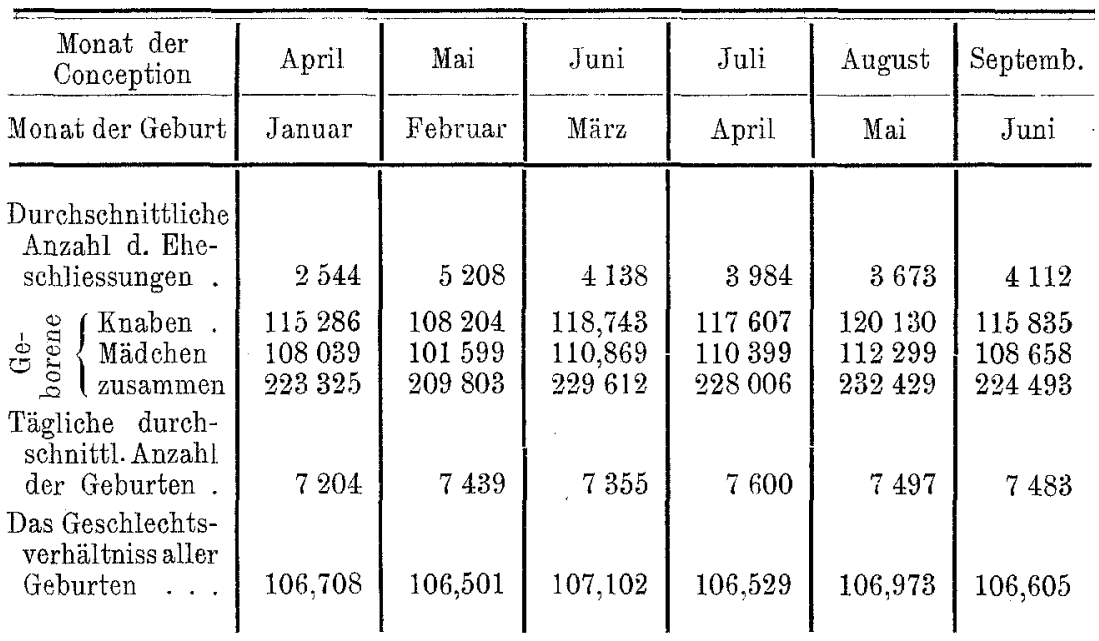

T a b e 11 e 8.

\begin{tabular}{|c|c|c|c|c|c|c|}
\hline $\begin{array}{l}\text { Monat der } \\
\text { Conception }\end{array}$ & October & Novemb. & Decemb. & Januar & Februar & März \\
\hline Monat der Geburt & Juli & August & Septemb. & Oetober & Novemb. & Decemb. \\
\hline $\begin{array}{l}\text { Durchschnittliche } \\
\text { Anzahl d. Whe- } \\
\text { sehliessungen. }\end{array}$ & 5407 & 7836 & 180 & 5135 & 7767 & 298 \\
\hline 邑异 $\left\{\begin{array}{l}\text { Knaben . } \\
\text { Mädchen } \\
\text { zusammen }\end{array}\right.$ & $\begin{array}{l}118977 \\
111283 \\
230260\end{array}$ & $\begin{array}{l}115405 \\
109520 \\
224925\end{array}$ & $\begin{array}{l}114052 \\
107428 \\
221480\end{array}$ & $\begin{array}{l}116342 \\
108747 \\
228089\end{array}$ & $\begin{array}{l}109593 \\
103200 \\
212793\end{array}$ & $\begin{array}{l}108247 \\
102070 \\
210317\end{array}$ \\
\hline $\begin{array}{l}\text { Tägliche durch- } \\
\text { schnittl. AnzahI } \\
\text { der Geburten. }\end{array}$ & 7427 & 7255 & 7382 & 7260 & 7093 & 6784 \\
\hline $\begin{array}{l}\text { Das Geschlechts- } \\
\text { verhältniss aller } \\
\text { Geburten } . . .\end{array}$ & 106,914 & 105,372 & 106,166 & 106,986 & 106,196 & 106,052 \\
\hline
\end{tabular}

Das Geschlechtsverhältniss ist aber in keinerlei Weise bestimmt an die tägliche durchschnittliche Anzahl der Geburten gebunden. Ich bemerke, was man hier einwenden könnte, dass nämlich die Gruppen der Geburten nach den einzelnen Monaten verhältnissmässig klein sind, da sie bloss durchschnittlich ungefähr 220000 Geburten im Monat umfassen, und da der wahrscheinliche Fehler des aus dieser Zahl berechneten Geschlechtsverhältnisses sich um 0,3 bewegt. Daher will ich auch überhaupt keine Schlussfolgerungen aus diesen Zahlen ziehen und gehe zu den aus allen Geburten 
Oesterreichs nach den Monaten zusammengestellten analogen Tabellen 9 und 10 über.

Ta b e lle 9 .

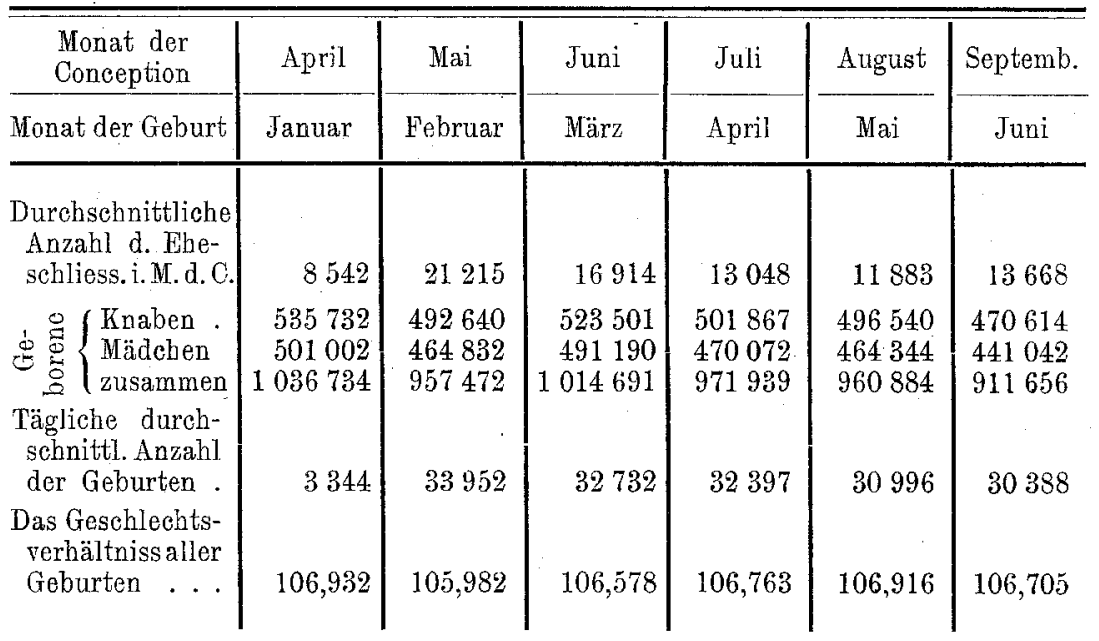

T a b e Ile 10 .

\begin{tabular}{|c|c|c|c|c|c|c|}
\hline $\begin{array}{l}\text { Monat der } \\
\text { Conception }\end{array}$ & October & Novemb. & Decemb. & Januar & Februar & März \\
\hline Monat der Geburt & Juli & August & Septemb. & October & Novemb. & Decemb. \\
\hline $\begin{array}{l}\text { Durchschnittliche } \\
\text { Anzahl d. Ehe- } \\
\text { schliessungen . }\end{array}$ & 19814 & 37892 & 1326 & 17240 & 40085 & 2216 \\
\hline 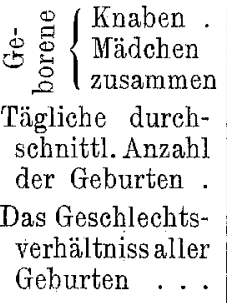 & $\begin{array}{l}498792 \\
477208 \\
976000\end{array}$ & $\begin{array}{l}490007 \\
462588 \\
952595\end{array}$ & $\begin{array}{l}483749 \\
454301 \\
938050\end{array}$ & $\begin{array}{l}508032 \\
475203 \\
983235\end{array}$ & $\begin{array}{l}483981 \\
456410 \\
940391\end{array}$ & $\begin{array}{l}487169 \\
456737 \\
943906\end{array}$ \\
\hline
\end{tabular}

Diese Tabellen sind genau so wie die für Böhmen zusammengestellt und deshalb sind zu ihrer Erklärung keine weiteren Worte nöthig. Das Maximum der Geburten fällt in den Februar (Conceptionsmonat Mai) und das Minimum in den Juni (Conceptionsmonat September). Dies ist vollkommen übereinstimmend mit dem, was $\mathrm{D}$ üsing in Preussen constatirt hatte. Das Maximum der 
Conception fällt also in Oesterreich in den Frühling und das Minimum in den Herbst. Diesem Maximum der täglichen durchschnittlichen Anzahl der Geburten im Maj sollte ein Minimum des Geschlechtsverhältnisses entsprechen und dem Minimum des Geschlechtsverhältnisses im September sollte ein Maximum des Geschlechtsverhältnisses entsprechen. Ich fand aber, dass das Minimum des Geschlechtsverhältnisses nicht in den Mai, sondern in den October fällt, und dass auch das Maximum nicht im September, sondern im April sich zeigt. Die Düsing'schen Resultate für Deutschland sind also allgemein nicht gültig. Auf den folgenden Tabellen 11 und 12 ist klar bewiesen, dass einer grösseren Anzahl der täglichen durchschnittlichen Geburten nicht immer ein kleineres Geschlechtsverhältniss entspricht und umgekehrt.

Tabel e 11 .

\begin{tabular}{|c|c|c|c|c|}
\hline Land & \multicolumn{2}{|c|}{$\mathrm{B} \ddot{o} \mathrm{~h} m \mathrm{e}$} & \multicolumn{2}{|c|}{ Oesterreieh } \\
\hline $\begin{array}{l}\text { Monat der } \\
\text { Conception }\end{array}$ & April-Sept. & Oct.-März & April-Sept. & Oet.-März \\
\hline Nonat der Geburt & Jan.-Juni & Juli--Dec. & Jan.-Juni & Juli-Dec. \\
\hline 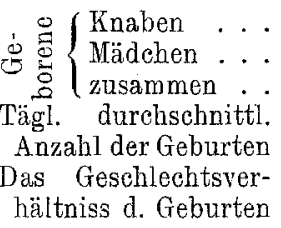 & $\begin{array}{r}695805 \\
651863 \\
1347668\end{array}$ & $\begin{array}{r}682616 \\
642248 \\
1324864 \\
7200 \\
106,28\end{array}$ & $\begin{array}{c}3020894 \\
2832482 \\
5853376 \\
32318 \\
106,65\end{array}$ & $\begin{array}{rl}2 & 951730 \\
2 & 782447 \\
5 & 734177 \\
& 31165 \\
& 106,08\end{array}$ \\
\hline
\end{tabular}

$\mathrm{T} a \mathrm{~b}$ e $11 \mathrm{e} 12$.

\begin{tabular}{|c|c|c|c|c|}
\hline \multirow{2}{*}{$\begin{array}{c}\text { Land } \\
\text { Monat der } \\
\text { Conception }\end{array}$} & \multicolumn{2}{|c|}{$\mathrm{B} \ddot{o} \mathrm{hm} \mathrm{en}$} & \multicolumn{2}{|c|}{0 esterreich } \\
\hline & Mai-October & Nov.-April & Mai-Oct. & Nov.-April \\
\hline Monat der Geburt & Febr.-Juli & Aug:-Jan. & Febr-TJuli & Aug.-Jan. \\
\hline 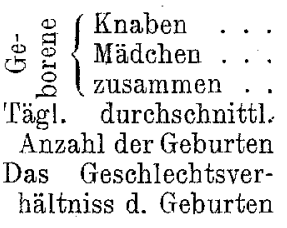 & $\begin{array}{r}699496 \\
658107 \\
1354603 \\
7466 \\
106,77\end{array}$ & $\begin{array}{r}678975 \\
679004 \\
1317929 \\
7163 \\
106,24\end{array}$ & $\begin{array}{c}2983954 \\
2808688 \\
5792642 \\
31991 \\
106,23\end{array}$ & $\begin{array}{r}2988670 \\
2806241 \\
5794911 \\
31491 \\
106,50\end{array}$ \\
\hline
\end{tabular}


Auf der Tabelle 11 sind die Monate für Böhmen und Oesterreich in zwei Gruppen eingetheilt, und zwar in die wärmeren Conceptionsmonate rom April bis September und in die kälteren Conceptionsmonate rom October bis März. Es stellt sich dann heraus, dass der Gruppe der wärmeren Conceptionsmonate eine grössere Anzahl der täglichen durchschnittlichen Geburten entspricht, während die Gruppe der kälteren Conceptionsmonate wieder eine kleinere Anzahl der täglichen durchschnittlichen Geburten nach sich zieht. Das Geschlechtsverhältniss in Böhmen und in Oesterreich auf Tabelle 11 regelt sich nach der Anzahl der täglichen durchsehnittlichen Geburten, es steigt, wenn diese Anzahl grösser wird, und fällt, wenn diese sich erniedrigt. Dies widerspricht den Schlussfolgerungen von Düsing. Auf Tabelle 12 habe ich absichtlich nach demselben Princip die Geburten in Böhmen und in Oesterreich ähnlich wie auf Tabelle 11 zusammengestellt, nur habe. ich die Gruppe der kälteren und wärmeren Monate um einen Monat später verlegt. Unter die wärmeren Monate habe ich die Monate vom Mai bis October, unter die kälteren die Monate vom November bis April eingereiht. Aus dieser Tabelle ersieht man, dass in Oesterreich und in Böhmen in den wärmeren Monaten mehr Kinder concipirt werden als in den kälteren Monaten. Das Geschlechtsverhältniss ist aber in Böhmen in den wärmeren Monaten grösser; d. h. es werden mehr Knaben gezeugt, während in den kälteren Monaten wieder mehr Mädchen gezeugt werden. In ganz Oesterreich ist dies umgekehrt. .Dort stimmen die Zahlen mit den Düsing'schen Zahlen überein; der grösseren Geburtenanzahl in den Sommermonaten entspricht eine kleinere Anzahl von Knabengeburten und der kleineren Geburtenanzahl in den kälteren Monaten entspricht eine grössere Anzahl von Knabengeburten.

Ich mache noch auf einen Umstand aufmerksam, worin auch Düsing derselben Meinung ist, nämlich dass die tägliche Geburtenanzahl und das Geschlechtsverhältniss nicht im geringsten von der durchschnittlichen Anzahl der jn irgend einem Monat geschlossenen Ehen abhängig sind, denn wie aus den Tabellen ersichtlich ist, fällt das Minimum der durchschnittlichen Eheschliessungen in Oesterreich sowie auch in Böhmen in den Conceptionsmonat December und dann in den März. Dieser Umstand übt aber gar keinen Einfluss weder auf die durchschnittliche Geburtenanzahl, noch auf das Geschlechtsverhältniss. Aus diesem Capitel sehen wir also, dass in Oesterreich und in Böhmen in den wärmeren 
Honaten mehr Kinder gezeugt werden, dass aber das Geschlechtsverhältniss sich nicht $\mathrm{zu}$ sehr nach der Jahreszeit zu richten scheint, wie dies Düsing in Deutschland gefunden hatte. 'Dic Ursache davon ist vielleicht die grosse geographische Gliederung des Reiches und ich vermuthe und werde mich auch nach Möglichkeit davon zu überzeugen suchen, ob die Düsing'sche Behauptung, dass in der wärmeren Zeit weniger Knaben, in der kälteren Zeit mehr Knaben gezeugt werden, nicht wenigstens für den mittlerẹn und nördlichen Theil des Reiches Gültigkeit besitzt.

\section{Capitel III.}

\section{Das Geschlechtsverhältniss bei den Geburten in der Stadt und am Lande oder nach der 0rtsgrösse.}

Es ist eine längst bekannte Thatsache, dass in der Stadt verhältnissmässig mehr Mädchen geboren werden als am Lande. Diese Erscheinung wird dadurch erklärt, dass die Stadtbewohner sich besser ernähren als die Landbevölkerung. Ploss benützte die statistischen Daten von Ducpetiaux und von Le Play über den Nahrungsverbrauch der arbeitenden Klassen, worin bewiesen wird, dass die Bevölkerung der Stadtgemeinden, besonders der Arbeiterorte, sich in besseren physischen und materiellen Verhältnissen befindet als die Landbevölkerung. Die Frauen in der Stadt geniessen eine bessere Nahrung als die Frauen am Lande und können deshalb ihre Eier und Leibesfrucht besser ernähren. Die Arbeiterfamilien in den Städten verbrauchen jährlich nicht nur mehr Geld für ihre Nahrung als die Familien am Lande, sondern auch der Consum ist bei den Landbewohnern viel kleiner (in Frankreich um 60 pCt.) als bei den Stadtbewohnern.

In Italien kam Corradi zu demselben Resultate.

Girou de Bouzarainques constatirte, dass das Geschlechtsverhältniss bei den Geburten auch in den einzelnen Bezirken des Reiches verschieden ist. Es schwankt zwischen 1000:920 und $1000: 964$, und zwar in den landwirthschaftlichen Bezirken ist es am grössten, in den anderen viel kleiner. Derselbe Autor hat schon früher den Satz aufgestellt, dass dort, wo schwere Arbeit verrichtet wird, z. B. am Lande, relativ viej Knaben geboren werden.

Horn gelangte zu ähnlichem Resultate. Nach seinen Berechnungen betrug das Geschlechtsverhältniss in Paris 104,7, in ganz Frankreich (vom Jahre 1841-1850) 106,7. 
Auch Quetelet führt in seinem Buch "Sur l'homme" Facten an, welche zu demselben Ergebniss führen. Am Kap der guten Hoffnung wurden vom Jahre 1813 bis zum Jahre 1820 bei den freien Weissen 6604 Knaben und 6789 Mädchen geboren, bei den Sklaven in derselben Zeit 2936 Knaben und 2826 Mädchen. Das Geschlechtsverhältniss beträgt also bei den freien Weissen 97,2 , bei den Sklaven 103,9.

Derselbe Autor giebt uns auch die Geburten in Belgien vom Jahre 1815 bis zum Jahre 1829 an, bei denen ebenfalls das Geschlechtsverhältniss am Lande grösser ist als in den Städten. Es ist also unzweifelhaft, dass die Lebensweise einen Einfluss auf das Geschlecht der Kinder ausübt.

Düsing fand in allen Städten und Dörfern Preussens in der Zeit von 13 Jahren (1875-1887) folgendes Geschlechtsverhältniss bei den Geburten:

In den Städten: 2523592 Knaben, 2384945 Mädchen, das Geschlechtsverhältnis 105,813; am Lande: 4772212 Knaben, 4482856 Mädchen, das Geschlechtsverhältniss 106,566.

Das relative Uebergewicht von Knaben am Lande tritt aus den genannten Zahlen deutlich hervor. Die Dif̣erenz der beiden Geschlechtsverhältnisse beträgt 0,75, ihr wahrscheinlicher Fehler bloss 0,08, also kaum den neunten Theil davon. Es steht also fest, dass in Preussen am Lande mehr Knaben geboren werden als in den Städten.

Auch Oettingen lässt die Verschiedenheit des Geschlechtsverhältnisses am Lande und in der Stadt zu.

Düsing hat noch weiter festgesellt, dass nicht nur zwischen Stadt und Land ein. Unterschied bestehe, sondern auch zwischen den verschiedenen Städten nach ihrer Grösse. Dabei führt er diese Tabelle an, welche er auf Grund ron Geburten binnen 13 Jahren zusammengestellt hat.

Geschlechtsveṛhältniss

Berlin . 105,193

Grossstädte (über 100000 Einw.) . . . . 105,31

Mittelgrosse Städte $(20000-100000$ Einw.) . 105,64

Kleine Städte (unter 20000 Einw.) . . . . . 106,18 Land . . . . . . . . . . . . . . . 106,56

Daraus ersehen wir, dass das Geschlechtsverhältniss am Lande am grössten ist, in den kleinen Städten etwas kleiner, in den mittelgrossen woch kleiner and in Berlin am kleinsten. 
Ploss als Erster erklärte, wie schon erwähnt wurde, diese Lischeinung durch die bessere Ernährung der Mütter in den Städten. Düsing bemerkt dazu, dass nach seiner Meinung die Ernährung nicht die einzige Ursache davon sei. Der Kreuzungsgrad ist am Lande ein ganz anderer als in der Stadt; je mehr getrennt und abgeschlossen die Leute auf dem Lande leben, desto mehr kommt es zu verwandtschaftlichen Verbindungen. In der Stadt bieten sich schlechtere Bedingungen dazu, so dass hier die Kreuzung oder geschlechtliche Mischung grösser ist. Da, wie uns die Erfahrung über das Geschlechtsverhältniss bei den Geburten aus religiös gemischten Ehen und aus jüdischen Ehen dagegen lehrt, verwandtschaftliche Ehen verhältnissmässig mehr Knabengeburten aufweisen, kann man auch die Grösse des Geschlechtsverhältnisses am Lande der schwächeren Kreuzung zuschreiben. Wahrscheinlich haben hier gleichzeitig sowohl die Ernährung als auch die Kreuzung Einfluss.

Düsing betrachtete näher die Städte und theilte sie in Fabrikstädte und andere Städte ein, wobei er censtatirte, dass die Fabrikstädte ein kleineres Geschlechtsverhältniss aufweisen. Wir seben also, dass unter den Städten, welche überhaupt ein kleineres Geschlechtsverhältniss aufweisen, in den Fabrikstädten verhältnissmässig am wenigsten Knaben geboren werden. Die Fabrikarbeiter, welche den Hauptbestandtheil der Bevölkerung solcher Städte ausmachen, werden im Durchschnitt nicht besser ernährt als die Bevölkerung anderer Städte und deshalb kann man diese Erscheinung nicht durch den Einfluss der besseren Ernährung erklären. Eine stärkere Mädchenproduction lässt sich bloss durch den Einfluss der stärkeren Kreuzung in den Fabrikstädten erklären.

Weiter untersuchte Düsing noch den Untersehied zwischen den Geschlechtsverhältnissen der unehelichen Kinder in der Stadt und am Lande. Der Beweggrund dazu war eine Erwähnung von Horn, welcher bemerkt, dass das Geschlechtsverhältniss bei den unehelichen Kindern am Lande, wo diese "Früchte der Liebe" sind, kleiner ist als in den Städten.

Düsing erhielt in dieser Richtung binnen 13 Jahren folgende Zahlen:

in der Stadt unehelich 104,95, ehelich 105,90, am Lande "105,96, "106,61.

Daraus ersehen wir, dass die Behauptung Horn's für Preussen nicht gültig ist. Auch darin ist Düsing nicht derselben Meinung, 
dass die Charakteristik der unehelichen Kinder gerade der Umstand wäre, dass sie oft Früchte der Liebe sind. Im Gegentheil sucht $D$ üsing die Ursache in der grösseren Kreuzung, welche in den Städten stärker ist. Diese Kreuzung tritt gerade bei den unehelichen Conceptionen am deutlichsten hervor. Darnach kommt Düsing zu dem Resultate, dass die stärkere Kreuzung die Ursache des niedrigen Geschlechtsverhältnisses ist.

Dio Lebensweise hat nicht bloss Einfluss auf das Geschlechtsverhältniss bei den Geburten in der Stadt and am Lande, sondern auch in den einzelnẹ Ländern. Ein höheres Geschlechtsverhältniss finden wir in jenen Ländern, welche erst für die Cultur erschlossen wurden, und wo die körperliche Arbeit überwiegt, z. B. in Australien. Dieselbe Erscheinung tritt in den neueren Staaten Nordamerikas gegenüber den älteren Staaten hervor.

Der Einfluss des Klimas wurde in seiner Wirkung auf das Geschlechtsverhältniss bei den Geburten nicht nach geographischer Breite, sondern was die Seehöhe anbelangt untersucht. $\quad$ Ploss bewies, dass die Zahl der Knabengeburten mit der Seehöhe wächst. Nach ihm hetrug in Sachsen in der Seehöhe:

bis zu 300 Fuss . . . . . das Geschlechtsverhältniss 105,9, von $1000-1500$ Fuss . . n " n 107,3, zwischen 1500 und 2000 Fuss $" ~ " 107,8$.

Ebenso wie das Klima wirkt auch die jährliche Wärmeänderung auf das Entstehen des Geschlechtes bei der Conception ein. Es kann bemerkt werden, dass in den wärmeren Monaten mehr Kinder gezeugt werden als in den kälteren, und dass mit der Conceptionsvermehrung das Geschlechtsverhältniss sich erniedrigt, wie dies Düsing in Preussen festgestellt hatte.

In der von der Centralcommission in Wien herausgegebenen österreichischen Statistik sind die Geburten nach der Ortsgrösse und nach der Legitimität zusammengestellt, und zwar sind darin die gesammten österreichischen Orte in 6 Klassen eingetheilt. In die erste Klasse gehören Orte mit bis zu 500 Einwohnern, in die zweite mit 501-2000, in die dritte mit 2001-5000, in die vierte mit $5001-10000$, in die fünfte mit $10001-20000$ und in die sechste Orte mit über 20000 Einwohnern.

Zur Berechnung folgender Tabelle benützte ich Daten aus 8 Jahren (vom Jahre 1895 bis zum Jahre 1902). Die zugehörigen Zahlen aus den angeführten 8 Jahren habe ich zusammengestellt und aus ihnen habe ich dann das Geschlechtsverhältniss für diese 
780 Srdínko, Geschlechtsverhältniss bei den Geburten in Oesterreich.

12

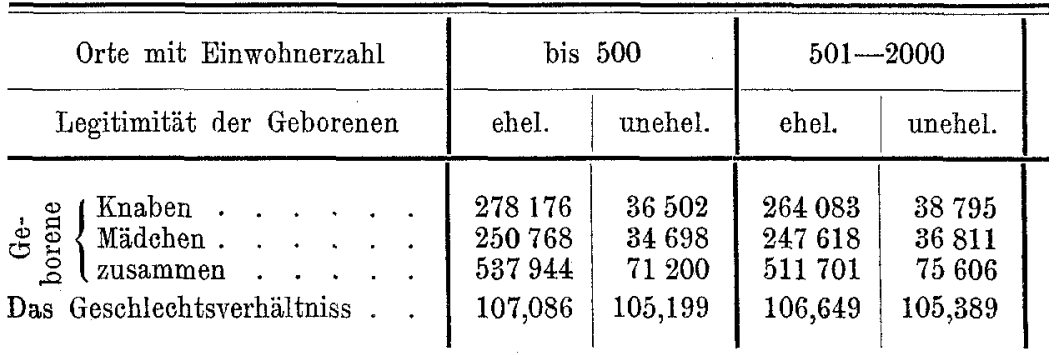

Ta -

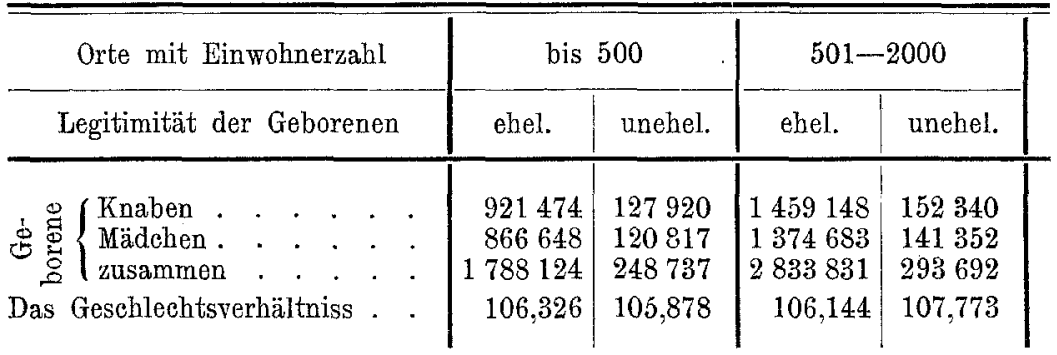

Zeit berechnet, wie dies aus Tabelle 13 und aus Tabelle 14 ersichtlich ist. Tabelle 13 giebt uns die Berechnungen für Böhmen an. Tabelle 14 ähnliche Berechnungen für Oesterreich.

Zur Uebersicht habe ich die Geburtenanzahl ausgelassen und habe bloss die Zahlen, welche das Geschlechtsverhältniss für $\mathrm{T}$ a be l l e 15.

\begin{tabular}{|c|c|c|}
\hline Ortsgrösse & Böhmen & Oesterreich \\
\hline $\begin{array}{r}\text { bis } 500 \\
501-2000 \\
2001-5000 \\
5001-10000 \\
10001-20000 \\
\text { über } 20000\end{array}$ & $\begin{array}{l}107,086 \\
106,649 \\
105,485 \\
106,957 \\
105,782 \\
106,365\end{array}$ & $\begin{array}{l}106,326 \\
106,144 \\
106,617 \\
106,978 \\
106,468 \\
106,372\end{array}$ \\
\hline
\end{tabular}

Ta be 11 e 16

\begin{tabular}{|c|c|c|}
\hline Ortsgrösse & Böhmen & Oesterreich \\
\hline 跣 $\begin{array}{r}\text { bis } 500 \\
501-2000 \\
2001-5000 \\
5001-10000 \\
10001-20000 \\
\text { über } 20000\end{array}$ & $\begin{array}{l}105,199 \\
105,389 \\
107,256 \\
108,777 \\
104,331 \\
107,538\end{array}$ & $\begin{array}{l}105,878 \\
107,773 \\
108,197 \\
109,590 \\
107,430 \\
106,366\end{array}$ \\
\hline
\end{tabular}


b e 11 e 13.

\begin{tabular}{|c|c|c|c|c|c|c|c|}
\hline \multicolumn{2}{|c|}{$2001-5000$} & \multicolumn{2}{|c|}{$5001-10000$} & \multicolumn{2}{|c|}{$10001-20000$} & \multicolumn{2}{|c|}{ über 20000} \\
\hline ehel. & unchel. & ehel. & unehel. & ehel. & unehel. & ehel. & unehel. \\
\hline 105537 & 16171 & 53471 & 8068 & 41545 & 6191 & 57712 & 19201 \\
\hline 100049 & 15077 & 49993 & 7417 & 39274 & 5934 & 54258 & 17855 \\
\hline 205586 & 31248 & 103464 & 15485 & 30819 & 12125 & 111970 & 37056 \\
\hline 105,485 & 107,256 & 106,957 & 108,777 & 105,782 & 104,331 & 106,365 & 107,538 \\
\hline
\end{tabular}

b e ll e 14.

\begin{tabular}{|c|c|c|c|c|c|c|c|}
\hline \multicolumn{2}{|c|}{$2001-5000$} & \multicolumn{2}{|c|}{$5001-10000$} & \multicolumn{2}{|c|}{$10001-20000$} & \multicolumn{2}{|c|}{ über 20000} \\
\hline ehel. & unehel. & ehel. & unehel. & ehel. & unehel. & ehel. & unehel. \\
\hline 500962 & 84027 & 155563 & 36488 & 110000 & 26501 & 328165 & 144854 \\
\hline 469867 & 77661 & 145414 & 33295 & 103317 & 24668 & 308505 & 136184 \\
\hline 970829 & 161688 & 300977 & 69783 & 213317 & 51169 & 636670 & 281038 \\
\hline 106,617 & 108,197 & 106,988 & 109,590 & 106,468 & 107,430 & 106,372 & 106,366 \\
\hline
\end{tabular}

Böhmen und für Oesterreich angeben, in einer besonderen Tabelle zusammengestellt, und zwar einerseits für eheliche Geburten (Tab. 15) andererseits für uneheliche Geburten (Tab. 16).

Aus den Tabellen ist ersichtlich, dass das Geschlechtsverhältniss bei den ehelichen Geburten in Böhmen zwischen 105,48 und 107,08 schwankt, in Oesterreich zwischen 106,14 und 106,97. Bei den unehelichen Geburten in Böhmen schwankt das Geschlechtsverhältniss zwischen 104,33 und 108,77 und in Oesterreich zwischen 105,87 und 109,59. Dieses Schwanken tritt bei der graphischen Darstellung (Tab. 17) am deutlichsten hervor.

Tabelle 17 .

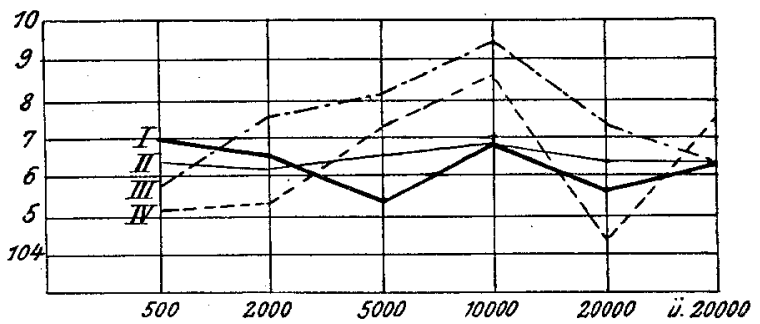

I. Böhmen, ehelich.

II. Oesterreich
III. Böhmen, unehelich.

IV. Oesterreich " 
Auf der Basis sind Zahlen aufgetragen, welche die Ortsgrösse angeben, links auf der Senkrechten: Anzahl Knaben auf 100 Mädchen, von 103-110. Die Linie I bedeutet die ehelichen Geburten in Böhmen, Linie II die ehelichen Geburten in Oesterreich, Linie III die unehelichen Geburten in Böhmen und Linie IV die unehelichen Geburten in Oesterreich.

Aus der Abbildung ist ersichtlich, dass in den kleinsten Orten das Geschlechtsverhältniss der unehelichen Kinder in Böhmen und Oesterreich niedriger ist als bei den ehelichen Kindern, in den Orten mit 2000-20000 Einwohnern ist das Geschlechtsverhältniss bei den unehelichen Kindern in ganz Oesterreich höher als bei den ehelichen Kindern. Aus der Abbildung lassen sich folgende Facten entnehmen: 1. Die Linien II, III und IV stejgen in den Orten mit 2000-10000 Einwohnern, worauf sie dann fallen. 2. Dieselben Linien eulminiren in Orten mit 10000 Einwohnern. 3. Alle vier Linien fallen in Städten mit 10000-20000 Einwohwern. Besehen wir genau den Verlauf der Linien II und III, welche uns die ehelichen und unehelichen Geburten in ganz Oesterreich nach der Ortsgrösse andeuten, so können wir constatiren, dass bloss in den kleinsten Dörfern das Geschlechtsverhältniss der unehelichen Kinder niedriger ist als bei den ehelichen, wogegen in allen übrigen Orten das Geschlechtsverhältniss bei den unehelichen Kindern in ganz Oesterreich höher ist als bei den ehelichen Kindern. Seinen Höhepunkt erreicht dieses Geschlechtsverhältniss bei den unehelichen Kindern in ganz Oesterreich in den Orten mit 10000 Einwohnern und die Erklärung dieser Thatsache ist darch den Einfluss von mehreren Factoren zu liefern, wobei die jüdischen Geburten, welche in den Orten mit 2000--20000 Einwohnern mit einbegriffen sind, eine nicht unbedeutende Rolle spielen. Ich bemerke besonders, dass in Galizien, Bukowina und anderen Ländern viele Juden ansässig sind, welche einerseits überhaupt viele uneheliche Geburten aufweisen, andererseits sich durch ein hohes Geschlechtsverhältniss kennzeichnen.

Die Erläuterung und Zerlegung der Linien auf der beigefügten Abbildung würde sehr viel Raum einnehmen, und da ich nichts Bestimmtes mehr anführen kann, beschränke ich mich bloss auf die Constatirung des Angeführten. Betrachten wir die ehelichen Geburten in Böhmen und Oesterreich näher, so sehen wir, dass thatsächlich am Lande um etwas mehr Knaben geboren werden als in den grösseren Orten mit 2000-5000 Einwohnern (in Böhmen). 
Von einem bestimmten Verlauf der Linie I und II, welcher absteigend von links nach rechts genannt werden könnte, kann man aber nicht sprechen.

Die österreichische Statistik theilt leider nicht alle Orte in Oesterreich in zwei Kategorien ein, nämlich in die Stadt- und Landgemeinden, und erst nach einer mühevollen Zusammenstellung kann mit einer solchen Eintheilung begonnen werden.

Ich will noch einige österreichische Städte und ihr Geschlechtsverhältniss anführen. Zu diesem Zwecke wählte ich neun österreichische Städte, wie sie auf der Tabelle 18 angeführt sind nnd habe alle Geburten in ihnen in der Zeit von 6 Jahren (vom Jahre 1897-1902) zusammengerechnet.

T a b e 11 e 18 .

\begin{tabular}{|c|c|c|c|c|c|c|c|c|c|}
\hline$S t a d t$ & Wien & $\operatorname{Linz}$ & $\begin{array}{l}\text { Salz- } \\
\text { burg }\end{array}$ & Graz & $\begin{array}{c}\text { Klagen- } \\
\text { furt }\end{array}$ & $\begin{array}{l}\text { Lai- } \\
\text { bach }\end{array}$ & Prag & $\begin{array}{l}\text { Lem- } \\
\text { berg }\end{array}$ & Triest \\
\hline Knaben & 165938 & 5686 & 2715 & 13374 & 2573 & 3560 & 22764 & 18960 & 17519 \\
\hline 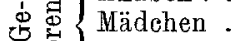 & 156990 & 5395 & 2482 & 12350 & 2378 & 3478 & 21404 & 17800 & 16445 \\
\hline 范 | zusammen & 322928 & 11081 & 5197 & 25724 & 4951 & 7038 & 44168 & 36760 & 33964 \\
\hline $\begin{array}{l}\text { Das Geschlechts- } \\
\text { verhältniss aller }\end{array}$ & & & & & & & & & \\
\hline Geburten ... & 105,69 & 105,39 & 109,39 & 108,29 & 108,20 & 102,35 & 106,35 & $106, \grave{51}$ & 106,53 \\
\hline Der wahrscheinl. & & & & & & & & & \\
\hline Fehler d. G. ... & 0,25 & - 1,39 & 2 & 0,92 & 2,1 & 1,7 & 0,70 & 0,78 & 0,8 \\
\hline
\end{tabular}

Aus der Gesammtsumme der Geburten habe ich dann das Geschlechtsverhältniss berechnet. Die, Tabelle 18 giebt uns die Anzahl der Knaben- und Mädchengeburten in den einzelnen Städten an, dann das Geschlechtsverhältniss aller dieser Geburten und den wahrscheinlichen Fehler des berechneten Geschlechtsverhältnisses:

Zur besseren Uebersicht habe ich die Städte noch in einer anderen Tabelle (19) zusammengestellt, in welcher die Einwohnerzahl nach der Volkszäblung aus dem Jahre 1900, die durchschnittliche Jahreswärme in den einzelnen Städten, die Seehöhe und das Geschlechtsverhältniss aller Geburten angeführt sind.

Diese Tabelle beweist klar, dass auf das Geschlechtsverhältniss mehrere Factoren einwirken und nicht bloss die Kreuzung, die nach der Ortsgrösse abgeschätzt wird. Aus der Tabelle ist ersichtlich, dass z. B. die grösste Stadt, Wien, ein viel höheres Geschlechtsverhältniss besitzt als Laibach und man kann also in keiner Weise behaupten, dass das Geschlechtsverhältniss sich nur einigermassen nach der Ortsgrösse richtet. Auch die durchschnitt- 
T a b e 11 e 19.

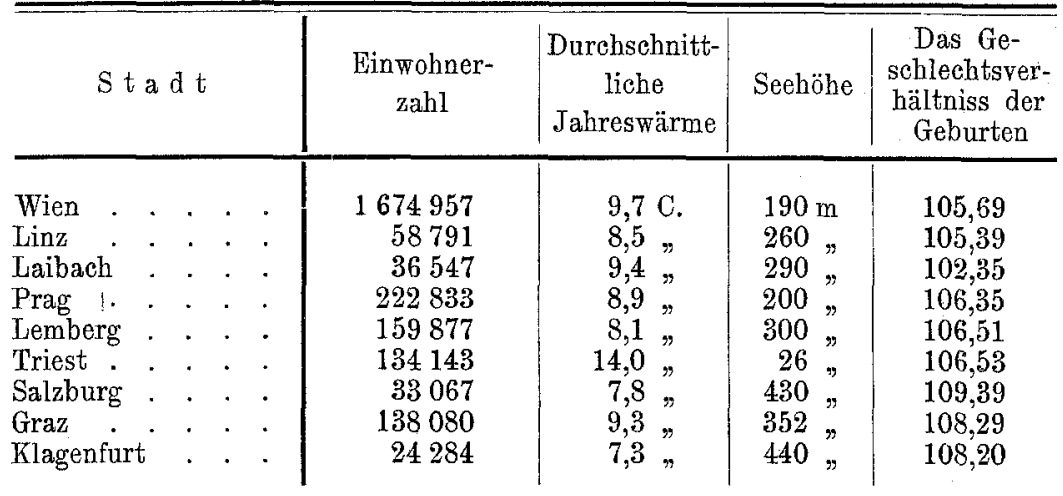

liche Jahreswärme und die Seehöhe bilden ebenfalls keinen allgemeinen Maassstab des Geschlechtsverhältnisses für alle Städte. Man kann nur soviel vermuthen, dass das hohe Geschlechtsverhältniss bei den Geburten in Klagenfurt, Graz und Salzburg mit der grossen Seehöhe dieser Städte correspondirt, so dass man hier die Behauptung von Ploss anführen könnte, nämlich dass die Anzahl Knabengeburten mit der Seehöhe wächst. In Laibach fällt wieder das slavische Element auf die Waage, bei dem, wie noch später in einem anderen Capitel gezeigt wird, das Geschlechtsverhältniss am niedrigsten ist von ganz Oesterreich.

\section{Capitel IV.}

\section{Das Geschlechtsverhältniss bei den Geburten nach der Religion.}

Firks untersuchte, unter welchen besonderen Umständen das Geschlechtsverhältniss bei den Geburten von der Durchschnittszahl abweicht, berücksichtigte aber dabei nie die Religion der Eltern. Er ging wahrscheinlich von dem Standpunkt aus, dass die Religion keinen Einfluss auf das Geschlecht der Kinder haben könnte. Obgleich der Religion kein solcher unmittelbarer Einfluss zugeschrieben werden kann, können doch mit der Religion solche Umstände zusammenhängen, welche einen Einfluss auf das Geschlecht der Geburten ausüben.

So ist z. B. schon längst bekannt, dass die Juden bei ihren Geburten ein sehr hohes Geschlechtsverhältniss besitzen, dass ihnen also viel mehr Knaben geboren werden als den Christen. So wurden z. B. in dem Wieselburger Comitate in den Jahren 1835 bis 1855 auf 100 jüdische Mädchen 117,1 Knaben geboren. In 
Preussen betrug das Geschlechtsverhältniss bei den Juden in den Jahren 1820-1834: 111, in Schweden in den Jahren 1851 bis 1855: 108. Diese Zahlen beweisen uns noch nicht viel, da sie grösstentheils auf einer kleinen Anzahl beruhen.

Düsing hat die binnen 13 Jahren in Preussen geborenen jüdischen Kinder zusammengezählt und fand bei ihnen ein Geschlechtsrerhältniss von 107,64, während es bei den evangelischen 106,37 , bei den katholischen 106,43 und bei den übrigen christlichen Kindern 106,36 betrug. Daraus ersehen wir, dass alle Christen ein viel kleineres Geschlechtsverhältniss aufweisen als die Juden, denn die hohen Geschlechtsverhältnisszahlen wurden aus einer bedeutenden Gesammtsumme aller jüdischen Geburten berechnet und sind auch in allen übrigen Ländern viel grösser als bei den Christen, wie ich auch für Oesterreich beweisen werde. Diese Erscheinung erklärt $D$ üsing durch die bei den Juden üblichen verwandtschaftlichen Eheschliessungen, wobei eine kleine Kreuzung eintritt, und eine kleine Kreuzung sei nach seinen eigenen Forschungen und nach den Ergebnissen vieler anderer Forscher die Ursache, dass mebr männliche Individuen geboren werden. Im Gegentheil dazu werden bei grösserer Kreuzung, wie wir sie bei unehelichen Kindern oder in den Fabrikstädten vorfinden, wieder mehr Mädchen geboren.

Ich werde mich nicht ausführlich mit den Düsing'schen und mit anderen Auslegungen, wie sie uns Thary liefert, weiter beschäftigen, sondern beschränke mich bloss darauf, die Resultate anzuführen, wie ich sie für die einzelnen Confessionen berechnet habe.

Auf Tabelle 20 sind Geschlechtsverhältnisszahlen für die fünf am meisten vertretenen Confessionen angeführt.

$\mathrm{T}$ a b e 11 e 20 .

\begin{tabular}{|c|c|c|c|c|c|c|}
\hline & $\begin{array}{l}\text { Römisch- } \\
\text { kathol. }\end{array}$ & $\begin{array}{l}\text { Griech.- } \\
\text { kathol. }\end{array}$ & $\begin{array}{c}\text { Griech.- } \\
\text { orient. }\end{array}$ & Evang. & Israel. & Andere \\
\hline 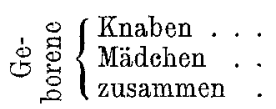 & $\begin{array}{l}3078427 \\
2899108 \\
5977535\end{array}$ & $\begin{array}{r}607104 \\
572658 \\
1179762\end{array}$ & $\begin{array}{r}96324 \\
90960 \\
187284\end{array}$ & $\begin{array}{r}81523 \\
76014 \\
157537\end{array}$ & $\begin{array}{l}182361 \\
161824 \\
344185\end{array}$ & $\begin{array}{l}3010 \\
2839 \\
5849\end{array}$ \\
\hline $\begin{array}{l}\text { Das Geschlechtsver- } \\
\text { hältniss d.Geburten }\end{array}$ & 106,185 & 106,015 & 105,897 & 107247 & 112691 & 106023 \\
\hline
\end{tabular}

Die Tabelle, welche aus allen Geburten (todten und lebenden, ehelichen und unehelichen) binnen 8 Jahren (1895-1902) in 
Oesterreich zusammengestellt ist, zeigt uns, dass unter die auf Tabelle 5 für ganz Oesterreich angegebene Durchschnittszahl $(106,557)$ die Geschlechtsverhältnisse der römischkatholischen, griechischkatholischen und griechischorientalischen Geburten fallen. Ueber diese Zahl steigt das Geschlechtsverhältniss bei den Evangelischen und bei den Juden. Das Minimum aller angeführten Confessionen finden wir bei der griechischorientalischen Confession, dann folgt die griechischkatholische, die römischkatholische, die evangelische und endlich die Juden.

Die auf Tabelle 20 angeführten Zahlen kann man nach der Vitalität und Legitimität, wie dies auf Tabelle 21 und 22 gemacht wurde, gruppiren. Tabelle 21 enthält alle lebendgeborenen und ehelichen Geburten in ganz Oesterreich aus 8 Jahren (1895-1902).

T a b e 11 e 21 .

\begin{tabular}{|c|c|c|c|c|c|c|}
\hline & $\begin{array}{l}\text { Römisch- } \\
\text { kathol. }\end{array}$ & $\begin{array}{l}\text { Griech.- } \\
\text { kathol. }\end{array}$ & $\begin{array}{l}\text { Griech.- } \\
\text { orient. }\end{array}$ & Evang. & Israel. & Andere \\
\hline 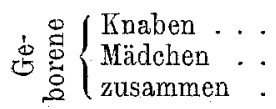 & $\begin{array}{l}2588420 \\
2449593 \\
5038013\end{array}$ & $\begin{array}{r}564634 \\
534735 \\
1099369\end{array}$ & $\begin{array}{r}86854 \\
82557 \\
169411\end{array}$ & $\begin{array}{r}70880 \\
66505 \\
137385\end{array}$ & $\begin{array}{r}61693 \\
57505 \\
119198\end{array}$ & $\begin{array}{l}2545 \\
2416 \\
4961\end{array}$ \\
\hline $\begin{array}{l}\text { Das Geschlechtsver- } \\
\text { hältniss d.Geburten }\end{array}$ & 105,667 & 105591 & 105204 & 106,578 & 107,282 & 105,339 \\
\hline
\end{tabular}

Tabelle 22 enthält alle lebenden unehelichen Geburten in ganz Oesterreich aus derselben Zeit.

T a b e 11 e 22 .

\begin{tabular}{|c|c|c|c|c|c|c|}
\hline & $\begin{array}{c}\text { Römisch- } \\
\text { kathol. }\end{array}$ & $\begin{array}{l}\text { Griech.- } \\
\text { kathol. }\end{array}$ & $\begin{array}{l}\text { Griech.- } \\
\text { orient. }\end{array}$ & Evang. & Israel. & Andere \\
\hline 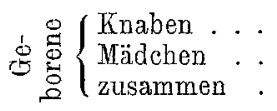 & $\begin{array}{l}391414 \\
373357 \\
764771\end{array}$ & $\begin{array}{l}28329 \\
27327 \\
55656\end{array}$ & $\begin{array}{r}6717 \\
6330 \\
13047\end{array}$ & $\begin{array}{r}8049 \\
7593 \\
15687\end{array}$ & $\begin{array}{l}115096 \\
100179 \\
215275\end{array}$ & $\begin{array}{l}366 \\
355 \\
721\end{array}$ \\
\hline $\begin{array}{l}\text { Das Geschlechtsver- } \\
\text { hältniss d.Geburten }\end{array}$ & 104,836 & 103,666 & 106,113 & 106,598 & 114,890 & 103,098 \\
\hline
\end{tabular}

Vergleichen wir die zugehörigen Zahlen dieser beiden Tabellen mit einander, so sehen wir, dass bei den römischen und griechischen Katholiken das Geschlechtsverhältniss bei den unehelichen Lebendgeborenen wirklich kleiner ist, wie dies auch in dem ersten Capitel gezeigt wurde. Dafür finden wir bei den Griechischorientalen und bei den Juden ein höheres Geschlechtsverhältniss bei den unehelichen Geburten als bei den ehelichen. Die Resultate der Unter- 
suchung bei diesen zwei Confessionen stimmen also nicht mit dem überein, was Düsing in Preussen und ich in Oesterreich und anch in Böhmen gefunden haben. Gleichzeitig ersieht man daraus, dass die Erhöhung des Geschlechtsverhältnisses bei den unehelichen Kindern in Oesterreich, wovon im ersten Capitel bei der Tabelle 5 die Rede war, einerseits im kleinen Maasse durch die griechischorientalische Confession grösstentheils durch die Jùden verursacht wird.

Auf Tabelle 23 sind alle todtgeborenen ehelichen Geburten von ganz Oesterreich in den erwähnten 8 Jahren zusammengestellt, während auf Tabelle 24 wieder alle todtgeborenen unebelichen $\mathrm{Ge}$ burten angeführt sind. Diese Tabellen umfassen in einigen Zahlen nur eine kleine Anzahl ron Geburten und obgleich sie den Grundsatz ' bestätigen, dass die todten Geburten sich durch ein hohes Geschlechtsverhältniss kennzeichnen, werde ich mich doch weiter nicht mit ihnen beschäftigen

Tabelle 23 .

\begin{tabular}{|c|c|c|c|c|c|c|}
\hline & $\begin{array}{l}\text { Römisch- } \\
\text { kathol. }\end{array}$ & $\begin{array}{l}\text { Griech.- } \\
\text { kathol. }\end{array}$ & $\begin{array}{l}\text { Griech.- } \\
\text { orient. }\end{array}$ & Evang. & Israel. & Andere \\
\hline 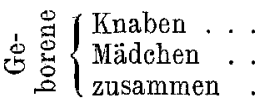 & $\begin{array}{r}80683 \\
61533 \\
142206\end{array}$ & $\begin{array}{r}12996 \\
9674 \\
22670\end{array}$ & $\begin{array}{l}2413 \\
1818 \\
4231\end{array}$ & $\begin{array}{ll}2 & 181 \\
1 & 605 \\
3 & 786\end{array}$ & $\begin{array}{l}1854 \\
1415 \\
3269\end{array}$ & $\begin{array}{r}76 \\
51 \\
127\end{array}$ \\
\hline $\begin{array}{l}\text { Geschlechtsverhälts- } \\
\text { niss der Geburten }\end{array}$ & 131,105 & 134,339 & 132,783 & 135,888 & 131,028 & 149,019 \\
\hline
\end{tabular}

Tabelle 24.

\begin{tabular}{|c|c|c|c|c|c|c|}
\hline & $\begin{array}{c}\text { Römisch- } \\
\text { kathol. }\end{array}$ & $\begin{array}{l}\text { Griech.- } \\
\text { kathol. }\end{array}$ & $\begin{array}{c}\text { Griech.- } \\
\text { orient. }\end{array}$ & Evang. & Israel. & Andere \\
\hline$\stackrel{0}{\stackrel{0}{0}}\left\{\begin{array}{l}\text { Kuaben } \\
\text { Mädchen } \\
\text { zusammen }\end{array}\right.$ & $\begin{array}{l}17920 \\
14625 \\
32545\end{array}$ & $\begin{array}{r}1145 \\
922 \\
2067\end{array}$ & $\begin{array}{l}340 \\
255 \\
595\end{array}$ & $\begin{array}{l}368 \\
311 \\
679\end{array}$ & $\begin{array}{l}3718 \\
2725 \\
6443\end{array}$ & $\begin{array}{l}23 \\
17 \\
40\end{array}$ \\
\hline $\begin{array}{l}\text { Geschlechtsverhält- } \\
\text { niss der Geburten }\end{array}$ & 122,530 & 124,186 & 133,333 & 118,328 & 136,440 & 135,294 \\
\hline
\end{tabular}

Capitel $V$.

\section{Das Geschlechtsverhältuiss bei den Geburten nach der Ehedauer.}

Die Untersuchung des Geschlechtsverhältnisses bei den Geburten nach der Dauer der Ehe ist eigentlich nur ein Hüifskriterium, um zu erkennen, welchen Einfluss das Elternalter auf das Ge- 
schlecht der Kinder ausübt. Dabei fallen hier einerseits das absolute Alter beider Eltern, andererseits ihr relatives Alter in die Waage. Da dieser Einfluss in einem anderen Capitel erwähnt wird, beschränke ich mich bloss darauf, die bisherigen Kenntnisse in dieser Richtung und die aus der Statistik für Böhmen und für Oesterreich erhaltenen Resultate anzuführen.

Bertillon hat eine statistische Beobachtung abgefasst, aus welcher hervorgeht, dass die Knabengeburten in den späteren Jahren der Ehe abnehmen. Nach ihm beträgt das Geschlechtsverhältniss

$$
\begin{aligned}
& \text { bei Ehen von } 1 \text { bis } 6 \text { Jahren } 116 \text { Knaben auf } 100 \text { Mädchen }
\end{aligned}
$$

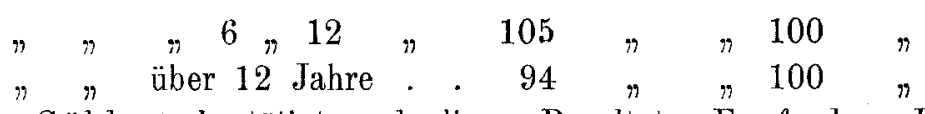

Göhlert bestätigt auch dieses Resultat. Er fand z. B. bei den in der Ehe letztgeborenen Kindern ein Geschlechtsverhältniss von 92 Knaben auf 100 Mädchen.

Düsing meint, dass bei langdauernden Ehen das relative Alter der Eltern nicht in gleicher Weise auf das Geschlechtsverhältniss einwirkt und demnach andere Einflüsse hier eintreten müssen.

Ich habe alle Geburten in Böhmen und in Oesterreich binnen 8 Jahren (1895-1902) nach der Ehedauer und gleichzeitig nach der Vitalität zusammengestellt.

In der officiellen Statistik Oesterreichs finden wir die Geburten nach der Dauer der Ehe zusammengestellt, und zwar vom ersten Jahre bis zu 6 Monaten, von 6-9 Monaten, von 9-12 Monaten, dann Geburten bei einer Ehedauer von 1-2 Jahren, von 2 bis 3 Jahren, von 3-5 Jahren, von 5-10 Jahren, von 10-20 Jahren und endlich Geburten aus über 20 Jahre dauernden Ehen.

Auf der Tabelle 25 sind die Ergebnisse der Untersuchung bei den lebend Geborenen in Böhmen und Oesterreich verzeichnet. Tabelle 26 giebt uns wieder alle todten Geburten von Böhmen und Oesterreich in der erwähnten Zeit an. In beiden Tabellen ist die Gesammtzahl der Geburten und ihr Geschlechtsverhältniss angeführt.

Auf den beigefügten Tabellen 27 und 28 treten die für die einzelnen Phasen der Ehedauer berechneten Geschlechtsverhältnisse in graphischer Darstellung deutlich hervor. Betrachten wir die Linien auf Tabelle 27 näher, so finden wir, dass das Geschlechtsverhältniss bei den lebenden Geburten in Böhmen unregelmässig 
Tabelle 25.

\begin{tabular}{|c|c|c|c|c|c|}
\hline & \multicolumn{2}{|c|}{ Böhmen } & \multicolumn{2}{|c|}{ Oesterreich } \\
\hline & & $\begin{array}{c}\text { Anzahl der } \\
\text { Geburten }\end{array}$ & $\begin{array}{l}\text { Geschlechts- } \\
\text { verhältniss } \\
\text { der Geburten }\end{array}$ & $\begin{array}{l}\text { Anzahl der } \\
\text { Geburten }\end{array}$ & $\begin{array}{l}\text { Geschlechts- } \\
\text { verhältniss } \\
\text { der Geburten }\end{array}$ \\
\hline 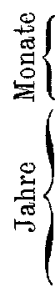 & $\begin{array}{c}\text { bis } 6 \\
6-9 \\
9-12 \\
1-2 \\
2-3 \\
3-5 \\
5-10 \\
10-20 \\
\text { über } 20\end{array}$ & $\begin{array}{r}81829 \\
48626 \\
77627 \\
144431 \\
141245 \\
221884 \\
378361 \\
345746 \\
37057\end{array}$ & $\begin{array}{l}105,57 \\
106,84 \\
104,96 \\
105,39 \\
106,39 \\
104,17 \\
105,33 \\
105,76 \\
106,07\end{array}$ & $\begin{array}{r}217009 \\
149993 \\
332439 \\
616712 \\
579614 \\
918532 \\
1659871 \\
1628317 \\
237652\end{array}$ & $\begin{array}{l}106,86 \\
108,39 \\
105,21 \\
105,31 \\
105,70 \\
105,79 \\
105,46 \\
105,00 \\
105,84\end{array}$ \\
\hline
\end{tabular}

Tabelle 26 .

\begin{tabular}{|c|c|c|c|c|c|}
\hline & \multicolumn{2}{|c|}{ Böhmen } & \multicolumn{2}{|c|}{ Oesterreich } \\
\hline & & $\begin{array}{c}\text { Anzahl der } \\
\text { Geburten }\end{array}$ & $\begin{array}{l}\text { Geschlechts- } \\
\text { verhältniss } \\
\text { der Geburten }\end{array}$ & $\begin{array}{c}\text { Anzahl der } \\
\text { Geburten }\end{array}$ & $\begin{array}{l}\text { Geschlechts- } \\
\text { verhältniss } \\
\text { der Geburten }\end{array}$ \\
\hline 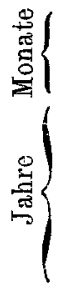 & $\begin{array}{c}\text { bis } 6 \\
6-9 \\
9-12 \\
1-2 \\
2-3 \\
3-5 \\
5-10 \\
10-20 \\
\text { über } 20\end{array}$ & $\begin{array}{r}2646 \\
1682 \\
2091 \\
4550 \\
3543 \\
5999 \\
11476 \\
12885 \\
1793\end{array}$ & $\begin{array}{l}134,58 \\
133,29 \\
117,81 \\
120,49 \\
134,32 \\
134,19 \\
126,48 \\
133,42 \\
127,83\end{array}$ & $\begin{array}{r}6485 \\
5027 \\
7293 \\
15254 \\
11920 \\
20672 \\
39731 \\
45718 \\
7792\end{array}$ & $\begin{array}{l}134,96 \\
132,88 \\
126,94 \\
129,00 \\
129,72 \\
132,67 \\
134,36 \\
131,00 \\
127,30\end{array}$ \\
\hline
\end{tabular}

sehwankt und man darf also nicht behaupten, dass es bei 5 Jahren Ehedauer bis zum Schluss steige. Was die Linien für Oesterreich anbelangt, weisen einerseits die Kinder aus 9 Monate dauernden Ehen ein sehr hohes Geschlechtsverhältniss auf (ein ähnliches Aufsteigen sehen wir auch bei Böhmen), andererseits bewegt sich das Geschlechtsverhältniss die ganze Zeit in ziemlich gleicher Höhe.

Das Geschlechtsverhältniss bei den lebend Geborenen in Böhmen und in Oesterreich lässt in keiner Weise auf die Ehedauer schliessen.

Bei der näheren Betrachtung der auf Tabelle 28 graphisch dargestellten todten Geburten finden wir, dass das Geschlechtsverhältniss in Böhmen und in Oesterreich sehr schwankt, besonders niedrig zeigt es sich bei Ehen von 12 Monaten bis 2 Jahren. 
Tabelle 27.

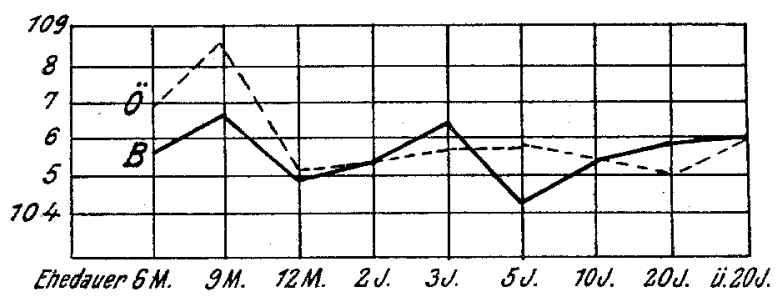

Tabelle 28.

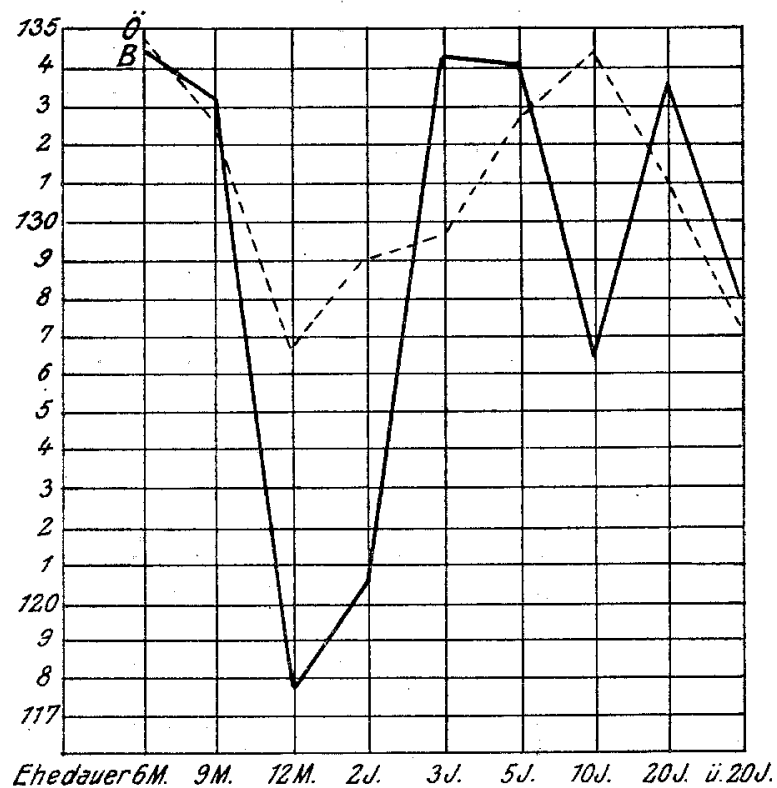

Am höchsten ist das Geschlechtsverhältniss (in Böhmen und in Oesterreich) bei den 6 Monate dauernden Ehen. Auch bei den todten Geburten lässt sich also kein deutlicher Einfluss der Ehedauer auf das Geschlechtsverhältniss feststellen.

\section{Capitel VI.}

\section{Das Geschlechtsverhältniss bei den Gebmrten und das Alter der Eltern.}

Der Einfluss des Alters der Eltern auf das Geschlechtsverhältniss der geborenen Kinder kann von verschiedenen Standpunkten aus untersucht werden. Erstens kann das absolute Alter jedes der beiden Eltern in Betracht gezogen werden und man kann untersuchen, welchen Einfluss das Alter des Vaters ohne Rücksicht auf 
das Alter der Mutter, oder das Alter der Mutter ohne Rücksicht auf das Alter des Vaters auf das Geschlechtsverhältniss der Kinder ausüben, zweitens kann auch das relative Alter der beiden Eltern untersucht werden.

Dabei ist es wünschenswerth, einige Daten anzuführen, welche in dieser Richtung festgestellt wurden.

Jene Frauen, welche in: Folge der socialen Verhältnisse sehr spät zum ersten Mal gebären, welche also auf die erste Conception lange warten mussten, weisen ein sehr hohes Geschlechtsverhältniss bei den geborenen Kindern auf. Ueber diese Thatsache haben schon Ahlfeld, Hecker, Winckel und Schramm geschrieben. Namentlich haben aber der Letztere und A hIfeld unter 1038 Kindern, welche aus über 28 Jahre alten Müttern Erstgebärerinnen entstammten, ein Geschlechtsverhältniss von 124:100 festgestellt. Die von Schramm zusammengestellte Tabelle soll nachweisen, dass das Geschlechtsverhältniss mit dem Alter der Erstgebärerinnen wächst.

\begin{tabular}{c|c|c}
\hline $\begin{array}{c}\text { Alter der } \\
\text { Erstgebärenden }\end{array}$ & $\begin{array}{c}\text { Anzahl der } \\
\text { Geburten }\end{array}$ & $\begin{array}{c}\text { Geschlechts- } \\
\text { verbältniss }\end{array}$ \\
\hline & & \\
28 Jahre & 273 & 110 \\
$29 \%$ & 172 & 118 \\
$30 \%$ & 164 & 115,8 \\
$31 \%$ & 103 & 139,5 \\
$32 \%$ & 80 & 110,5 \\
$33 \%$ & 66 & 127,6 \\
$34 \%$ & 58 & 152 \\
35 & 40 & 265 \\
36 & 29 & 190 \\
37 & 70 & 119 \\
& &
\end{tabular}

Ebenfalls Bieder führt eine ähnliche Tabelle an, aus welcher er abzuleiten sucht, dass die älteren Erstgebärerinnen verhältnissmässig mehr Knaben gebären.

Die beiden Tabellen der letztgenannten zwei Autoren sind aber im Ganzen auf Grund von einer kleinen Anzahl von Geburten zusammengestellt und man kann ihnen deshalb nach meiner Erfahrung keinen grossen Werth beilegen. Ein etwas umfangreicheres Material stand Düsing zur Verfügung, welcher aus den Geburten in einigen Gebäranstalten Deutschlands folgende Tabelle zusammengestellt hat.

Diese Tabelle besagt uns also, dass die jüngsten Mütter bis zu ungefähr 20 Jahren verhältnissmässig viẹl Knaben gebären, dass dann das Geschleohtsverhältniss bei den älteren Erstgebärenden 
T a b e 11 e 29 .

\begin{tabular}{|c|c|c|c|c|c|}
\hline $\begin{array}{c}\text { Alter der } \\
\text { Erstgebärenden }\end{array}$ & Leipzig & Dresden & Jena & zusammen & $\begin{array}{l}\text { Geschlechts- } \\
\text { verhältniss }\end{array}$ \\
\hline 15 Jahre & $1:-$ & $1: 2$ & $1:-$ & $3: 2$ & \\
\hline 16 & $4: 4$ & $6 ; 10$ & $2: 2$ & $12: 16$ & \\
\hline $17 \%$ & $23: 13$ & $20: 15$ & $9: 7$ & $52: 35$ & $549: 494=$ \\
\hline 18 & $67: 55$ & $103: 100$ & $17: 13$ & $187: 168$ & 111,1 \\
\hline 19 & $110: 103$ & $152: 141$ & $33: 29$ & $295: 273$ & \\
\hline 20 & $148: 147$ & $187: 185$ & $32: 45$ & $367: 377$ & $807: 781=$ \\
\hline 21 & $157: 146$ & $241: 201$ & $42: 57$ & $440: 404$ & 103,3 \\
\hline 22 & $120: 133$ & $191: 207$ & $48: 53$ & $359: 393$ & $90^{\circ}=969$ \\
\hline 23 & $106: 108$ & $168: 149$ & $51: 51$ & $325: 308$ & $\begin{array}{c}903: 962 \\
020\end{array}$ \\
\hline 24 & $71: 105$ & $111: 118$ & $37: 38$ & $219: 261$ & \\
\hline 25 & $79: 57$ & $73: 72$ & $35: 27$ & $187: 156$ & \\
\hline 26 & $45: 35$ & $60: 43$ & $20: 20$ & $125: 98$ & \\
\hline 27 & $31: 35$ & $52: 55$ & $10: 12$ & $93: 102$ & $531: 469=$ \\
\hline 28 & $32: 23$ & $26: 33$ & $19: 16$ & $77: 72$ & \\
\hline 29 & $19: 10$ & $26: 18$ & $4: 13$ & $49: 41$ & \\
\hline 30 & $9: 15$ & $30: 13$ & $9: 6$ & $48: 34$ & \\
\hline 31 & $3: 8$ & $15: 11$ & $3: 3$ & $21: 22$ & \\
\hline 32. & $5: 6$ & $12: 9$ & $7: 3$ & $24: 18$ & \\
\hline 33 & $2: 2$ & $5: 5$ & $5: 2$ & $12: 9$ & \\
\hline 34 & $4:-$ & $8: 5$ & $2:-$ & $14: 5$ & \\
\hline 35 & $2:-$ & $9: 3$ & $2: 1$ & $13: 4$ & $156: 104=$ \\
\hline 36 & $1 ;-$ & $3: 3$ & $1: 1$ & $5: 4$ & 150 \\
\hline 37 & $4: 1$ & $4: 3$ & $1:-$ & $9: 4$ & \\
\hline 38 & $-:-$ & $-: 1$ & $1:-$ & $1: 1$ & \\
\hline 39 & - : - & $4:-$ & $1:-$ & $5:-$ & \\
\hline 40 & $1: 1$ & $2: 1$ & $1:-$ & $4: 2$ & \\
\hline 41 J. u. darüber & $-:-$ & $-: 1$ & - : - & $-: 1$ & \\
\hline
\end{tabular}

fällt und mit dem weiteren Alter der Erstgebärenden wieder langsam steigt. Diese Erscheinung wird folgendermaassen ausgelegt. Die jüngsten Erstgebärenden bis zu 20 Jahren haben noch nicht den Gipfelpunkt ihrer Entwicklung erreicht, auch ihre Geschlechtsorgane sind noch nicht gehörig ausgebildet und in Folge dessen wird der sich entwickelnde Fötus nicht so ernährt, wie bei den völlig entwickelten Müttern, und eine schlechte Ernährung der Leibesfrucht bei jungen Müttern sei die Ursache, dass mehr Knaben geboren werden. Mütter über 20 Jahre, völlig entwickelt, gebären verhältnissmässig mehr Mädchen, da sie die grösste geschlechtliche Conceptionsfähigkeit besitzen. Daraus ersehen wir, dass der Einfluss des absoluten Alters der Mutter auf den Einfluss der Ernährung überführt wurde.

Auch bei den Thieren wurde dieselbe Erscheinung festgestellt. Wilckens beobachtete nämlich Folgendes: 1. Die über 14 Jahre alten Stuten haben mit Hengsten beliebigen Alters verhältnissmässig mehr männliche Nachkommenschaft, 2. 9-14 Jahre alte 
Stuten haben mit Hengsten beliebigen Alters mehr weibliche Nachkommen, 3. auch erstgebärende Stuten mit Hengsten beliebigen Alters weisen ebenfalls mehr weibliche Nachkommenschaft auf. Daraus schliesst Wilckens, dass das Alter des Hengstes gar keinen Einfluss auf das Geschlechtsverhältniss besitze und dass hier bloss das Alter der Mütter entscheidend ist. Düsing hat dagegen an 314456 Geburten einen Einfluss des Alters des Vaters auf das Geschlechtsverhältniss festgestellt und giebt an, dass bei demselben Alter der Mutter jüngere Männer (15-30 Jahre) und ältere über 45 Jahre mehr Knaben erzeugen, als im mittleren Alter.

Zum absoluten Alter der Mütter sei noch hinzugefügt, dass eine ganze Reihe Forscher einstimmig nachweist, dass, je jünger die Mütter sind (die jüngsten ausgenommen), desto mehr Mädchen gebären sie.

Das Geschlechtsverhältn. bei der Nachkommensch. von 17-19 J. alten Müttern $=122,0$

\begin{tabular}{|c|c|c|c|}
\hline & " & $"$ & $=104,0$ \\
\hline 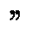 & $"$ & भ & $=119,0$ \\
\hline & $"$ & $\because$ & $=131,0$ \\
\hline
\end{tabular}

Dasselbe wurde auch bei den Pferden constatirt.

Das Geschlechtsverhältn. bei der Nachkommensch. von bis $9 \mathrm{~J}$. alten Stuten $=95,0$

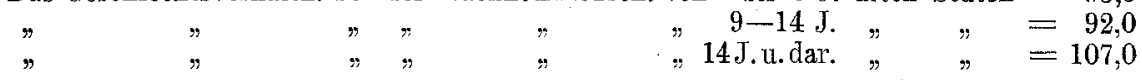

Im mittleren Alter der Frauen und Thiere, wo also die Conceptionsfähigkeit am meisten entwickelt ist, wird verhältnissmässig am meisten weibliche Nachkommenschaft geboren. Düsing bemerkt ferner, dass bei dem absoluten Alter der Mütter eigentlich der Umstand in die Waage fällt, wann die Conception nach der ersten Menstruation eingetreten ist. Er kam dann zu dem Resultate, dass, je länger die Mutter nach der ersten Menstruation auf die Conception warten muss, desto mehr Knaben gebiert sie. Demnach stellt Düsing den Satz auf, dass die späte Befruchtung des Weibes mehr Knabenconceptionen bewirkt.

Was das relative Alter der beiden Eltern anbelangt, ist in dieser Hinsicht das Gesetz von Hofacker-Sadler bekannt.

Hofacker constatirte in Tübingen folgende Regelmässigkeit:

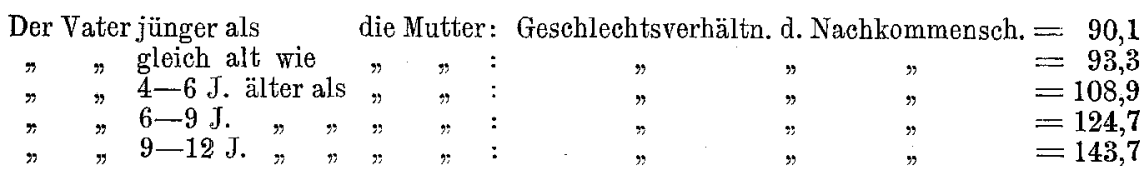


Unabhängig davon kam Sadler zu demselben Resultat.

Der Vater jünger als

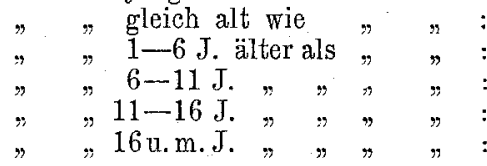

Geschlechtsverhältn. der Nachkommensch. $=86$

$\begin{array}{llll}" & " & & =94 \\ " & " & " & =103 \\ " & " & " & =106 \\ " & " & n & =147 \\ " & " & & =163\end{array}$

Inwiefern die statistischen Angaben mit diesem HofackerSadler'schen Gesetz übereinstimmen, geht aus der folgenden Tabelle von Oesterlen hervor.

\begin{tabular}{|c|c|c|c|c|}
\hline Name des Autors & $\begin{array}{l}\text { Anzahl } \\
\text { der Fälle }\end{array}$ & $\begin{array}{l}\text { Der Vater } \\
\text { älter }\end{array}$ & $\begin{array}{l}\text { Eltern } \\
\text { gleich alt }\end{array}$ & $\begin{array}{l}\text { Die Mutter } \\
\text { älter }\end{array}$ \\
\hline $\begin{array}{l}\text { Hofacker } \\
\text { Sadler } \\
\text { Göhlert. } \\
\text { Noirot } \\
\text { Legoyt }\left\{\begin{array}{l}\text { Calais } \\
\text { Paris }\end{array}\right. \\
\text { Breslau } . \\
.\end{array}$ & $\begin{array}{r}1996 \\
2068 \\
4584 \\
4000 \\
6006 \\
52311 \\
8084\end{array}$ & $\begin{array}{r}117,8 \\
121,4 \\
108,3 \\
99,7 \\
109,9 \\
104,4 \\
103,9\end{array}$ & $\begin{array}{r}92,0 \\
94,8 \\
93,3 \\
\overline{107,9} \\
102,1 \\
103,1\end{array}$ & $\begin{array}{r}90,6 \\
86,5 \\
82,6 \\
116,0 \\
101,6 \\
97,5 \\
117,6\end{array}$ \\
\hline
\end{tabular}

Diese Tabelle zeigt uns, dass bloss die Zahlen von Breslau und Noirot mit dem Gesetz nicht übereinstimmen. Gegen das genannte Gesetz hat sich Göhlert ansgesprochen und meint, dass auch die todten Geburten in den Tabellen mit gezählt werden müssten, und dass überdies die Ehedauer berücksichtigt werden muss.

Ebenfalls fand auch Franke das Gesetz von HofackerSadler in der Statistik Norvewen's nicht bestätigt. Schuhmann hat das Hofacker-Sadler'sche Gesetz untersucht und behauptet, dass, je grösser das Geschlechtsvermögen der Erzeuger sei, desto grösser ist ihr Einfluss auf das Geschlecht des Fötus, wobei in erster Reihe die Fähigkeit des Mannes wichtig sei, und dass endlich mit der Steigerung dieser Fähigkeit des Mannes auch das Geschlechtsverhältniss der Geburten sich ändert.

Ich führe hier eine von Düsing zusammengestellte Tabelle an, in welcher die Geburten nach dem Alter der Mutter und des Vaters gruppirt sind. (Siehe Tabelle, 30.)

Aus der Tabelle geht hervor, dass bei demselben Alter der Mütter jüngere Männẹr mehr Knaben produciren als Männer mittleren Alters. In der Zeit ihres grössten Geschlechtsvermögens zeugen die Männer mehr Mädchen. Diese Erscheinung bietet uns nach Düsing einen Beweis für die Richtigkeit der HofackerSadler'schen Modificationstheorie. 
T a b e l l e 30 .

\begin{tabular}{|c|c|c|c|c|c|c|c|c|c|}
\hline $\begin{array}{l}\text { Alter der } \\
\text { Mutter }\end{array}$ & \multicolumn{3}{|c|}{$30-34$ Jahre } & \multicolumn{3}{|c|}{$25-29$ Jahre } & \multicolumn{3}{|c|}{$20-24$ Jahre } \\
\hline $\begin{array}{l}\text { Alter des } \\
\text { Vaters }\end{array}$ & Knab. & Mädch. & $\begin{array}{c}\text { Geschl.- } \\
\text { Verhältn. }\end{array}$ & Knab. & Mädch. & $\begin{array}{l}\text { Geschl.- } \\
\text { Verhältn. }\end{array}$ & Knab. & Mädch. & $\begin{array}{l}\text { Geschl.- } \\
\text { Verhältn. }\end{array}$ \\
\hline $\begin{array}{r}15-19 \\
30-24 \\
35-39 \\
40-44 \\
\text { über } 45\end{array}$ & $\begin{array}{r}8525 \\
23283 \\
17885 \\
7972 \\
4220\end{array}$ & $\begin{array}{r}7887 \\
21823 \\
17070 \\
7681 \\
3997\end{array}$ & $\begin{array}{l}108,1 \\
106,9 \\
104,7 \\
103,8 \\
105,6\end{array}$ & $\begin{array}{r}27389 \\
24394 \\
10272 \\
3165 \\
1734\end{array}$ & $\begin{array}{r}25843 \\
23486 \\
9838 \\
3058 \\
1525\end{array}$ & $\begin{array}{l}106,0 \\
103,9 \\
104,4 \\
103,5 \\
113.8\end{array}$ & $\begin{array}{r}21560 \\
7954 \\
2426 \\
\} 1154\end{array}$ & $\begin{array}{r}20330 \\
7469 \\
2416 \\
1100\end{array}$ & $\begin{array}{l}106,0 \\
106,5 \\
100,4 \\
105,0\end{array}$ \\
\hline
\end{tabular}

Ich komme nun zu meinen eigenen Untersuchungen aus der Statistik Oesterreichs, und zwar führe ich zuerst eine Tabelle an, worauf alle unehelichen Geburten zusammengestellt sind. Wir finden dort alle todten und lebendigen, unehelichen Geburten nach dem Alter der Mütter, und zwar in Böhmen (Tab. 32), sowie auch in Oesterreich (Tab. 31) in der Zeit von 7 Jahren (vom J. 1896 bis zum J. 1902).

Die unehelichen Mütter sind in ihr dem Alter nach im Ganzen in 7 Gruppen eingetheilt. Wie aus der Tabelle 31 und aus der folgenden graphischen Darstellung auf Tab. 33 (Linie Oe) ersichtlich ist, weisen die jüngsten Mütter bis zu 17 Jahren das höchste Geschlechtsverhältniss auf; dann sinkt dieses. Verhältniss, steigt wieder allmählich mit dem Alter bis zu 40 Jahren, worauf es dann nach 40 Jahren wieder herabfällt.

T a b e 11 e 31 .

\begin{tabular}{|c|c|c|c|c|c|c|}
\hline $\begin{array}{l}\text { Alter d. unehelichen } \\
\text { Mrutter in Jahren }\end{array}$ & bis 17 & $17-20$ & $20-25$ & $25-30$ & $30-40$ & über 40 \\
\hline 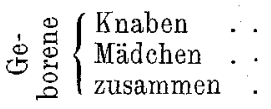 & $\begin{array}{l}3546 \\
3204 \\
6750\end{array}$ & $\begin{array}{l}48432 \\
45977 \\
94409\end{array}$ & $\begin{array}{l}180095 \\
169268 \\
349363\end{array}$ & $\begin{array}{l}114007 \\
106365 \\
220372\end{array}$ & $\begin{array}{r}88503 \\
-82365 \\
170868\end{array}$ & $\begin{array}{l}11467 \\
10886 \\
22353\end{array}$ \\
\hline $\begin{array}{c}\text { Geschlechtsverhältn. } \\
\text { der Geburten ... }\end{array}$ & 110,7 & 105,3 & 106,4 & 107,2 & 107,4 & 105,4 \\
\hline
\end{tabular}

Auf der Basis der Tab. 33 ist das Alter der unehelichen Mütter, eingetheilt in 7 Gruppen, aufgetragen und auf der Senkrechten das Geschlechtsverhältniss von 104 bis 115 .

Tab. 32 und die zugehörige graphische Darstellung auf Tab. 33 (Linie B) stellen die analogen Berechnungen für das Königreich Böhmen vor. Wie dann aus der Tab. 32 zu ersehen ist, stützt 
796 Srdínko, Geschlechtsverhältniss bei den Geburten in Oesterroich.

sich diese auf eine kleinere Anzahl von Fällen als die Tab. 31 von ganz Oesterreich.

$\mathrm{T}$ a b e 11 e 32 .

\begin{tabular}{|c|c|c|c|c|c|c|}
\hline $\begin{array}{l}\text { Alter d. unehelichen } \\
\text { Mutter in Jahren }\end{array}$ & bis 17 & $17-20$ & $20-25$ & $25-30$ & $30-40$ & über 40 \\
\hline 总总 $\left\{\begin{array}{l}\text { Knaben } \\
\text { Mädchen } \\
\text { : }\end{array}\right.$ & $\begin{array}{r}973 \\
846 \\
1819\end{array}$ & $\begin{array}{l}16562 \\
18857 \\
32419\end{array}$ & $\begin{array}{r}52914 \\
49682 \\
102596\end{array}$ & $\begin{array}{l}21590 \\
20904 \\
42494\end{array}$ & $\begin{array}{l}12362 \\
11779 \\
24141\end{array}$ & $\begin{array}{l}1763 \\
1676 \\
3439\end{array}$ \\
\hline $\begin{array}{l}\text { Geschlechtsverhältn. } \\
\text { der Geburten ... }\end{array}$ & 115 & 104,5 & 106,5 & 103,3 & 105,0 & 105,2 \\
\hline
\end{tabular}

T a belle 33.

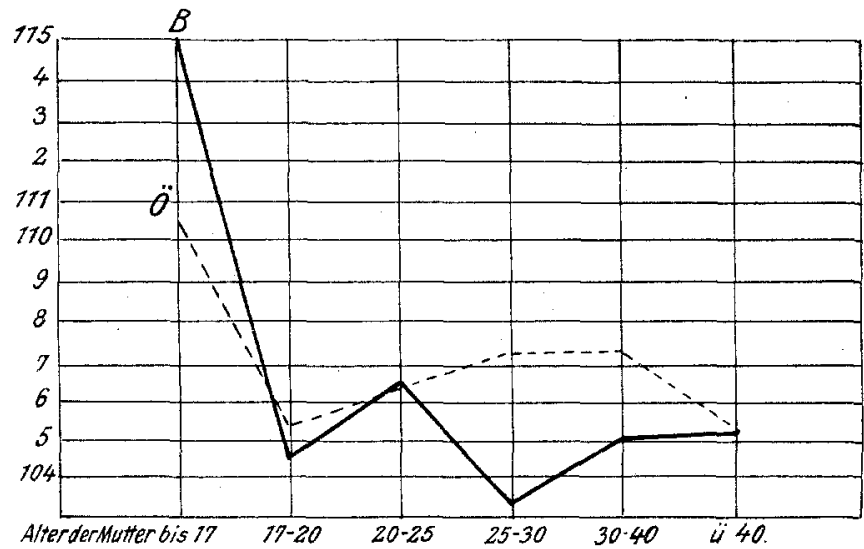

Was den Werth meiner Tabellen anbelangt, haben sie den Vortheil vor den Berechnungen anderer Autoren, dass sie alle todten und lebendigen Geburten enthalten, wie dies von Göhlert erfordert wird, und dass ihnen eine grosse Anzahl von Fällen unterlegt ist.

Bei der Vergleichung meiner Tabelle für Oesterreich (31) mit den Tabellen von Schramm and Düsing bemerken wir einen Parallelismus in den Zahlen, welche uns das Geschlechtsverhältniss angeben. Der Unterschied ist aber darin, dass die Linie des Geschlechtsverhältnisses (Tab. 33, Linie 0 e) auf meiner Tabelle früher zu steigen beginnt, d. h. bei jüngeren Müttern als bei $D$ üsing: Düsing hat das niedrigste Geschlechtsverhältniss bei 22 - 24 Jahre alten Müttern constatirt, ich fand es dagegen bei Müttern von 17-20 Jahren (Linie Oe). Im Princip aber bestätigt mein Resultat das Ergebniss anderer Autoren, nämlich, dass die jüngsten Vütter verhältnissmässig mehr Knaben gebären, die älteren 
Mütter weniger und die ältesten bis zu 40 Jahren wieder mehr Knaben. Bei den Geburten von über 40 Jahre alten Müttern finden wir (vielleicht zufällig) nach meinen Berechnungen ein niedrigeres Geschlechtsverhältniss.

Folgende 5 Tabellen zeigen uns den Einfluss des relativen Alters der Eltern auf das Geschlecht der Kinder. Es sind hier alle todten und lebendigen ehelichen Geburten in Oesterreich binnen כ Jahren (1898-1902) nach dem Alter der Väter und Mütter zusammengestellt, und zwar finden wir auf Tab. 34 alle lebendigen Geburten von ganz. Oesterreich in der erwähnten Frist, und auf Tab. 35 alle todten Geburten.

Das Alter der Mütter ist oben auf der Tabelle parallel zur Basis aufgetragen, das AIter der Väter auf der Senkrechten dazu. Auf der Tabelle ist immer die Anzahl der geborenen Knaben und Mädchen angegeben, dann die daraus berechneten Geschlechts-

$\mathrm{T}$ a b e $11 \mathrm{e} 34$.

\begin{tabular}{|c|c|c|c|c|c|c|c|c|c|c|c|}
\hline \multirow{2}{*}{\multicolumn{2}{|c|}{$\begin{array}{c}\text { Alter der } \\
\text { Eltern }\end{array}$}} & \multirow{2}{*}{ 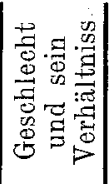 } & \multicolumn{7}{|c|}{ Alter der Mutte } & \multirow{2}{*}{ 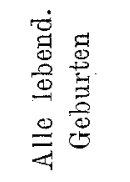 } & \multirow{2}{*}{ 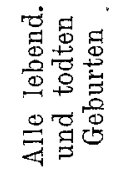 } \\
\hline & & & $\begin{array}{l}\text { bis } 17 \\
\text { Jahre }\end{array}$ & $\begin{array}{c}17-20 \\
\text { Jahre }\end{array}$ & $\begin{array}{c}20-25 \\
\text { Jahre }\end{array}$ & $\begin{array}{c}25-30 \\
\text { Jahre }\end{array}$ & $\begin{array}{c}30-40 \\
\text { Jahre }\end{array}$ & $\begin{array}{c}\text { über } 40 \\
\text { Jahre }\end{array}$ & & & \\
\hline & $\begin{array}{l}\text { bis } 20 \\
\text { Jahre }\end{array}$ & $\begin{array}{c}\text { Knab. } \\
\text { Mädch. } \\
\text { G.-V. }\end{array}$ & $\begin{array}{l}23 \\
18 \\
-\end{array}$ & $\begin{array}{r}67 \\
66 \\
-\end{array}$ & $\begin{array}{r}126 \\
125 \\
100,8\end{array}$ & $\begin{array}{r}70 \\
53 \\
-\end{array}$ & $\begin{array}{r}61 \\
53 \\
-\end{array}$ & $\begin{array}{r}1 \\
-\end{array}$ & $\begin{array}{r}18 \\
8 \\
-\quad \\
\end{array}$ & $\begin{array}{r}377 \\
334 \\
112,9\end{array}$ & $\begin{array}{r}390 \\
340 \\
114.5\end{array}$ \\
\hline & $\begin{array}{c}20-25 \\
\text { Jahre }\end{array}$ & $\begin{array}{c}\text { Knab. } \\
\text { Mädch. } \\
\text { G.-V. }\end{array}$ & $\begin{array}{r}578 \\
431 \\
134,0\end{array}$ & & & & $\begin{array}{c}3978 \\
3600 \\
110,5\end{array}$ & $\begin{array}{r}246 \\
197 \\
124,8\end{array}$ & $\begin{array}{r}441 \\
345 \\
127,8\end{array}$ & $\begin{array}{r}74 \\
70 \\
104\end{array}$ & $\begin{array}{r}76235 \\
72377 \\
105,3\end{array}$ \\
\hline $\begin{array}{c}5 \\
0 \\
+ \\
+ \\
\pi\end{array}$ & $\begin{array}{c}25-30 \\
\text { Jahre }\end{array}$ & $\begin{array}{c}\text { Knab. } \\
\text { Mädch. } \\
\text { G.-V. }\end{array}$ & $\begin{array}{l}1579 \\
1430 \\
109,7\end{array}$ & & & & & & & & \\
\hline $\begin{array}{l}n \\
0 \\
0\end{array}$ & $\begin{array}{c}30-40 \\
\text { Jahre }\end{array}$ & $\begin{array}{r}\text { Kna } \\
\text { Mäd } \\
\text { G. }\end{array}$ & $\begin{array}{r}506 \\
531 \\
95,3\end{array}$ & & & & & & & & $\begin{array}{l}95 \\
10\end{array}$ \\
\hline $\begin{array}{l}5 \\
0 \\
0 \\
+\end{array}$ & $\begin{array}{c}40-50 \\
\text { Jahre }\end{array}$ & $\begin{array}{c}\text { Knab. } \\
\text { Märdch. } \\
\text { G.-V. }\end{array}$ & $\begin{array}{r}136 \\
113 \\
120,3\end{array}$ & $\begin{array}{r}754 \\
700 \\
107,7\end{array}$ & & & & & & & \\
\hline & $\begin{array}{c}\text { über } 50 \\
\text { Jahre }\end{array}$ & $\begin{array}{c}\text { Knab. } \\
\text { Mädch. } \\
\text { G.-V. }\end{array}$ & $\begin{array}{l}28 \\
19 \\
-\end{array}$ & $\begin{array}{r}142 \\
139 \\
102,1\end{array}$ & & $\begin{array}{c}6620 \\
6482 \\
102,1\end{array}$ & & & $\begin{array}{r}1020 \\
855 \\
119,2\end{array}$ & & $\begin{array}{c}86887 \\
106,0\end{array}$ \\
\hline & $\begin{array}{l}\text { unbe-: } \\
\text { lannt }\end{array}$ & $\begin{array}{c}\text { Knab. } \\
\text { Mädch. } \\
\text { G.-V. }\end{array}$ & $\begin{array}{l}55 \\
35 \\
-\end{array}$ & \begin{tabular}{r|}
348 \\
371 \\
93,8
\end{tabular} & $\begin{array}{l}1 \\
9\end{array}$ & $\begin{array}{l}1,952 \\
2039 \\
95,7\end{array}$ & & $\begin{array}{r}805 \\
875 \\
92,0\end{array}$ & $\begin{array}{l}67 \\
42 \\
7\end{array}$ & & $\begin{array}{l}54088 \\
5088 \\
106,3\end{array}$ \\
\hline & $\begin{array}{l}\text { ge- } \\
\text { aten } \\
\text { eburt. }\end{array}$ & $\begin{array}{r}K n \\
M a ̈ \\
G\end{array}$ & $\begin{array}{l}2905 \\
2687 \\
108,1\end{array}$ & $\begin{array}{r}47424 \\
45179 \\
104,9\end{array}$ & $\begin{array}{c}387033 \\
366618 \\
105,5\end{array}$ & $\begin{array}{c}581197 \\
549822 \\
105,7\end{array}$ & $\begin{array}{c}873127 \\
828008 \\
105,4\end{array}$ & $\begin{array}{c}180968 \\
171664 \\
105,4\end{array}$ & $\begin{array}{r}57233 \\
51283 \\
111,6\end{array}$ & $\begin{array}{l}130087 \\
015254 \\
105,7\end{array}$ & $\begin{array}{c}2192934 \\
2063105 \\
106,29\end{array}$ \\
\hline
\end{tabular}


T a b e 11 e 35.

\begin{tabular}{|c|c|c|c|c|c|c|c|c|c|c|c|}
\hline \multirow{2}{*}{\multicolumn{2}{|c|}{$\begin{array}{l}\text { Alter der } \\
\text { Eltern }\end{array}$}} & \multirow{2}{*}{ 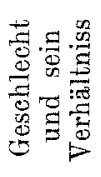 } & \multicolumn{7}{|c|}{ Alter $d \operatorname{er} \mathbb{N} u t t e r$} & \multirow{2}{*}{ 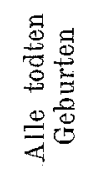 } & \multirow{2}{*}{ 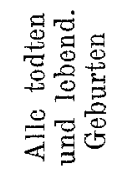 } \\
\hline & & & $\begin{array}{l}\text { bis } 17 \\
\text { Jahre }\end{array}$ & $\begin{array}{c}17-20 \\
\text { Jahre }\end{array}$ & $\begin{array}{c}20-25 \\
\text { Jahre }\end{array}$ & $\begin{array}{c}25-30 \\
\text { Jahre }\end{array}$ & $\begin{array}{c}30-40 \\
\text { Jahre }\end{array}$ & Ja & $\begin{array}{l}\text { unbe- } \\
\text { kannt }\end{array}$ & & \\
\hline & $\begin{array}{l}\text { bis } 20 \\
\text { Jahre }\end{array}$ & $\begin{array}{l}\text { Knab. } \\
\text { Mädch. } \\
\text { G.-V. }\end{array}$ & $\frac{1}{-}$ & $\begin{array}{r}3 \\
3 \\
-\end{array}$ & $\begin{array}{l}3 \\
- \\
-\end{array}$ & $\begin{array}{r}2 \\
1 \\
-\end{array}$ & $\begin{array}{r}3 \\
1 \\
-\end{array}$ & $\begin{array}{r}1 \\
- \\
-\end{array}$ & - & $\begin{array}{r}13 \\
-\quad 6 \\
-\end{array}$ & $\begin{array}{r}390 \\
340 \\
114,5\end{array}$ \\
\hline & $\begin{array}{c}20-25 \\
\text { Jahre }\end{array}$ & $\begin{array}{l}\text { Knab. } \\
\text { Mädch. } \\
\text { G.-V. }\end{array}$ & $\begin{array}{r}12 \\
8 \\
-\end{array}$ & $\begin{array}{c}187 \\
142 \\
131,7\end{array}$ & $\begin{array}{r}1001 \\
777 \\
128,8\end{array}$ & $\begin{array}{r}438 \\
355 \\
123,4\end{array}$ & $\begin{array}{l}144 \\
111 \\
-\end{array}$ & $\begin{array}{r}12 \\
5 \\
-\end{array}$ & $\begin{array}{r}13 \\
5 \\
-\end{array}$ & $\begin{array}{l}1807 \\
1403 \\
128,8\end{array}$ & $\begin{array}{c}76235 \\
72377 \\
105,4\end{array}$ \\
\hline $\begin{array}{l}0 \\
+ \\
+\end{array}$ & $\begin{array}{c}25-30 \\
\text { Jahre }\end{array}$ & $\begin{array}{l}\text { Kna } \\
\text { Mäd } \\
\text { G.- }\end{array}$ & $\begin{array}{l}42 \\
19 \\
-\end{array}$ & $\begin{array}{l}564 \\
395 \\
142,8\end{array}$ & & & & $\begin{array}{r}99 \\
80 \\
-\end{array}$ & $\begin{array}{l}62 \\
55 \\
-\end{array}$ & $\begin{array}{r}12124 \\
9344 \\
129,7\end{array}$ & $\begin{array}{l}198 \\
883 \\
4\end{array}$ \\
\hline & $\begin{array}{l}30-40 \\
\text { Jahre }\end{array}$ & $\begin{array}{l}\text { Kn } \\
\text { Mäd } \\
\text { G.- }\end{array}$ & $\begin{array}{r}13 \\
5 \\
-\end{array}$ & $\begin{array}{r}129 \\
95 \\
-\end{array}$ & $\begin{array}{l}2322 \\
1818 \\
127,7\end{array}$ & $\begin{array}{l}7323 \\
5508 \\
132,9\end{array}$ & & & $\begin{array}{l}178 \\
138 \\
-\end{array}$ & & $\begin{array}{c}020761 \\
958165 \\
106,5\end{array}$ \\
\hline & $\begin{array}{c}40-50 \\
\text { Jahre }\end{array}$ & $\begin{array}{l}\text { Knab. } \\
\text { Mädch. } \\
\text { G.-V. }\end{array}$ & $\begin{array}{r}3 \\
2 \\
-\end{array}$ & $\begin{array}{l}20 \\
13 \\
-\end{array}$ & $\begin{array}{r}224 \\
173 \\
129,5\end{array}$ & $\begin{array}{r}884 \\
713 \\
123,9\end{array}$ & & & $\begin{array}{r}108 \\
75 \\
-\end{array}$ & & $\begin{array}{l}115 \\
568 \\
5,8\end{array}$ \\
\hline & $\begin{array}{c}\text { über ว0 } \\
\text { Jahre }\end{array}$ & $\begin{array}{l}\text { Knab. } \\
\text { Mädeh. } \\
\text { G.-V. }\end{array}$ & $\begin{array}{r}1 \\
2 \\
-\end{array}$ & $\begin{array}{r}1 \\
3 \\
-\end{array}$ & $\begin{array}{l}56 \\
23 \\
-\end{array}$ & $\begin{array}{l}164 \\
119 \\
-\end{array}$ & $\begin{array}{c}1579 \\
1134 \\
139,2\end{array}$ & & $\begin{array}{l}51 \\
32 \\
-\end{array}$ & $\begin{array}{l}3329 \\
2548 \\
130,6\end{array}$ & $\begin{array}{c}92143 \\
86,887 \\
106,0\end{array}$ \\
\hline & $\begin{array}{l}\text { unbe- } \\
\text { kannt }\end{array}$ & $\begin{array}{l}\text { Knab. } \\
\text { Mädch. } \\
\text { G.-V. }\end{array}$ & $\begin{array}{r}4 \\
1 \\
-\end{array}$ & $\begin{array}{l}15 \\
16 \\
-\end{array}$ & $\begin{array}{r}135 \\
107 \\
126,1\end{array}$ & $\begin{array}{r}221 \\
179 \\
123,5\end{array}$ & 125 & $\begin{array}{c}114 \\
79 \\
-\end{array}$ & $\begin{array}{c}3535 \\
2946 \\
119,99\end{array}$ & $\begin{array}{l}3641 \\
121,2\end{array}$ & $\begin{array}{c}54092 \\
50885 \\
106,3\end{array}$ \\
\hline & $\begin{array}{l}\text { Alle } \\
\text { odten } \\
\text { burten }\end{array}$ & $\begin{array}{l}\text { Knab. } \\
\text { Mädch. } \\
\text { G.-V. }\end{array}$ & $\begin{array}{l}76 \\
37 \\
-\end{array}$ & $\begin{array}{c}919 \\
667 \\
137,8\end{array}$ & $\begin{array}{l}8074 \\
6247 \\
129,2\end{array}$ & $\begin{array}{c}14023 \\
10795 \\
129,9\end{array}$ & $\begin{array}{c}27828 \\
20840 \\
133,5\end{array}$ & $\begin{array}{c}7980 \\
6044 \\
132\end{array}$ & $\begin{array}{l}3947 \\
3251 \\
121,7\end{array}$ & $\begin{array}{r}47851 \\
181,3\end{array}$ & $\begin{array}{c}2192934 \\
2063105 \\
106,29\end{array}$ \\
\hline
\end{tabular}

T a be 11 e 36 .

\begin{tabular}{|c|c|c|c|c|c|c|c|c|c|}
\hline \multirow{2}{*}{$\begin{array}{l}\text { Alter der } \\
\text { Eltern } \\
\text { Jahre }\end{array}$} & \multicolumn{7}{|c|}{ A I ter der Mutter } & \multirow{2}{*}{ 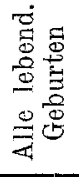 } & \multirow{2}{*}{ 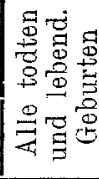 } \\
\hline & $\begin{array}{l}\text { bis } 17 \\
\text { Jahre }\end{array}$ & $\begin{array}{c}17-20 \\
\text { Jahre }\end{array}$ & $\begin{array}{l}20-25 \\
\text { Jahre }\end{array}$ & $\begin{array}{c}25-30 \\
\text { Jabre }\end{array}$ & $\begin{array}{c}30-40 \\
\text { Jahre }\end{array}$ & $\begin{array}{l}\text { über } 40 \\
\text { Jahre }\end{array}$ & $\begin{array}{l}\text { unbe- } \\
\text { kannt }\end{array}$ & & \\
\hline bis 20 & - & - & 100,8 & - & - & - & - & 112,8 & 114,5 \\
\hline $20-25$ & 134,0 & 100,3 & 104,2 & 105,8 & 110,5 & 124,8 & 127,8 & 104,8 & 105,3 \\
\hline $25-30$ & 109,7 & 106,4 & 105,5 & 105,4 & 107,8 & 10 & 140,3 & 105,9 & 106,4 \\
\hline $30-40$ & 95,3 & 106,0 & 106,3 & 106,2 & 105,4 & 106,1 & 126,8 & 105,9 & 106,5 \\
\hline $40-50$ & 120,3 & 107,7 & 104,0 & 104,2 & 104,9 & 105,6 & 119,4 & 105,1 & 105,8 \\
\hline über 50 & - & 102,1 & 105,0 & 102,1 & 106,4 & 107,1 & 119,2 & 105,3 & 106,0 \\
\hline द kannt & 一 & 93,8 & 94,1 & 95,7 & 86,8 & 92,0 & 107,7 & 105,1 & 106,3 \\
\hline $\begin{array}{l}\text { Alle } \\
\text { ebendigen }\end{array}$ & & & & & & & & & \\
\hline & 108,1 & 104,9 & 105,5 & 105,7 & 105,4 & 105,4 & 111,6 & 105,7 & 106,29 \\
\hline
\end{tabular}


Ta belle 37 .

\begin{tabular}{|c|c|c|c|c|c|c|c|c|c|}
\hline \multirow{2}{*}{$\begin{array}{c}\text { Alter der } \\
\text { Eltern } \\
\text { Jahre } \\
\end{array}$} & \multicolumn{7}{|c|}{ Alter der Mutter } & \multirow{2}{*}{ 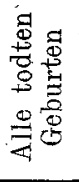 } & \multirow{2}{*}{ 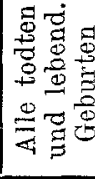 } \\
\hline & $\begin{array}{l}\text { bis } 17 \\
\text { Jahre }\end{array}$ & $\begin{array}{c}17-20 \\
\text { Jahre }\end{array}$ & $\begin{array}{c}20-25 \\
\text { Jahre }\end{array}$ & $\begin{array}{l}25-30 \\
\text { Jahre }\end{array}$ & $\left\{\begin{array}{c}30-40 \\
\text { Jahre }\end{array}\right.$ & $\begin{array}{l}\text { über } 40 \\
\text { Jahre }\end{array}$ & $\begin{array}{l}\text { unbe- } \\
\text { kannt }\end{array}$ & & \\
\hline bis 20 & - & 一 & - & - & - & 一 & - & - & 114,5 \\
\hline$\pm(20-25$ & 一 & 131,7 & 128,8 & 123,4 & - & - & 一 & 128,8 & 105,4 \\
\hline$=25-30$ & -- & 142,8 & 129,4 & 127,3 & 133,2 & - & - & $-129,7$ & 106,4 \\
\hline $30-40$ & - & - & 127,7 & 132,9 & 13 & 13 & - & 133,6 & 106,5 \\
\hline $40-50$ & - & - & 129,5 & 123,9 & 131,5 & 134,1 & - & 132,3 & 105,8 \\
\hline \begin{tabular}{l|l} 
& über 50 \\
unbe-
\end{tabular} & 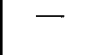 & - & - & - & 139,2 & 111,4 & - & 130,6 & 106,0 \\
\hline य) kannt & - & - & 126,2 & 123,5 & 125,0 & - & 119,99 & 121,2 & 106,3 \\
\hline $\begin{array}{l}\text { Alle } \\
\text { todten }\end{array}$ & & & & & & & & & \\
\hline Geburten & - & 137,8 & 129,2 & 129,9 & 133,5 & 132,0 & 121,7 & 131,3 & 106,29 \\
\hline
\end{tabular}

verhältnisse in solchen Fällen, wo die Summe der Geburten beider Geschlechter wenigstens mehr als 200 beträgt.

Aehnlich ist auch die Tabelle 35 für die todten Geburten zusammenge stellt.

Zur Vereinfachung beider Tabellen ist hier noch eine Uebersicht der Geschlechtsverhältnisse für lebendig Geborene (Tab. 36) und für todt Geborene (Tab. 37).

Die graphische Darstellung der Resultate ist auf Tabelle 38 durchgeführt. Linie I zejgt uns das Schwanken des Geschlechtsverhältnisses bei den lebenden Geburten nach dem Alter der Mütter (welches auf der Basis aufgetragen ist), ohne Rücksicht auf das Alter der Väter, Linie II das Schwanken der Geschlechtsverhältnisse bei den lebenden Geburten nach dem Alter der Väter (welches ebenfalls anf der Basis aufgetragen ist) ohne Rücksicht auf das Alter der Mütter; Linie III bedentet das Schwanken des Geschlechtsverhältnisses bei den todten Geburten nach dem Alter der Mütter (ohne Rücksicht auf das Alter der Väter) und Linie IV dieses. Schwanken bei den todten Geburten nach dem Alter der Väter bei beliebigem Alter der Mütter. Diese graphische Darstellung besitzt also Gültigkeit nur mit Rücksicht auf das absolute Alter des einen der beiden Eltern.

Bei der Anwendung des Hofacker-Sadler'schen Gesetzes auf diese Tabellen zeigt es sich, dass dieses Gesetz durch sie nicht bestätigt wird, denn sonst sollten wir in jenen Fällen, wo die Väter jünger sind als die Mütter, das niedrigste Geschlechts- 


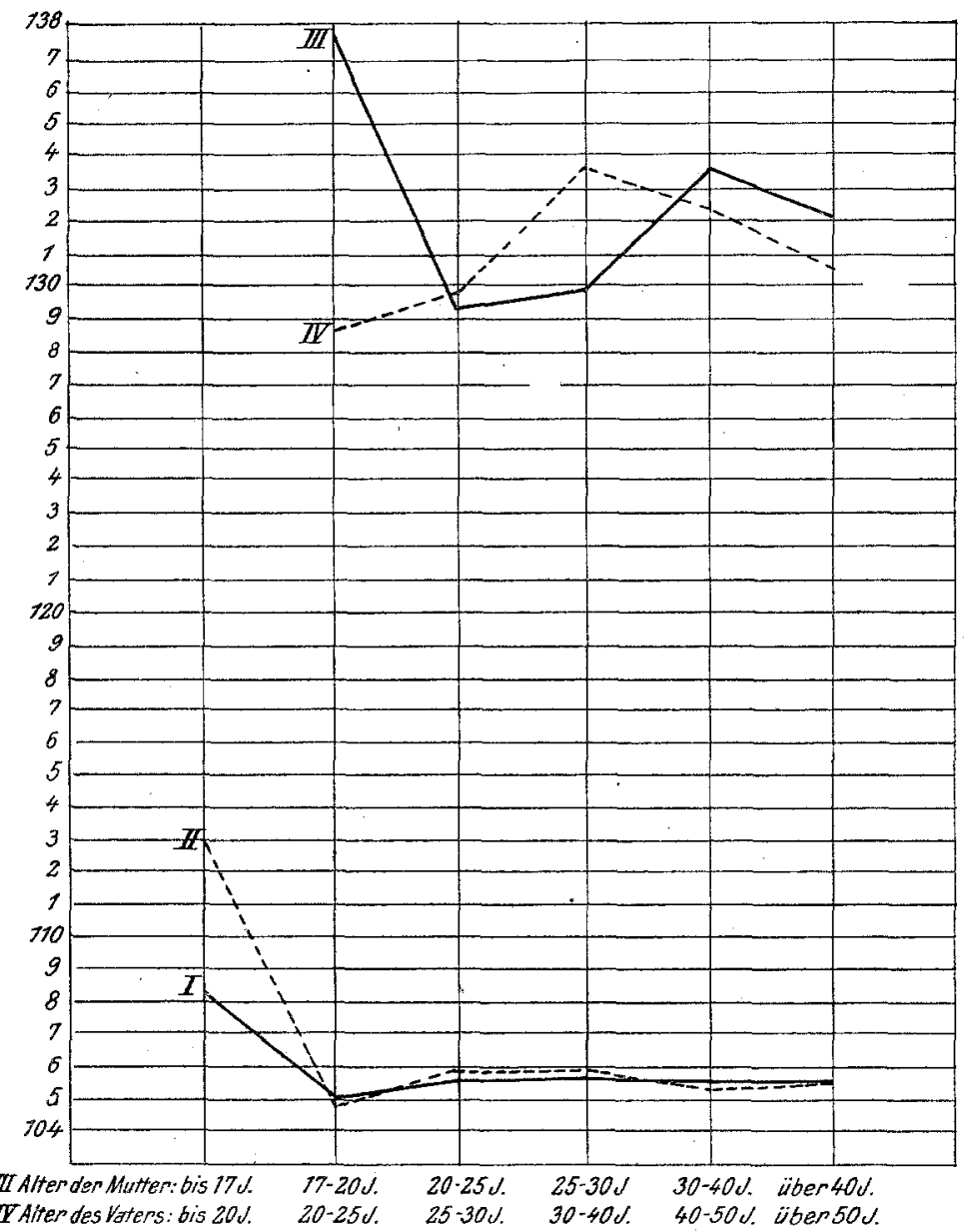

verhältniss vorfinden; in solchen Füllen, wo beide Eltern gleich alt sind, hätten wir ein mittleres Geschlechtsverhältniss, und wo die Väter älter sind als die Mütter, das höchste Geschlechtsverhältniss. Suchen wir alle Fälle dieser drei Eventualitäten auf der Tabelle 34 auf, so finden wir, dass das Hofacker-Sadler'sche Gesetz nicht bestätigt wird. Bloss das kann bestimmt gesagt werden, dass bei relativ höherem Alter des Vaters das Geschlechtsverhältniss in den meisten Combinationen, die sich aus der Tabelle herauslesen lassen, höher ist als bei gleichem Alter beider Eltern.

Aus der Tabelle 35 für todte Geburten kann überhaupt nichts Sicheres entnommen werden, was sich in einen gemeinschaftlichen Satz zusammenstellen liesse. 
Sehen wir noch weiter, ob wir in den Tabellen die Düsingsche Modification des Hofacker-Sadler'schen Gesetzes bestätigt finden, nämlich dass bei gleichem Alter der Mütter jüngere Männer mehr Knaben zeugen als Männer mittleren Alters. Untersuchen wir alle Fälle dieser Eventualität in den Tabellen, so finden wir, dass der Düsing'sche Satz weder für lebende, noch für todte, in diesen Tabellen zusammengestellte Geburten gültig ist.

Die Linien auf Tabelle 38 stellen uns das Schwanken des Geschlechtsverhältnisses vor bei der Berücksichtigung des Alters bloss eines der Eltern und haben deshalb Bedeutung nur für den Einfluss des absoluten Alters des Vaters oder der Mutter.

Linie I stellt uns das Schwanken des Geschlechtsverhältnisses lebender Geburten bei verschiedenem Alter der Mütter ohne Rücksicht auf das Alter des Vaters vor, aber giebt uns keine Möglichkeit, irgend eine Regel für diese Fälle abzuleiten. Auch der hohe Beginn jener Linie (Geschlechtsverhältniss der Geburten bei bis 17 Jahre alten Müttern) besitzt keine Bedeutung, da er im Ganzen aus einer kleinen Anzahl von Fällen bereehnet wurde. Sonst hält sich die Linie rom Alter von 20 Jahren bis zum Aufhören der Productionsfähigkeit in gleicher Höhe.

Was von der Linie I gesagt wurde gilt auch wörtlich für die Linie II, welche das Schwanken des Geschlechtsverhältnisses lebender Geburten bei verschiedenem Alter des Vaters ohne Rücksicht auf das Alter der Mutter vorstellt.

Linie III zeigt uns das Schwanken des Geschlechtsverhältnisses bei todten Geburten bei verschiedenem Alter der Mutter, ohne Rücksicht auf das Alter des Vaters, und bestätigt die früheren Angaben, dass nämlich die Mütter mittleren Alters verhältnissmässig weniger Knaben gebären als die noch ganz jungen oder alten Mütter.

Linie IV bedeutet das Schwanken des Geschlechtsverhältnisses bei todten Geburten bei verschiedenem Alter des Vaters, ohne Rücksicht auf das' Alter der Mutter, und es ist aus ihr ersichtlich, dass das Geschlechtsverhältniss der todten Geburten bei jungen Vätern ein ganz niedriges ist, mit dem Alter der Väter steigt bis zu 40 Jahren und dann wieder herabfällt.

Den Linien III und IV kann aber kein grosser Werth beigelegt werden, da ihnen eine kleine Anzahl von Fällen unterlegt ist, wie dies aus Tabelle 35 ersichtlich ist.

Fassen wir also alles das, was wir in diesem Capitel kennen gelernt haben, in einen Schluss zusammen, so müssen wir bekennen, 
dass der Einfluss des absoluten und auch des relativen Alters des einen resp. der beiden Eltern auf das Geschlecht ihrer Nachkommenschaft von verschiedenen Autoren überschätzt wurde, und dass von irgend welchen Gesetzen, wie z. B. das von Hofacker-Sadler aufgestellte, keine Rede sein kann, Der Einfluss des Alters kreuzt sich oder combinirt sich in gleicher oder in entgegengesetzt verlaufender Richtung mit verschiedenen anderen Einflüssen und die Bestimmung des blossen, mit anderen Einflüssen nicht combinirten Einflusses des Alters ist im Sinne von Hofacker-Sadler unmöglich.

Capitel VII.

\section{Beruf der Eltern und das Geschlechtsverhältniss ihrer Nach- kommenschaft.}

In dem amtlichen Ausweis der österreichischen statistischen Commission sind die Geburten auch nach der socialen Stellung oder nach Beschäftigung der Eltern zusammengestellt und es ist deshalb möglich auch in dieser Richtung den Einfluss dieses Factors auf das Geschlechtsverhältniss bei den Geburten zu untersuchen.

Düsing machte einige hier hereinfallende Beobachtungen in Preussen, aus den Folgendes anzuführen wäre:

Die öffentlichen Beamten, das sind solche, welche eine gesicherte Stellung besitzen, weisen eine sehr niedrige Zahl für das Geschlechtsverhältniss auf; bei den Privatbeamten zeigt sich dagegen ein sehr hohes Geschlechtsverhältniss bei den Geburten.

Selche Personen, welche mit Landescultur, Weinbau, Gartenbau, Forstwesen beschäftigt sind, weisen ein sehr hohes Geschlechtsverhältniss bei ihren Nachkommen auf, d. h. es werden verhältnissmässig mehr Knaben geboren.

Bei den Bergleuten findet man den anderen Arbeitern gegenüber ein höheres Geschlechtsverhältniss. Düsing legt diese Erscheinung durch die kleinere Kreuzung aus.

Die mit der Erzeugung von Nahrungsmitteln und dem Handel damit beschäftigten Personen weisen ein niedrigeres Geschlechtsverhältniss bei ihrer Nachkommenschaft auf. Düsing ist der Meinung, dass jene Personen, welche Speise und Trank besorgen, auch selber mehr essen und sich deshalb im besseren Ernährungszustande befinden. Dies sei dann die Ursache, dass sie mehr Mädchen zeugen und gebären als andere. 
Die socialen und materiellen Verhältnisse der Eltern üben einen besonders grossen Einfluss auf die Anzahl der todt Geborenen. So wie die unehelichen Kinder unterliegen auch die Kinder der ärmeren Eltern während ihrer embryonalen Entwickelung öfter den Einflüssen der mangelhaften Ernährung als die Kinder reicher Eltern.

Auch Girou de Busareingues stellte ebenfalls fest, dass in den Landbezirken das Geschlechtsverhältniss am grössten ist, in den übrigen Bezirken kleiner, und dass dort, wo schwere körperliche Arbeit verrichtet wird, relativ mehr Knaben geboren werden.

Dasselbe wurde auch von Horn bestätigt.

Es besteht also kein Zweifel darüber, dass die durch die sociale Stellung bedingte Lebensweise einen Einfluss auf das Geschlechtsverhältniss ausübt. In letzter Instanz wird dieser Einfluss durch die schlechtere oder bessere Ernährung der Eltern ausgelegt.

Ich habe alle Geburten in Oesterreich während 8 Jahren (1895-1902) bei 8 verschiedenen Berufen znsammengestellt und habe anch das Geschlechtsverhältniss der Nachkommenschaft für jedén Beruf besonders berechnet.

Das Resultat ist in einer Tabelle 39 zusammengestellt.

$\mathrm{Tab}$ e 11 e 39 .

\begin{tabular}{|c|c|c|c|c|c|c|c|c|}
\hline Beruf der Väter & Bauern & 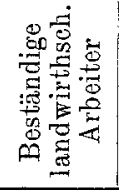 & $\begin{array}{l}\text { Land- } \\
\text { wirthseh. } \\
\text { Tage- } \\
\text { löhner }\end{array}$ & 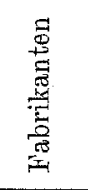 & 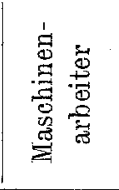 & Maurer & $\begin{array}{l}\text { Berg- } \\
\text { leute }\end{array}$ & Beamte \\
\hline 号 & $\begin{array}{l}1438650 \\
1354284 \\
2792934\end{array}$ & $\begin{array}{l}271922 \\
259494 \\
531416\end{array}$ & $\begin{array}{r}542322 \\
513507 \\
1058829\end{array}$ & $\begin{array}{l}2528 \\
2291 \\
4819\end{array}$ & $\begin{array}{r}84686 \\
71995 \\
156681\end{array}$ & $\begin{array}{l}137315 \\
129386 \\
266701\end{array}$ & $\begin{array}{r}100467 \\
95085 \\
195589\end{array}$ & $\begin{array}{r}86151 \\
81073 \\
167224\end{array}$ \\
\hline $\begin{array}{l}\text { Geschlechtsverhältn. } \\
\text { der Geburten ... }\end{array}$ & 106,3 & 104,8 & 106,2 & 110,3 & 117,6 & 106,2 & 105,6 & 106,3 \\
\hline
\end{tabular}

Diese acht Berufe lassen sich, was das Geschlechtsverhältniss anbelangt, in folgende Reihe zusammenstellen, wobei das Geschlechtsverhältniss vom ersten Glied angefangen bis zum letzten steigt:

1. Beständige landw. Arbeiter . . 104,8

2. Bergleute . . . . . . . . 105,6

3. Landw. Tagelöhner . . . . 106,2 

4. Maurer .
106,2
5. Bauern
106,3
6. Beamte
106,3
7. Fabrikanten
110,3
8. Maschinenarbeiter
117,6

Man könnte erwarten, dass bei den ersten 4, eventuell 6 Berufen eine schlechtere Ernährung vorherrsche, als bei den Fabrikanten (7) und bei den gut bezahlten Industriearbeitern, und doch findet man bei "den erwähnten 6 Berufen ein niedrigeres Geschlechtsverhältniss, als bei den Gruppen 7 und 8 .

Würde man dieser Tabelle einen grossen Werth beilegen, würde dadurch auch sehr die Meinung erschüttert werden, dass durch die gute Ernährung die Entwickelung der weiblichen Nachkommenschaft (niedriges G.-V.), durch die schlechte Ernährung die Entwickelung der männlichen Nachkommenschaft (hohes G.-V.) unterstützt wird.

Ich mache bloss darauf aufmerksam, dass die Landberufe $(1-5)$ ein niedrigeres G. $(104,8$ bis 106,3$)$ aufweisen, als die durchschnittliche Zahl des.G. aller Geburten von Oesterreich beträgt $(106,5)$. Bei den städtischen Berufen (7. Habrikanten und 8. Industriearbeitern) zeigt sich ein höheres G. $(110,3-117,6)$.

Das Criterium der guten und schlechten Ernährung hat sich also für Oesterreich nicht bewährt; auch die bekannte Thatsache, dass am Lande mehr Knaben geboren werden, als in den Städten, wird in diesem Capitel für Oesterreich nicht bestätigt, obgleich die einzelnen Gruppen auf Grund einer sehr grossen Anzah] von Fällen berechnet wurden.

\section{Capitel VIII.}

\section{Das Geschlechtsverhältniss bei Mehrgebnrten.}

Ist der Satz, dass die Ernährungsverhältnisse einen Einfluss auf das Geschlechtsverhältniss der Nachkommenschaft ausüben, richtig, müssen dann nach Düsing bei gleicher Ernährung der in der Gebärmutter gleichzeitig sich befindenden Leibesfrüchte mehr Nachkommen desselben Geschlechtes geboren werden, als bei den Geburten einzelner Kinder.

Die Richtigkeit des obigen Satzes beweist Düsing durch das Factum, dass die Zwillinge mit gemeinsamem Chorion immer desselben Geschlechts sind. 
Hueter und Ploss legen dies durch die gleichen Ernährungsverhältnisse der $Z$ willinge aus.

Mayrhofer stimmt aber mit dieser Auslegung im Allgemeinen nicht überein, da Hyrtl bei dem gemeinsamen Chorion zweier Kinder die Placenten vollständig getrennt von einander gefunden hat.

Untersuchen wir das Gesehlechtsverhältniss bei den Zwillingen und Drillingen, finden wir, dass das gleiche Geschlecht mehr überwiegt, als sich der Wahrscheinlichkeit nach erwarten liesse.

Moser fand unter 33556 Zwillingsgeburten 36,21 pCt. verschiedenen Geschlechts, Ploss in Sachsen bloss 32,37 pCt., Berg in Schweden unter 19297 Zwillingsgeburten 37,36 pCt., Neefo 36,4 pCt., Meckel Edl. v. Hemsbach 36,15 pCt. versehiedenen Geschlechts.

Bei den Drillingsgeburten warde dieselbe Erscheinung festgestellt. Der Wahrscheinlichkeit nach sollten $25 \mathrm{pCt}$. Drillingsgeburten gleichen Geschlechts sein (drei Knaben oder drei Mädchen). In der Wirklichkeit kommt dies aber öfter vor.

Meckel fand unter 1594 Drillingsgeburten fast dic Hälftc Geburten (719) gleichen Geschlechts.

Nach Neefe beträgt das Procent der Drillingsgeburten gleichen Geschlechts in Preussen, Oesterreich und Italien 49,6 pCt. (unter 4327 Drillingsgeburten 2146 Geburten gleichen Geschlechts).

Für die Vierlinge gilt dasselbe. Fircks constatierte bei 85 Vierlingsgeburten 30 Geburten gleichen Geschlechts, obgleich nach der Wahrscheinlichkeitsreshnung bei den Vierlingsgeburten nur 12 pCt. gleichen Geschlechts sein sollten.

Diese Zahlen beweisen uns, wie sehr bei den Mehrgeburten das gleiche Geschlecht vorherrscht.

Wie ist diese Erscheinung zu erklären?

Manche Forscher erklärten diesं durch die gleiche Ernährung der Föten, andere widersprechen dieser Meinung.

Schultze und Ahlfeld stellten die Ansicht auf, dass die Mehrgeburten gleichen Geschlechts aus einem Ei entstammen.

Mayrhofer legt dies folgendermaassen aus: Bei zwei verschiedenen menschlichen Eiern können die Conceptionen durch die Frist von zwei Tagen von einander getrennt werden und so kann bei Zwillingen, welche aus zwei Eiern entstammen, irgend ein erst. nach der Conception wirkender Einfluss das Geschlecht des ersten Eies bestimmen, bevor noch das zweite $\mathrm{Ei}$ befruchtet wurde, oder che noch für das zweite Ei das Moment eingetreten ist, in welchem 
durch einen anders wirkenden Einfluss die Bestimmung des Geschlechts anders vor sich geht. Zwillinge, welche ein gemeinsames Chorion besitzen, stammen aus einem einzigen $\mathrm{Ei}$, für solche Zwillinge ist nur eine einzige Conception nöthig und deshalb tritt das Moment, in welchem das Geschlecht durch irgend einen Einfluss bestimmt wird, in gleicher Zeit nach der Conception ein und daher sind solche Zwillinge gleichen Geschlechts. Das gleiche Geschlecht der Zwillinge aus einem einzigen Ei liesse sich durch die Auslegung von Mayrhofer ziemlich leicht erklären.

Man könnte glauben, dass sich das gleiche Geschlecht bei Zwillingen auf die Zwillinge aus einem Ei überhaupt überführen liesse, da diese immer gleichen Geschlechts sind. Dem ist aber nicht so, da die Zwillinge gleichen Geschlechts öfters vorkommen, als sich nach dem Procent, in welchem die aus einem Ei entstammenden Zwillinge vorkommen, erwarten liesse. Nach Ahlfeld fällt nämlich anf 8,15 Zwillingsgeburten eine mit einem einzigen Chorion. Sollte man das gleiche Geschlecht bei Zwillingen durch die aus einem Ei entstammenden Zwillinge auslegen, käme dann auf 3,84 Zwillingsgeburten eine Zwillingsgeburt mit einem einzigen Chorion, das ist aber nicht der Fall.

Aus allem Angeführten lässt sich also schliessen, dass das gleiche Geschlecht bei Zwillingsgeburten bloss durch die gleichen oder ähnlichen Verhältnisse der in der Gebärmutter sich befindenden Zwillinge herbeigeführt werden kann.

Die Thatsache, dass die Föten, bei denen die Conception und die Entwickelung unter ähnlichen oder gleichen äusseren Umständen vor sich geht, sehr oft desselben Geschlechts sind, spricht für die Ansicht, dass die äusseren Umstände einen Einfluss auf die Bildung des Geschlechts besitzen.

Durch die Zahlen aus der preussischen Statistik versuchte Düsing zu beweisen, dass das Procent der Geburten und Mehrgeburten mit der wachsenden Prosperität der Nation steigt.

Derselbe Autor führt für Preussen folgende Tabelle der Mehrgeburten an. (Siehe S. 807.)

Was die todten Geburten bei Mehrgeburten anbelangt, überwiegen die Todtgeborenen. Es lässt sich zwar nicht bestreiten, dass die Zwillinge in Folge gegenseitiger Concurrenz verhältnissmässig schlecht ernährt werden, man muss aber dabei im Auge behalten, dass diese Concurrenz erșt bei den grösseren Föten auftritt, am Anfange aber, wo die Embryen sehr klein sind, und wo 


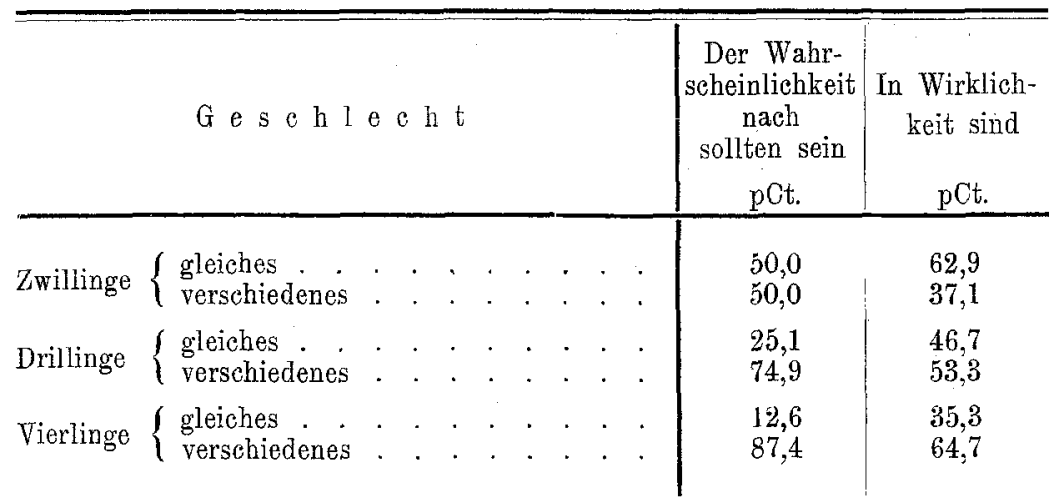

noch der das Geschlecht bestimmende Einfluss einwirkt, diese Concurrenz um die Nahrung noch nicht auftritt. Und in der That zeigt sich diese Concurrenz um die Nahrung nicht durch ein erhöhtes Geschlechtsverhältniss zu Gunstén der Knaben, wie nach allen Erfahrungen zu erwarten wäre, sondern ihr Einfluss macht sich später bloss durch die grössere Anzahl der Todtgeborenen bei den Mehrgeburten geltend.

Mit Rüeksicht auf das Geschlechtsverhältniss bei Mehrgeburten stellte Düsing seine Zahlen und die von Fircks in Preussen vom Jahre 1824-1887 zusammen und bestimmte im Ganzen 582184 männliche and 557396 weibliche Mehrgeburten, was dem G. $=104,447$ entspricht. Daraus folgt, dass bei den Mehrgeburten in Preussen verhältnissmässig mehr Mädchen geboren werden, als bei den Einzelgeburten, bei denen d. G. $=106,305$ betrug. Auch bei den Drillingen fand $D$ üsing ein niedrigeres $G$. $(=105,04)$ als bei den Einzelgeburten.

Nun stellt sich die Frage, warum bei den Zwillingsgeburten weniger Knaben geboren werden.

Es wurde früher gelegentlich gezeigt, dass in der Zeit, wo besonders viele Kinder geboren werden, verhältnissmässig viele Mädchen auf die Welt kommen. Es hat also den Anschein, als ob die eine grössere Production von Kindern bewirkenden Umstände die Tendenz besässen, die befruchteten Embryen in weibliches Geschlecht zu unterscheiden (determiniren). Die grössere Production von Kindern hängt aber von der grösseren Production von Eiern ab, und diese führt wieder zu öfteren Mädchengeburten. Die eine grössere Production von Eiern bewirkenden Umstände wirken auch hei der Entstehung von. Zwillings- und Mehrgeburten, und gerade bei diesen erzielen sie eine grössere Anzahl Mädchen- 
geburten. Die letzte Erscheinung stände also in Beziehung zur grösseren Production von Kindern, besonders von Mädchen in bestimmter (warmer) Jahreszeit bei wachsender Prosperität der Nation.

Das Geschlechtsverhältniss der Nachkommenschaft aus Mehrgeburten wurde auch von anderen Forschern untersucht. Neefe berechnete in Preussen in den Jahren $1860-1873$ d. G. überhaupt auf 104,07, bei Drillingen 104,55, in Oesterreich in denselben Jahren d. G. überhaupt 105,26, bei Drillingen 106,10.

Zwei in entgegengesetzter Richtung wirkende Momente haben auf die Bestimmung des Geschlechts bei den Mehrgeburten folgenden Einfluss: Die schwächere Ernährung von mehreren Embryonen wirkt zu Gunsten eines höheren G.; die Prosperität der Eltern, bei denen die Mehrgeburten öfters vorkommen, verursacht eine Verkleinerung der Zahl d. G. Da bei den Zwillingen die Concurrenz in der Zeit, in welcher das Geschlecht bestimmt wird, nicht die die Waage fällt, so ist daher bei ihnen d. G. niedriger, als bei den Einzelgeburten. Hier würde also bloss die Prosperität der Eltern einen Einfluss besitzen. Bei den Drillingen könnte diese Concurrenz in vielen Fällen früher auftreten, und deshalb glaubt Düsing, dass d. G. bei Drillingen höher sei. Wir werden sehen, dass diese Ansicht von $\mathrm{D}$ üsing nicht bestätigt wird.

Ich theile nun die Resultate meiner eigenen Untersuchungen bei Mehrgeburten in Oesterreich mit. Ich hảbe die zugehörigen Zahlen für Oesterreich binnen 7 Jahren (1896-1902) zusammengestellt und theile zuerst mit; wie oft die Mehrgeburten gleichen Geschlechts vorkommen, und welches Geschlechtsverhältniss die Kinder aus Mehrgeburten aufweisen.

Während der erwähnten 7 Jahre wurden in Oesterreich im Ganzen 83378 Zwillingsgeburten verzeichnet. Davon waren 72341 eheliche und 11037 uneheliche Geburten.

Aus diesen 83378 Zwillingsgeburten waren 52755 , also 63,2 pCt., gleichen Geschlechts und 30623 (36,8 pCt.) verschiedenen Geschlechts. Aus den 52755 Zwillingen gleichen Geschlechts waren 27362 männliche und 25393 weibliche Zwillinge.

Berücksichtigen wir die Legitimität der Zwillinge, finden wir unter 72341 ehelichen Zwillingen 45720 (63 pCt.) gleichen Geschlechts (23696 männliche und 22024 weibliche) und 26621 (36,8 pCt.) Zwillinge verschiedenen Geschlechts; unter 11037 unehelichen Zwillingen sind $7035 \quad(63,7 \mathrm{pCt}$.) gleichen Geschlechts 
(3 666 männliche und 3369 weibliche) und 4002 (36,3 pCt.) ungleichen Geschlechts.

Während der erwähnten Zeit gab es 901 Drillingsgeburten und zwar 455 (50,4 pCt.) 'gleichen Geschlechts (229 männliche und 225 weibliche) und $446(49,6$ pCt.) ungleichen Geschlechts (200 Fälle mit 2 Knaben und 1 Mädchen und 246 Fälle mit 1 Knaben und 2 Mädchen).

In dieser Richtung bestätigen meine Ergebnisse die Angaben Düsing's und anderer Autoren, dass nämlich das gleiche Geschlecht bei Mehrgeburten in einem grösseren Procent auftritt, als der Wahrscheinlichkeit nach zu erwarten wäre. Ich habe also keine Ursache, gegen die früher in dieser Angelegenheit erfolgte Auslegung und Schlussfolgerung etwas einzuwenden.

Das Geschlecht der aus Mehrgeburten entstammenden Kinder ist in folgenden 2 Tabellen zusammengestellt, von denen die Tab. 40 für Zwillinge gilt und Tab. 41 für Drillinge, welche in Oesterreich während der erwähnten 7 Jahre geboren wurden.

T a b e l.1 e 40.

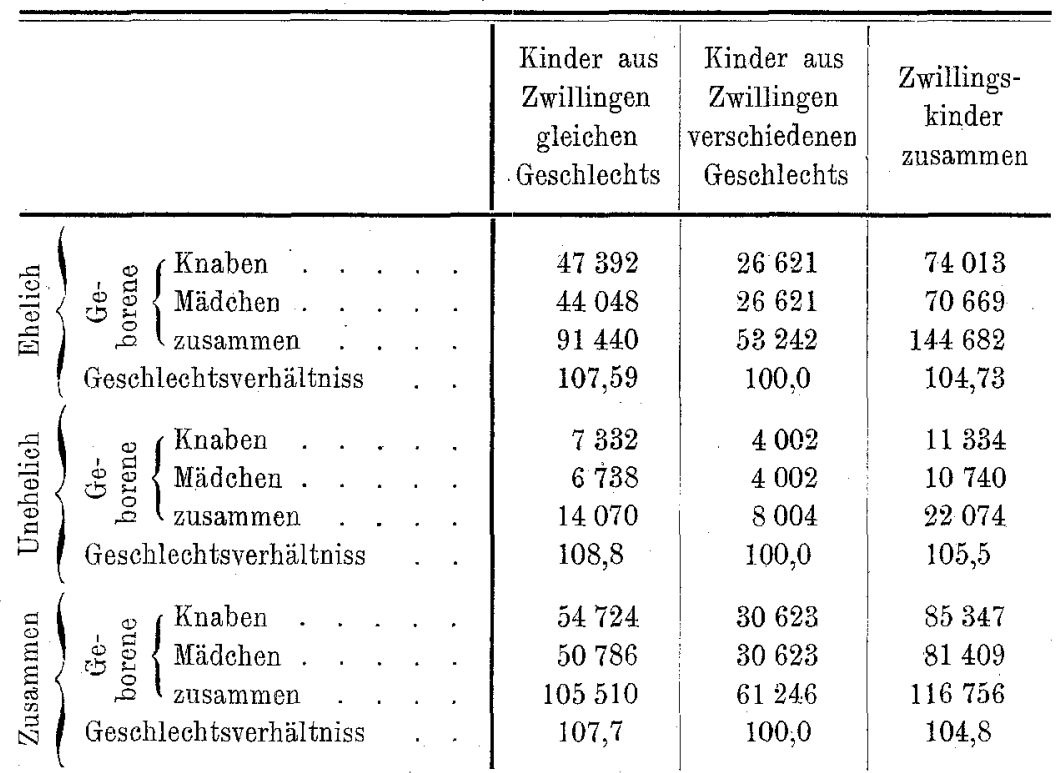

Aus der Tab. 40 ist ersichtlich, dass d. G. aller Zwillingskinder 104,8 beträgt; es ist also niedriger als d. G. der Kinder aus Einzelgeburten, welches für Oesterreich 106,3 beträgt. Es werden verhältnissmässig mehr Mädchen in Zwillingen geboren, als in den Einzelgeburten. Hier zeigt sich also kein Einfluss der 
Concurrenz um die Nahrung; welcher sich durch ein höheres G. kennbar machen würde, mit der Voraussetzung, dass die schlechtere Enährung verhältnissmässig mebr Knabengeburten nach sich zieht. Bei der Eintbeilung der Zwillinge in eheliche und uneheliche stellt sich für die ersteren das $G .=104,73$, für die letzeren d. $G$. $=105,5$ heraus; bei den unehelichen Kindern haben wir ein höheres G., was also nach dem in Cap. I dieser Arbeit Angeführten ganz richtig ist.

Ta $b$ e 11 e 41 .

\begin{tabular}{|c|c|c|c|c|}
\hline & $\begin{array}{l}\text { Drillings- } \\
\text { kinder } \\
\text { sleichen } \\
\text { Geschlechts }\end{array}$ & $\begin{array}{l}\text { Drillings- } \\
\text { kinder } \\
\text { zwei Knaben } \\
\text { ein Mädehen }\end{array}$ & $\begin{array}{c}\text { Drillings- } \\
\text { kinder } \\
\text { ein Knabe } \\
\text { zwei Mädchen }\end{array}$ & $\begin{array}{l}\text { Drillings- } \\
\text { kinder } \\
\text { zusammen }\end{array}$ \\
\hline 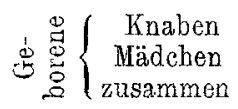 & $\begin{array}{r}687 \\
675 \\
1362\end{array}$ & $\begin{array}{l}399 \\
201 \\
600\end{array}$ & $\begin{array}{l}247 \\
494 \\
741\end{array}$ & $\begin{array}{l}1333 \\
1370 \\
2703\end{array}$ \\
\hline $\begin{array}{l}\text { Geschlechts- } \\
\text { verhältniss }\end{array}$ & 101,7 & \multicolumn{2}{|c|}{$\begin{array}{c}399+247: 201+494 \\
92,9\end{array}$} & 97,3 \\
\hline
\end{tabular}

Betrachten wir aber die Zwillingskinder gleichen Geschlechts näher, so finden wir, dass die indifferenten Zwillinge doch verhältnissmässig öfters in männliche als weibliche Zwillinge determinirt werden, denn d. G. der ehelichen Zwillingskinder gleichen Geschlechts beträgt nach der Tabelle 107,59 und erst durch die Zahl der Zwillingskinder ungleichen Geschlechts wird diese Ziffer auf 104,73 erniedrigt.

Dasselbe können wir auch bei den unehelichen Kindern beobachten, wo das G. der Zwillingskinder gleichen Geschlechts 108,8 beträgt; erst dureh die Zahl der Zwillingskinder verschiedenen Geschlechts fällt es auf 105,ว herab.

Dies ist eine neue, bisher noch nicht angeführte Analysis, aus welcher hervorleuchtet, dass bei der Berücksichtigung der Zwillingskinder gleichen Geschlechts der Einfluss der Concurrenz um die Nahrung sich doch durch eine erhöhte Geschlechtsverhältnisszahl kenntlich macht. Bei allen ehelichen und unehelichen Zwillingskindern gleichen Geschlechts war d. G. $=107,7$, bei den Einzelgeburten betrug es dagegen 106,8.

Tab. 41 giebt uns d. G. aller Drillingskinder auf 97,3 an, was eine überraschend niedrige Zahl ist. Das Geschlechtsverhältniss der Drillingskinder gleichen Geschlechts beträgt 101,7. Diese Zahl ist 
zwar grösser als die trühere Lahl 97,3, aber viel kleiner als d. G. der Kinder aus Einzelgeburten und Zwillingen. Ich mache keinen Versuch, diese Erscheinung zu erklären, da die Zahl der in der Tabelle enthaltenen Kinder (im Ganzen 2703) sehr klein ist und der wahrscheinliche Fehler demnach sehr gross ausfällt.

Fasse ich alle Mehrgeburten zusammen, also Zwillinge, Drillinge und die Mehrgeburten (der letzteren gab es in Oesterreich während der erwähnten 7 Jahre 18, davon 32 Knaben und 42 Mädchen), so finde ich im Ganzen 86733 Knaben und 82821 Mädchen, welche aus Mehrgeburten entstammen; ihr G. beträgt 104,72.

Im Ganzen ist also das G. der aus Mehrgeburten entstammenden Kinder niedriger, als d. G. der Kinder aus Einzelgeburten.

Aus diesem Capitel lässt sich Folgendes schliessen:

Das bedeutend grosse Procent der aus Mehrgeburten geborenen Kinder gleichen Geschlechts, ein grösseres Procent als nach der Wahrscheinlichkeitsrechnung zu erwarten wäre, spricht dafür, dass die äusseren Einflüsse, in erster Reihe die Ernährung, in bedeutendem Maasse auf die Bestimmung des Geschlechts einwirken. Das Geschlechtsverhältniss der Kinder aus Mehrgeburten ist kleiner als bei Kindern aus Einzelgeburten, d. h. es werden verhältnissmässig weniger Knaben geboren. Diese Erscheinung ist nur dadurch zu erklären, dass die Mädchengeburten und die Mehrgeburten überhaupt nur bei besserer Prosperität der Eltern vorkommen, und dass also diese die gemeinsame Ursache beider gleichzeitig auftretenden Erscheinungen ist.

\section{Capitel IX.}

\section{Das Geschlechtsverhältniss bei den Geburten nach der Nationalität.}

Zuerst beschäftigte ich mich mit den Geschlechtsverhältnisszahlen bei den Geburten in Galizien. Ich habe alle Geburten dieses Landes während 12 Jahre (1891-1902) zusammengestellt und fand ein Geschlechtsverhältniss von 106;71. Als ich aber die Geburten in katholische und israelitische eintheilte, stellte sich für die Katholiken (Polen und Ruthenen) das Geschlechtsverhältniss 106,00 beraus, während es bei den Juden 112,06 betrug. Daraus ersehen wir, dass das Geschlechtsverhältniss bei der Bevölkerung Galiziens, wovon 96 pCt. Slaven sind, niedriger ist, als die durchschnittliche Zahl für ganz Oesterreich angiebt. Dieser Umstand 
bewog mich also, auch die Geschlechtsverhältnisszahlen für die einzelnen, Oesterreich bewohnenden Nationen näher zu untersuchen.

Bei der Untersuchung der Arbeit Düsing's in Preussen, wo auch viele Polen leben, fand ich einen interessanten Absatz, worin der Autor bemerkt, dass schon Fircks angiebt, dass in solchen Bezirken, in welchen die Deutschen stark gemischt mit anderen Nationen leben, relativ mehr Mädchen geboren werden. Düsing bemerkt dann noch selbst dazu, dass in den überwiegend slavischen Bezirken verhältnissmässig viele Kinder, darunter wieder viele Mädchen geboren werden, so dass die Geschlechtsverhältnisszahl kleiner ist als in solchen Bezirken, wo 90 pCt. oder bloss Deutsche wohnen.

Weitere Schlussfolgerungen aus dieser Thatsache zieht aber Düsing nicht und berührt diese Frage nur im Vorbeigehen.

Es war also sehr anziehend für mich, da mir das Material von ganz Oesterreich, welches so bunt national gebildet ist, zur Verfügung stand, zu untersuchen, ob die Behauptung richtig sei, dass die Slaven ein anderes Geschlechtsverhältniss aufweisen, als die Deutsohen.

Dass das Geschlechtsverhältniss bei den verschiedenen Nationen auch verschieden ist, ist eine bekannte Thatsache. So führt Schuhmann folgende Tabelle an:

Das Geschlechtsverhältniss bei den Russen und Polen $=101$

$\begin{array}{llllll}n & n & n & & \text { Engländern } & =104 \\ " & n & n & n \text { Magyaren } & =110 \\ n & n & n & n & \text { Griechen } & =111\end{array}$

Diese Zahlen sind freilich unverlässlich, da die Anzahl der Geburten, aus denen sie berechnet wurden, nicht angegeben ist.

Keleti zeigte auch für Ungarn, dass das Geschlechtsverhältniss in den einzelnen Theilen des Landes verschieden ist; so werden im Norden und im Westen, wo Deutsche und Slovaken wohnen, relativ mehr weibliche Individuen geboren. Bei den Magyaren hat Keleti ein hohes Geschlechtsverhältniss festgestellt.

Soweit bekannt ist, zeigen ein hohes Geschlechtsverhältniss die Griechen, Juden, Magyaren und dann besonders auch die aussterbenden Rassen anderer Welttheile, namentlich Australiens. Düsing betrachtet in einer anderen älteren Abhandlung das hohe Geschlechtsverhältniss bei den Geburten für ein ungünstiges Zeichen für die weitere Existenz der Nation, und zwar mit Recht. Ich erlaube mir zur Erklärung folgende Erwägung hinzuzu- 
fügen. Die Vermehrung einer beliebigen Thiergattung oder des Menschen hängt im grossen Maasse von der Auswahl weiblicher Individuen, oder von der Anzahl Weibchen ab. Man könnte sich den äussersten Fall denken, wo es bei einer Thiergattung durch Einfluss beliebiger Umstände so weit käme, dass bloss ein Weibchen und einige Männchen übrig bleiben würden. Es ist klar, dass für diese Thiergattung die grosse Gefahr besteht, dass, wenn dem Weibchen ein Unglück zustösst, sie ausstirbt. Bei zwei Weibchen wird diese Gefahr zur Hälfte verkleinert und dies geht so weiter. Wir sehen also, dass für das Aussterben und für den weiteren Bestand die Anzahl Weibchen ein wichtiger Factor ist.

Für die Vermehrung der Menschen sind auch zwei Umstände besonders wichtig: 1. Wieviel Kinder bei einer Nation geboren werden, und 2. welches Geschlecht vorwiegt. Es wurde bei den meisten Nationen die interessante Thatsache festgestellt, dass überall mehr Knaben geboren werden, aber die Anzahl der auf 100 Mädchen kommenden Knaben ist nicht überall gleich. Die Sterblichkeit der Knaben schon bei der embryonalen Entwicklung und bald nach der Geburt ist zwar sehr gross, so dass sich das Geschlechtsverhältniss bei den meisten Nationen wieder verändert, and bei der Reife überwiegt dann das weibliche Geschlecht. Uns muss aber vom Standpunkte der Entwicklungsforscher bauptsächlich das interessiren, inwieweit eine Nation die innere Eigenschaft besitzt, mehr oder weniger Mädchen zu produciren. Nach der obigen Erwägung, welche mit den Ansichten vieler Forscher übereinstimmt, ist als ein gutes Zeichen für die Entwicklung der Nation eine grosse Geburtenanzahl, davon hauptsächlich viele Mädchen, also ein kleines Geschlechtsverhältniss bei den Geburten zu bezeichnen ${ }^{1}$ ). Wie sich dann das Geschlechtsverhältniss im Leben weiter noch ausbildet, ist nicht die Sache des Entwicklungsforschers, denn uns handelt es sich nur darum, festzustellen, dass die Eigenschaft, mehr Mädchen auszubilden oder zu produciren, durch die Organismen der Nation gegeben ist. Die Geborenen zu erhalten und die Erhaltenen festzustellen, gehört in ein anderes medicinisches Fach.

Ich lasse es bei diesen einigen Sätzen und führe die Resultate meiner Untersuchungen an.

1) Mit der biologischen Bedentung des Ueberschusses an Knabengeburten, worüber $R$ auber sehr interessante Arbeit veröffentlicht hatte, will ich mich an einer anderen Stelle beschäftigen. 
814 Srdínko, Geschlechtsverhältniss bei den Geburten in Oesterreich.

Tab. 42 enthält alle Geburten in Galizien während 12 Jahren, welche nach den Religionen zusammengestellt sind. Dazu wurde schon früher bemerkt, dass die römischen und griechischen Katholiken Polen und Ruthenen sind und 96 pCt. von der Gesammtbevölkerung bilden. Ihnen gegenüber stehen die jüdischen Geburten.

$\mathrm{T}$ a b e lle 42 .

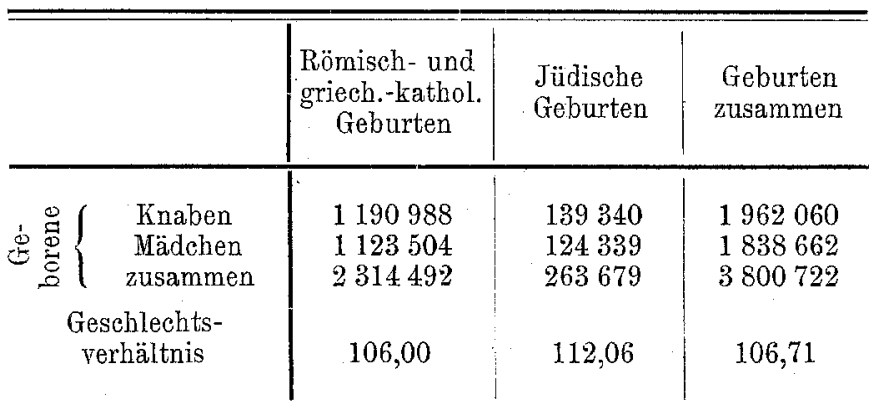

Wie aus der Tabelle zu ersehen ist, beträgt das Geschlechtsverhältniss bei den slavischen Geburten bloss 106,00.

Ich komme nun zur Tab. 43, in welcher die Geburten von fünf grösstentheils slavischen Ländern zusammengestellt sind, und zwar sind dies Böhmen, Mähren, Galizien, Krain und Dalmatien. Auf der Tabelle ist zuerst die Anzahl der Knabengeburten und Mädchengeburten angeführt, dann die Gesammtanzahl aller Geburten und endlich das Geschlechtsverhältniss. Bei Dalmatien, Krain und Mähren sind die gesammten Geburten überhaupt angegeben, bei Galizien und Böhmen sind die jüdischen, bei Böhmen noch die evangelischen Geburten ausgenommen.

$\mathrm{T}$ a b e 11 e 43

\begin{tabular}{|c|c|c|c|c|c|}
\hline & 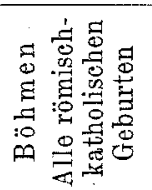 & 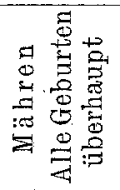 & 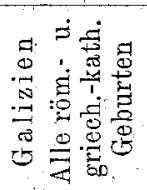 & 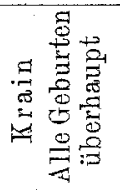 & 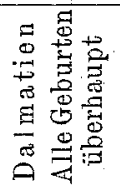 \\
\hline 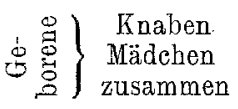 & $\begin{array}{r}896354 \\
843365 \\
1739719\end{array}$ & $\begin{array}{l}458702 \\
431976 \\
890678\end{array}$ & $\begin{array}{l}1190988 \\
1123504 \\
2314492\end{array}$ & $\begin{array}{r}94297 \\
89186 \\
183483\end{array}$ & $\begin{array}{l}115441 \\
109,825 \\
225226\end{array}$ \\
\hline $\begin{array}{l}\text { Geschleehts- } \\
\text { verhältniss }\end{array}$ & 106,28 & 106,18 & 106,00 & 105,73 & 105,11 \\
\hline
\end{tabular}

Wie aus der Tabelle ersichtlich ist,. zeichnen sich alle diese Länder durch verhältnissmässig niedrigere Geschlechtsverhältnisse aus, als wir bei ganz Oesterreich gefunden haben. Die Erniedri- 
gungen sind in den einzelnen Ländern verschieden und treten besonders auf Tab. 44 deutlich hervor. $\mathrm{Za}$ dieser Tabelle ist noch eine Rubrik bejgefügt, welche uns den Procentsatz der slavischen Bevölkerung angiebt.

T a b. e 11 e 44 .

\begin{tabular}{c|c|c|c}
\hline \hline Land & $\begin{array}{c}\text { pCt. der } \\
\text { Slaven von } \\
\text { der Gesammt } \\
\text { bevällkerung }\end{array}$ & $\begin{array}{c}\text { Geschlechts- } \\
\text { verhältniss }\end{array}$ & $\begin{array}{c}\text { Slavische Nationen; } \\
\text { welche das Land } \\
\text { bewohnen }\end{array}$ \\
\hline Böhmen & 62,6 & 106,28 & Böhmen \\
Mähren & 72,0 & 106,18 & Böhmen \\
Galiżien & 96,0 & 106,00 & Polen und Ruthenen \\
Krain & 93,0 & 105,73 & Slovener \\
Dalmatien & 95,0 & 105,11 & Serbo-Kroaten
\end{tabular}

Die Tab. 44 beweist klar, dass das Geschlechtsverhältniss in einem Lande in dem Maasse abfällt, d. h. dass verhältnissmässig mehr Mädchen geboren werden, ein je grösserer Procentsatz der Slaven das Land bewohnt.

Betrachten wir also ein niedriges Geschlechtsverhältniss für ein günstiges Zeichen bei einer Nation oder einem Lande, so sehen wir, dass die Serbokroaten am besten bestellt sind; ihnen folgen dann die Slovenen, dann Ruthenen und Polen und endlich die Bewohner Böhmens.

Bei der Zusammenstellung der Tab. 44 wollte ich mich auch überzeugen, ob die Böhmen ein anderes Geschlechtsverhältniss besitzen als Deutsche. Die Verhältnisse gestalten sich in Böhmen etwas anders, da die Bevölkerung, besonders aber in den deutschen Bezirken, ziemlich gemischt ist, und es war unsicher, ob die bei anderen Ländern constatirte Erscheinung sich auch im Königreich Böhmen zwischen den Böhmen und Deutschen zeigt. Ich habe zu diesem Zwecke 21 böhmische und 13 deutsche Bezirkshauptmannschaften zusammengestellt und habe alle Geburten in ihnen während 10 Jahren (1893-1902) zusammengezählt, und aus den erhaltenen Zahlen habe ich dann das Gesehlechtsverhältniss für die böhmischen und deutschen Bezirke berechnet.

Unter die böhmischen Bezirke wählte ich: Beneschau, Böhm. Brod, Caslau, Chrudím, Jicín, Jungbunzlau, Klattau, Kolin, Königgrätz, Kuttenberg, Laun, Melnik, Neu-Bydzow, Pardubitz, Pisek, Podebrad, Pribram, Raudnitz, Selcan, Wittingau und Tábor. Unter 
die deutschen Bezirke nahm ich: Asch, Aussig, Leipa, Braunau, Eger, Falkenau, Friedland, Kaaden, Kaplitz, Karlsbad, Reichenberg, Teplitz, Tetschen und Trautenau. In den böhmischen Bezirken bekam jch in jenen 10 Jahren 495694 Geburten und in den deutschen Bezirken 401879 Geburten.

Auf Tab. 45 und 46 sind die Resultate aus den böhmischen und deutschen Bezirken zusammengestellt. Vergleichen wir die beiden zugehörigen Zahlen mit einander, sehen wir, dass das Geschlechtsverhältniss aller Geburten in den böhmischen Bezirken um etwas kleiner ist als in den deutschen Bezirken und ebenfalls auch das Geschlechtsverhältniss bei den lebendigen Geburten ist in den böhmischen Bezirken kleiner als in den deutschen. Obgleich dieser Unterschied nicht so gross ausfällt, stellt es sich doch heraus, dass in den böhmischen Bezirken verhältnissmässig um etwas mehr Mädchen geboren werden als in den deutschen Bezirken. Die Bevölkerung der böhmischen Bezirke hat jene günstige Eigenschaft doch besser erhalten, als die Bevölkerung deutscher Bezirke. Vergleichen wir aber die todten Geburten, stellt sich bei den todt Geborenen in den böhmischen Bezirken ein grösseres Geschlechtsverhältniss heraus als in den deutschen Bezirken. Aber auch darin berubt ein Vortheil für die Böhmen, denn bei den todten Geburten ist ein hohes Geschlechtsverhältniss für eine Nation vortheilhaft, d. h. wenn bei einer gegebenen Anzahl mehr todte Knaben und dafür mehr lebendige Mädchen geboren werden.

T a b e 11 e 45. Böhmische Bezirke.

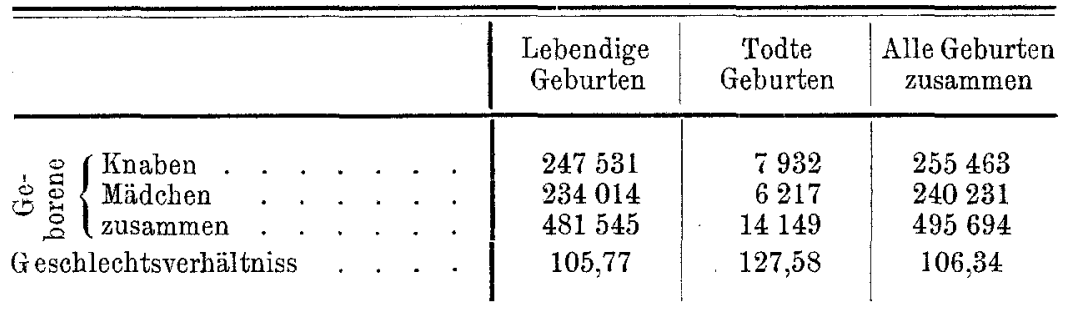

T a b e 11 e 46. Deutsche Bezirke.

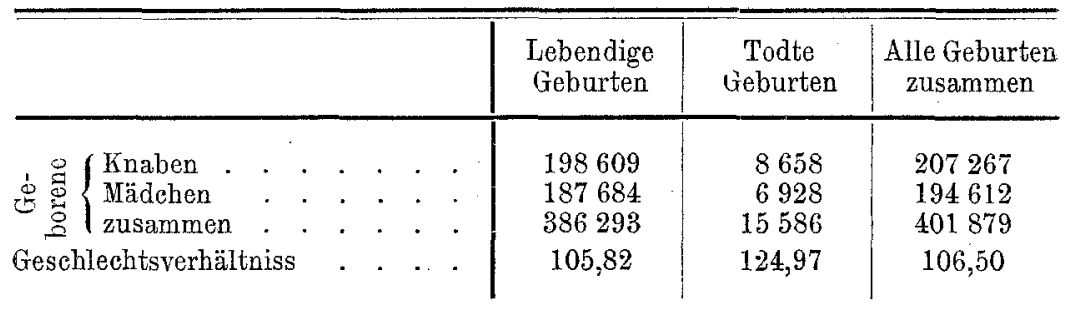


Aus dem bereits Erwähnten lässt sich constatiren, dass die slavische Bevölkerung Oesterreichs sich durch ein niedrigeres Geschlechtsverhältniss auszeichnet, als die deutsche Bevölkerung Oesterreichs und auch Preussens. Dies lässt sich wenigstens von der Zeit, auf welche sich die Untersuchung bezieht, behaupten. Dass man dasselbe auch von der früheren Zeit schliessen und auch für die Zukunft voraussagen kann, beweisen die Zahlen für Russland in den letzten 50 Jahren $(1853-1903)$, welche ich untersucht habe. Dort ist das durchschnittliche Geschlechtsverhältniss der orthodoxen Geburten auf 103,5 bestimmt. Es schwankt dann zwischen 106 und 102.

In Anbetracht dessen, dass die Geschlechtsverhältnisszahlen für Russland jedes Jahr aus 3-4 Millionen Geburten berechnet werden, beträgt der wahrscheinliche Fehler nur einige Hundertstel und wir finden also für Russland ein niedriges Geschlechtsverhältniss.

Fügen wir noch das hinzu, was Keleti bei den ungarischen Slovaken gefunden hatte, so sehen wir, dass die Slaven ein niedrigeres Geschlechtsverhältniss aufweisen als die Deutschen, und zwar ist es am niedrigsten bei den Russen; ihnen folgen dann die. SerboKroaten, Slovenen, Ruthenen, Polen und Böhmen.

Düsing schliesst dann seine Abhandlung aus dem Jahre 1882 mit folgenden Worten: „Wir sind berechtigt, das hohe Geschlechtsverhältniss bei den Geburten als ein ungünstiges Zeichen für die weitere Existenz einer Nation zu betrachten, denn auch die daraus gezogenen Consequenzen sind weitgehend." Indem ich dieses $\mathrm{Ca}$ pitel über das Geschlechtsverhältniss bei den Geburten in Böhmen und in Oesterreich beschliesse, betrachte ich es als bewiesen, dass alle Slaven eine in ihrem Organismus bestehende Eigenschaft besitzen, verhältnissmässig mehr Mädchen zu produciren als die Deutschen, und dass diese Eigenschaft vom Standpunkt des Entwicklungsforschers als ein gutes Zeichen für die weitere Vermehrung slaviseher Nationen zu betrachten ist.

\section{Schluss.}

Zur leichteren Uebersicht sind hier noch die Resultate dieser Arbeit nach den einzelnen Capiteln angeführt, wobei hauptsächlich neue oder in der Statistik anderer Reiche sich zeigende Erscheinungen berücksichtigt werden. 
In Böhmen, sowie auch in ganz Oesterreich zeigt sich die auch schon in anderen Ländern beobachtete Erscheinung, dass nämlich die lebendigen Geburten ein kleineres Geschlechtsverhältniss aufweisen als die todten Geburten, d. h. dass verhältnissmässig mehr Knaben todt geboren werden als Mädchen. Die Ursache daron liegt darin, dass gerade die Knaben mit Rücksicht auf ihre grösseren Nahrungsansprüche leichter den ungünstigen Verhältnissen unterliegen als Mädehen.

In Böhmen; sowie auch in Deutschland und anderen Ländern kennzeichnen sich die ehelichen Geburten durch ein böheres Geschlechtsverhältniss als die unehelichen Geburten. Nach Düsing ist diese Erscheinung durch die grössere Kreuzung der Eltern unehelicher Kinder zu erklären; die ehelichen Geburten dagegen, welche einen grösseren Procentsatz Knaben aufweisen, entstammen aus Verbindungen, bei denen eine kleinere Kreuzung der Eltern eintritt. Eine kleinere Kreuzung bedingt also verhältnissmässig mehr Knabengeburten; dies erhellt schon aus den jüdischen Geburten, welche aus sehr eng verwandtschaftlichen Verbindungen entstammen.

In ganz Uesterreich aber verhält es sich mit den ehelichen und unehelichen Geburten anders. Hier ist das Geschlechtsverhältniss der ehelichen Geburten niedriger als bei den unehelichen. Wir finden also, dass die unehelichen Geburten von ganz Oesterreich mehr Knaben aufweisen als die ehelichen Geburten. Nach meiner Meinung liegt die Ursache dieser Ausnahmeerscheinung in der grossen Anzahl der jüdischen unehelichen Geburten, welche ein sehr hohes Geschlechtsverhältniss aufweisen.

Die nach der Vitalität und Legitimität zusammengestellten Geburten Oesterreichs zeigen in allen Gruppen ein grösseres Geschlechtsverhältniss als die analog zusammengestellten Geburten in Preussen. Dies bedeutet also, dass in Oesterreich in allen Gruppen verhältnissmässig mehr Knaben und weniger Mädchen geboren werden als in Preussen. Dies ist eine für Oesterreich ungünstige Erscheinung und ich erkläre sie dadurch, dass 1 . in Preussen ein viel kleineres Procent Juden lebt als in Oesterreich, 2. dass die in Preussen lebenden Slaven sich durch ein niedriges Geschlechtsverhältniss kennzeichnen. Werm wir in Preussen und in Oesterreich alle jüdischen Geburten auslassen würden und dann alle Geburten Oesterreichs (slavische und dentsche) mit den deutschen Geburten (ohne die 
slavischen) in Preussen vergleichen würden, kämen wir bestimmt bei Preussen zu grösseren Zahlen als bei Oesterreich. Die Slaven zeichnen sich überhaupt in ganz Europa durch die günstige Eigenschaft aus, dass bei ihnen verhältnissmässig mehr Mädchen geboren werden als bei den Juden und Deutschen, wie dies schon 'im Capitel IX ausführlich bewiesen wurde.

II.

Das Maximum der Geburten in Böhmen fällt in den Conceptionsmonat Juli und das Minimum in den Conceptionsmonat März. Das Maximum des Geschlechtsverhältnisses finden wir im März (Conceptionsmonat Juni) und das Minimum im December (Conceptionsmonat März). Dies ist nicht vollkommen übereinstimmend mit dem, was Düsing in Preussen festgestellt hatte, und man kann bloss das behaupten, dass in Böhmen die Anzahl der täglichen Geburten vom März (Conceptionsmonat) bis zum Juli steigt und dann vom August bis Februar fällt. Das Geschlechtsverhältniss ist aber in keiner Weise an die durchsehnittliche tägliche Geburtenanzahl gebunden, wie dies Düsing bei Preussen behauptet.

In ganz Oesterreich fällt das Maximum der durchschnittlichen täglichen Geburtenanzahl in den Februar (Conceptionsmonat Mai) und das Minimum in den Juni (Conceptionsmonat September). Dies stimmt vollkommen mit den Resultaten von $D$ üsing in Preussen überein. In Oesterreich fällt also auch das Maximum der Conception in den Frühling und das Minimum in den Herbst. Diesem Maximum der durchschnittlichen täglichen Anzahl der Conceptionen im Mai sollte ein Minimum des Geschlechtsverhältnisses und dem Minimum der Conceptionen ein Maximum des Geschlechtsverhältnisses entsprechen. Das Minimum des Geschlechtsverhältnisses fällt aber nicht in den Mai, sondern in den October, und auch das Maximum zeigt sich nicht im September, sondern im April.

Das Resultat Düsing's ist also nicht im Allgemeinen gültig.

Wenn wir die Monate in eine wärmere und eine kältere Gruppe eintheilen, finden wir, dass in Böhmen sowie auch in ganz Oesterreich in den wärmeren Monaten verhältnissmässig mehr Conceptionen eintreten als in den kälteren Monaten. Das Geschlechtsverhältniss ist aber in Böhmen in den wärmeren Conceptionsmonaten höher, d. h. es werden mehr Knaben producirt als in den kälteren Monaten. In ganz Oesterreich aber verhält sich das Ge- 
schlechtsverbältniss umgekehrt wie in Böhmen: der grösseren Conceptionsanzahl in den wärmeren Monaten entspricht eine kleinere Anzahl von Knabengeburten und eine kleinere Anzahl von Conceptionen in den kälteren Monaten hat wieder eine grössere Anzahl von Knabengeburten zur Folge.

Das, was Düsing in Preussen festgestellt hatte, gilt also für die einzelnen Länder Oesterreichs nicht und die Ursache davon mag wohl die grosse geographische Gliederung des Reiches sein.

\section{III.}

Betrachten wir die Geburten nach der Ortsgrösse, so seben wir, dass, was die ehelichen Geburten in Oesterreich und Böhmen anbelangt, in den kleinsten Orten um etwas mehr Knaben geboren werden als in den grösseren Orten mit 2000-5000 Einwohnern (in Böhmen).

Was die Legitimität der Geburten anbelangt, ist das Geschlechtsverhältniss der unehelichen Kinder bloss in den kleinsten Dörfern niedriger als bei den ehelichen, während in allen übrigen Orten von ganz Oesterreich das Geschlechtsverhältniss der unehelichen Geburten höher ist als bei den ehelichen Geburten.

Die aus den Geburten von verschiedenen Städten Oesterreichs zusammengestellte Tabelle beweist uns deutlich, dass auf das Geschlechtsverhältniss mehrere Factoren einwirken und nicht bloss die nach der Ortsgrösse abgeschätzte Kreuzung. Wie aus der Tabelle ersichtlich ist, hat z. B. Wien ein viel höheres Geschlechtsverhältniss als Laibach. In gleicher Weise sind auch weder die durchschnittliche Jahreswärme noch die Seehöhe ein richtunggebender Maassstab für das Geschlechtsverhältniss in allen Städten.

$$
\text { IV. }
$$

Die Untersuchung des Geschlechtsverhältnisses bei den Geburten nach den verschiedenen Confessionen, mit denen verschiedene Gewohnheiten und verschiedene Lebensweisen zusammenhängen, hat auch in Oesterreich die bekannte Thatsache, dass die Juden sich durch das höchste Geschlechtsverhältniss auszeichnen, bestätigt.

Ausserdem zeigt uns noch diese Untersuchung, dass die Juden und die Griechischorientalen bei den unehelichen Geburten ein höheres Geschlechtsverhältniss aufweisen als bei den ehelichen Geburten. 
V.

Aus dem für Böhmen und für Oesterreich zusammengestellten Material liess sich kein deutlicher Einfluss der Ehedauer auf das G. der Kinder feststellen.

VI.

Der Einfluss des absoluten Alters der Mutter auf das Geschlecht der Kinder kommt in Oesterreich sowie auch in Preussen darin zum Ausdruck, dass die jüngsten Mütter verhältnissmässig mehr Knaben, ältere Mütter mehr Mädchen und die ältesten bis zu 40 Jahren wieder mehr Knaben gebären.

Was das relative Alter beider Eltern anbelangt, so wird das Gesetz von Hofacker-Sadler durch die Statistik der Geburten in Oesterreich nicht bestätigt. Ja auch die Düsing'sche Modification dieses Gesetzes, dass bei gleichem Alter der Mütter jüngere Männer mehr Knaben zeugen als Männer mittleren Alters, findet in dieser Arbeit keine Bestätigung.

Der Einfluss des Alters der Eltern combinirt sich in gleicher oder in entgegengesetzter determinirender Richtung mit versehiedenen anderen Einflüssen und die Erkennung des blossen mit anderen Factoren nicht combinirten Einflusses des Alters der Eltern auf das Geschlechtsverhältniss ist sehr schwierig, wenn nicht unmöglich.

VII.

Bei der Untersuchung des Geschlechtsverhältnisses nach dem Beruf und socialer Stellung der Eltern stellt sich heraus, dass die. landwirthschaftlichen Berufe eine niedrigere Zahl für das Geschleehtsverhältniss aufweisen als städtische Berufe (Fabrikanten und Industriearbeiter). Dies widerspricht dem, was Düsing in Preussen. gefunden hatte. Auch das schon öfter angeführte Factum, dass am Lande verhältnissmässig mehr Knaben geboren werden als in der Stadt, findet ebenfalls für Oesterreich keine allgemeine Bestätigung und gilt bloss für die kleinsten Dörfer (bis zü 500 Einwohnern).

VIII.

Die Mehrgeburten in Oesterreich bestätigen die schon in anderen Ländern beobachtete Erscheinung, dass das gleiche Gcschlecht bei den Mehrgeburten in einem viel grösseren Procent auftritt, als sich derWahrscheinlichkeit nach erwarten liesse. Das, was 
Düsing (Capital VIII) zur Erklärung dieser Erscheinung anführt, halte ich für richtig.

Was das Geschlechtsverhältniss anbelangt, so lässt sich in Oesterreich feststellen, dass in Zwillingsgeburten mehr Mädchen geboren werden als in den Einzelgeburten.

Doch bei der näheren Untersuchung der Zwillingskinder gleichen Geschlechts zeigt es sich, dass doch verhältnissmässig öfter ein indifferentes Zwillingspaar sich in männliche als weibliche Zwillinge determinirt.

Das grosse Procent der Kinder aus Mehrgeburten gleichen Geschlechts, ein grösseres Procent als der Wahrscheinlichkeit nach zu erwarten wäre, bedeutet uns, dass die äusseren Einflüsse, in erster Reihe die Ernährung, in bedeutendem Maasse auf die Bestimmung des Geschlechtes einwirken. Das Geschlechtsverhältniss der aus Mehrgeburten stammenden Kinder ist niedriger als bei den Kindern aus Einzelgeburten, d. h. es werden verhältnissmässig mehr Knaben als Mädchen geboren. Diese Erscheinung ist nur durch den Umstand zu erklären, dass die Mädchengeburten und Mehrgeburten überhaupt bei besserer Prosperität der Eltern vorkommen, und dass also diese Prosperität die gemeinsame Ursache beider gleichzeitie. auftretenden Erscheinungen ist.

IX.

Inwiefern die Organismen verschiedener Nationen die Eigenschaft besitzen, mehr Kinder des einen Geschlechtes zu produciren als des anderen, darüber wurde in Oesterreich Folgendes festgestellt:

Ein je grösseres Procent Slaven das Land bewohnt, desto mehr sinkt das Geschlechtsverhältniss, d. h. desto mehr Mädchen werden geboren.

Betrachten wir also ein niedriges Geschlechtsverhältniss nach der in Capitel IX angeführten Auslegung als ein günstiges Zeichen für die weitere Entwickelung einer Nation, so sehen wir, dass es am besten bei den Serbo-Kroaten erhalten ist, dann bei den Slovenen, ferner bei den Ruthenen und Polen und am wenigsten bei den Bewohnern von Böhmen und bei den Deutschen.

Auch die böhmische Bevölkerung von Böhmen weist bei den lebenden Geburten ein niedrigeres Geschlechtsverhältniss auf als die deutsche Bevölkerung. Bei den todten Geburten ist wieder umgekehrt das Geschlechtsverhältniss in den böhmischen Bezirken höher als in den deutschen. Aber auch darin beruht ein Vortheil 
für die böhmische Bevölkerung, denn es ist für eine Nation günstiger, wenn in einer gegebenen Anzahl von Geburten (todten und lebenden) mehr Knaben todt geboren werden als Mädchen.

Die slavische Bevölkerung Oesterreichs kennzeichnet sich durch ein niedrigeres Geschlechtsverhältniss bei den Geburten als die deutsche Bevölkerung. Dies lässt sich wenigstens von der Zeit behaupten, auf die sich die Untersuchung bezieht.

Berücksichtigen wir noch die an den Slovaken gemachte Beobachtung und die Statistik des europäischen Russlands, so sehen wir, dass überall in ganz Europa die Slaven ein niedrigeres Geschlechtsverhältniss bei den Geburten aufweisen als die Deutschen. Alle Slaven besitzen also in ihrem Organismus die Eigenschaft, mehr Mädchen zu produciren, und diese Eigenschaft ist vom Standpunkte des Entwickelungsforschers als ein gutes Zeichen für die weitere Vermehrung slavischer Nationen zu betrachten.

\section{Literatur.}

Ahlfeld, Die Geburten älterer Erstgeschwängerter. Dieses Archiv. Bd. IV. Ahlfeld, Ueber den Knabenüberschuss älterer Erstgebärenden. Dieses Archiv. Bd. IX.

Berg, Ueber Geburten mit mehreren Früchten. Schmidt's Jahrb.

Bidder, E., Ueber den Einfluss des Alters der Mutter auf das Geschlecht des. Kindes. Zeitschr. f. Geburtsh. u. Gyn. Bd. II.

Corradi, Dell' ostetricia in Italia ete. Citirt bei Düsing.

Düsing, C., Die Regulirung des Geschlechtsverhältnisses bei der Vermehrung der Menschen, Thiere und Pflanzen. Jenaische Zeitschr. f. Naturwissenschaft. XVIl. Bd. Neue Folge X. Bd. 1884.

Düsing, C., Das Geschlechtsverhältniss der Geburten in Preussen. Staatswissenschaftl. Studien. Jena 1899.

von Fircks, Die Geburten, Eheschliessungen u. Sterbefälle im preussischen Staate während des Jahres 1881.

von Fircks, Bevölkerungslehre und Bevölkerungspolitik. 1898.

Girou de Buzareignes, Schmidt's Jahrb. d. ges. Med. 1846.

Goehlert u. Bertillon, Zeitschr. f. Ethnologie. XIII. 1881.

Griesheim, A. v., Ueber die Zahlenverhältnisse der Geschlechter bei Rana fusca. Pflüger's Arch. 1881.

Hampe, C., Monatsb. f. medic. Statistilk. 1862.

Haycraft, On some physiological Results of Temperature variations. Transaction of the Royal Society of Edinbargh. Vol. XXIX.

Hecker, Statistik aus der Gebäranstalt zu München. Dieses Archiv. 1882.

Henneberg, Wodurch wird das Geschlechtsverhältniss beim Mensohen und den höheren Thieren beeinflusst? Ergebn. d. Anat. u. Entw. Merkel-Bonnet. VII. Bd. 1897 . 
824 Srdínko, Geschlechtsverhältniss bei den Geburten in Oesterreich.

Horn, Bevölkerungswissenschaftliche Studien aus Belgien. Bd. I. 1854.

Heyer, Berichte aus dem physiol. Institut d. Univ. Halle. S.-H. 1885.

Janke, H., Die Vorausbestimmung des Geschlechts beim Rinde.

Keleti, Statistik des Königr. Ungarn. 1877.

Mayerhoffer, K., Ueber die Entstehung des Geschlechts beim Menschen.

Wiener med. Presse. Ferner: Dieses Archiv. Bd. IX. Gegen die Hypothesen, die menschl. Eierstöcke enthielten männliche u. weibliche Eier.

Meckel v. Hemsbach, Ueber die Verhältnisse des Geschlechts, der Lebens-

fähigkeit u. d. Eihäute bei einfachen und Mehrgeburten. Müller's Arch.

f. Physiol. 1850.

Moser, Die Gesetze der Lebensdauer. 1839.

Neefe, Zur Statistik der Mehrgeburten. Ferner in den Jenenser Jahrb. f. Nationalöcon. u. Statistik. XV.

Oesterlen, Handbuch d. med. Statistik.

Ploss, Ueber die das Geschlechtsverhältniss der Kinder bedingenden Ursachen. Monatsschr. f. Geburtskunde u. Frauenkrankheiten. Bd. XII.

Ploss, Zur Zwillingsstatistik. Monatsbl. f. med. Statistik. 1861. Quetelet, Sur l'homme et le développement de ses facultés.

Rauber, Der Ueberschuss an Knabengeburten und seine biologische Bedeutung. 1900.

Sickel, Bericht über Gebäranstalten. Jahrb. d. ges. Med. 104.

Srdínko, O., Pomer pohlaví pri porodech v Rakousku vubec a v Cechách zyláste. Casopis lékaru ceskych. 1907.

Schultze u. Ahlfeld, Beiträge zur Lehre von den Zwillingen. Dieses Archiv. Bd. IX.

Schumann, Die Sexualproportion unter den Geburten.

Thury, La production de Sexes. Uebersetzt von Pagenstecher.

Wappäus, Allgemeine Bevölkerungsstatistik.

Wilckens, Untersuchung über d. Geschlechtsv. und d. Ursachen der Geschlechtsbildung bei Hausthieren. 1886.

Orschansky, Die Vererbung im gesunden und krankhaften Zustande und die Entstehung des Geschlechts beim Menschen. 1903. 